\title{
THE PRODUCTION OF INEQUALITIES WITHIN FAMILIES AND ACROSS GENERATIONS: THE INTERGENERATIONAL EFFECTS OF BIRTH ORDER AND FAMILY SIZE ON EDUCATIONAL ATTAINMENT
}

\author{
Kieron Barclay \\ Torkild Lyngstad \\ Dalton Conley \\ Working Paper 24530 \\ http://www.nber.org/papers/w24530
NATIONAL BUREAU OF ECONOMIC RESEARCH
1050 Massachusetts Avenue
Cambridge, MA 02138
April 2018

The views expressed herein are those of the authors and do not necessarily reflect the views of the National Bureau of Economic Research. Kieron Barclay was partially supported by a European Research Council Starting Grant awarded to Mikko Myrskylä (COSTPOST: 336475). We are also grateful for support from the Stockholm University SIMSAM Node for Demographic Research, Swedish Research Council (Grant 340-2013-5164).

NBER working papers are circulated for discussion and comment purposes. They have not been peer-reviewed or been subject to the review by the NBER Board of Directors that accompanies official NBER publications.

(C) 2018 by Kieron Barclay, Torkild Lyngstad, and Dalton Conley. All rights reserved. Short sections of text, not to exceed two paragraphs, may be quoted without explicit permission provided that full credit, including (C) notice, is given to the source. 
The Production of Inequalities within Families and Across Generations: The Intergenerational Effects of Birth Order and Family Size on Educational Attainment

Kieron Barclay, Torkild Lyngstad, and Dalton Conley

NBER Working Paper No. 24530

April 2018

JEL No. D1,I24,J1,J13

\section{ABSTRACT}

There has long been interest in the extent to which effects of social stratification extend and persist across generations. We take a novel approach to this question by asking whether birth order and sibling group size in the parental generation influences the educational attainment of their children. To address this question we use Swedish population data on cohorts born 1960-1982. To study the effects of parental birth order and family size we apply a cousin fixed effects design and exploit information on twin births in the parents generation. Relative to having a first-born mother, having a second-born or fifth-born mother is associated with educational attainment at age 30 being $4 \%$ and $8 \%$ of a standard deviation lower, respectively. After adjusting for attained parental education and social class, the parental birth order effect is heavily attenuated. Nevertheless, we do find that children who share the same birth order and gender as their parents attain slightly more education, and this is particularly pronounced when the parents have higher levels of education themselves. We do not find clear or consistent evidence for parental sibling group size effects. Overall our results suggest that birth order and family size effects operate through a Markovian process of transmission.

Kieron Barclay

Max Planck Institute for Demographic Research

Konrad-Zuse-Straße 1

18057 Rostock

Germany

barclay@demogr.mpg.de

Torkild Lyngstad

Department of Sociology and Human Geography

University of Oslo

Harriet Holters hus

Moltke Moesvei 31

0851 OSLO, NORWAY

t.h.lyngstad@sosgeo.uio.no
Dalton Conley

Department of Sociology

Princeton University

153 Wallace Hall

Princeton, NJ 08544

and NBER

dconley@princeton.edu 


\section{INTRODUCTION}

Research on the intergenerational transmission of status has a long history in the social sciences, and studies have consistently documented the importance of the family of origin for socioeconomic attainment (e.g. Sorokin, 1927; Blau and Duncan, 1967; Erikson and Goldthorpe, 1992; Ermisch, Jantti, and Smeeding, 2012). In recent years there has been a growing interest in the influence that grandparental socioeconomic status (SES) has on the attainment of grandchildren. A majority of studies have suggested that grandparental wealth and SES does influence the outcomes of grandchildren, even net of parental characteristics (Anderson, Sheppard, and Monden, 2018). Typically, these studies have pursued one of two strategies. Some research has regressed individuals' social statuses (education, occupation or income) on their grandparent(s)' SES, holding their parents' values on these measures constant. A residual effect of grandparental characteristics on grandoffspring holding the intervening generation constant is seen as evidence of a non-Markovian process of status transmission (e.g. see Warren and Hauser, 1997; Zeng and Xie, 2014; Hällsten and Pfeffer, 2017). Another approach decomposes variance in SES measures into a nuclear family component (sibling correlation) and an extended family component (cousin correlation). In this model, grandparents' characteristics need not be measured, and the interpretation of the cousin correlation is that it captures the omnibus effect of grandparents net of unmeasured, immediate family effects (Jæger, 2012; Hällsten, 2014).

This literature on stratification and social mobility suggests that there are indeed multigenerational processes of status transmission over and above a two-generational Markovian process. However, recent work suggests that grandparental effects may be an artifact of measurement error (Lundberg, 2018), particularly at the parental level (Ferrie, Massey, and Rothbaum, 2016). After such attenuation-inducing error is corrected, evidence of a multigenerational transmission of status disappears, and stratification seems to follow a two-generation Markovian model (Ferrie et al., 2016). Within this literature the multigenerational impact of demographic factors within the family has received much less attention than the multigenerational impact of socioeconomic conditions (Mare, 2011). This is unfortunate, as within-family sociodemographic factors such as birth order or 
sibling group size are measured with much less error than, say, education, occupational prestige, or income. As a consequence, research on the multigenerational impact of birth order or family size would be much less vulnerable to bias from measurement error, and would therefore shine a clear light on whether intergenerational transmission processes follow a Markovian model or not. Furthermore, to date research on the multigenerational transmission of advantage has focused largely, if not exclusively, on differences across families rather than within families. Although parental socioeconomic status and household income are powerful predictors of offspring attainment, sibling correlations on high school grades, educational attainment, and earnings in adulthood demonstrate that there are substantial differences in outcomes even amongst children who share the same parents (Conley, 2004; Björklund and Jäntti, 2012; Grätz et al., 2016). These differences in sibling outcomes suggest that there are important inequality generating processes operating even within families, and that processes of cumulative advantage based upon differences in relative access to resources within the household can lead to substantial differences in outcomes in the long-run, and potentially even over subsequent generations.

For these reasons, in the present study we seek to go beyond previous research examining whether grandparental SES influences grandchildren to ask whether grandparental fertility affects grandchild outcomes. In doing so we also attempt to address a broader question, which is: do inequality generating processes within families, such as differences in parental investment, have effects on the attainment of the subsequent generation? We address these questions by examining whether birth order and sibling group size in the parental generational are associated with the educational attainment of their children. We consider parental birth order and sibling group size a grandparental variable and its putative effect a three-generational effect because it is the grandparents' fertility that determines the parents' birth order and sibling group size, which may in turn affect their offspring's attainment, net of the grandchildren's own birth order and sibling group size. When sibling group size is held constant in an OLS model, or a family fixed effects analysis, birth order can be considered randomly assigned. Therefore, examining the multigenerational impact of birth order allows us to approximate the notion of a 'treatment' to the parental generation. The same applies to sibling group size in the parental generation if we use a twin birth at the 
grandparental generation as a exogenous shock to family size. If there are intergenerational birth order and family size effects in this context (net of each generation's fertility and ego's birth order and sibling group size), then it is reasonable to assume that three-generational effects are real (at least for birth order and family size). Furthermore, if there are no net effects once parental characteristics known to be influenced by birth order are controlled, then the random assignment nature of birth order within families offers the potential to consider parental birth order as an instrumental variable for parental education - an important background variable in the stratification literature for which there have been few, if any, instruments (Angrist and Keueger, 1991; Bound, Jaeger, and Baker, 1995; Lleras-Muney, 2005).

Our study is predicated on several points. First, in line with previous research, we assume that relative differences in childhood investment lead to potentially large differences in later attainment due to processes of cumulative advantage (Merton, 1968; DiPrete and Eirich, 2006; Heckman, 2006), that these relative differences in resources are consequential even when the absolute level of resources is high (Marmot, 2004), and that differences in parental attainment can affect offspring attainment (Holmlund, Lindahl, and Plug, 2011). Second, as we will argue, birth order can be used as a valuable indicator for relative levels of parental investment and access to resources within the family, and particularly indexes access to resources in the crucial early years of life. Thus, our interest in birth order is primarily driven by how this factor marks access to resources and parental investment during childhood. Research on birth order has been criticized on the grounds that it lacks policy relevance. However, the fact that birth order is essentially random and not amenable to policy intervention is also a strength when it is considered as a random assignment to relative advantage in terms of resource access and parental investment during childhood. We also use sibling group size, instrumented using twin births as an exogenous shock on family size, as a second indicator of resource dilution in the family, following the classic quantity-quality trade-off assumption (e.g. see Becker and Lewis, 1973; Becker and Tomes, 1976). Finally, we argue that the microcosm of the family is uniquely suited for studying how inequality generating processes related to relative access to resources and cumulative advantage produce differences in attainment, 
as the family context allows us to study the influence of these factors net of shared genetics, and the shared contextual environment.

Another motivating factor for the present research is the idea that parental birth order may act as a moderator for ego's birth order. A handful of existing studies indicate differential inheritance of parental characteristics by birth parity. For example, Black, Devereux, and Salvanes (2009) examined the IQ scores of Norwegian military conscripts and found that the natural logarithm of ability is more weakly inherited by first-born sons than by later-borns. It should be added that this effect was barely significant despite almost 25,000 cases, and disappeared when ability was not logged. Conversely, Lindahl (2008) reported that the strength of transmission of labor market earnings decreased with increasing parity in Sweden; she also reported that transmission was weaker in larger family sizes. One intuition behind birth order effects, at least as articulated by Lindahl (2008), is that later-borns may feel less attachment to their parents, they may be more influenced by older siblings (and thus less so by parents) and they may experience father absence more frequently and for longer durations. It may also be the case that there are higher order interactions at work; namely, it could be that transmission is stronger when fathers identify with particular offspring in terms of birth order. In other words, a last-born father may identify more strongly with his last-born son (and vice versa) resulting in a higher correlation than with earlierborn sons. Or, alternatively, there could be a magnified effect of dissociation from the family such that later-born offspring to later-born fathers resemble each other the least. In such a model, birth order would be a relational variable of parent-offspring identification and investment. That is, there may be heterogeneous effects of birth order contingent on parental birth order (and/or gender) that are averaged out by only looking at a single generation's parity.

Within-Family Inequality Generating Processes. The vast majority of research on how family background influences socioeconomic attainment focuses on differences across families. This literature examines how factors such as social class, education, and race and ethnicity influence opportunity structures and predict differences in the production of and transmission of skills and resources to children. Although differences between families are enormously important for the 
production and reproduction of patterns of social stratification in society, variation in how children are raised within the family may also play an important role in explaining individual differences in human capital formation and educational attainment. That is, the concept of a non-shared environment also has relevance within the family, particularly when one considers time-varying circumstances. Differences in how children within the same family are raised may be a consequence of numerous factors, including changes to family structure, such as parental divorce or changes in family size, differences in how parents treat their children, such as by gender or birth order, as well as within-family differences in parent-child relationships (Conley, 2004; Plomin and Daniels, 1987; Suitor et al., 2008). Parents are typically reluctant to report that they treat their children differently, but children do perceive substantial differences. Studies show that parental self-reports on how they treat each of their children are much more highly correlated than how children perceive they are treated (Daniels et al., 1985; Reiss et al., 2009). Furthermore, it is the childrens' perceptions that are corroborated by independent observers (Reiss et al., 2009).

Although full siblings share the same parents and kin network, live in the same house and neighbourhood, and often attend the same schools, there are substantial sibling differences in socioeconomic attainment. Sibling correlations on cognitive ability and educational and socioeconomic outcomes in Sweden have been estimated at 0.51 for high school GPA (Björklund, Lindahl, and Sund, 2003), 0.39 for educational attainment, 0.47 for IQ, and 0.22 for long-run earnings (Björklund and Jäntti, 2012). These correlations reflect the influence of both shared genetics and shared environment, and indicate that while there are substantial similarities amongst siblings in attainment, non-shared environment is important for explaining differences in sibling outcomes (Plomin and Daniels, 1987). One factor that consistently captures systematic sources of advantage in the sibling group is birth order. Research suggests that first- and earlier-born siblings are advantaged over later-born siblings on many dimensions. Studies show that parents differentially invest time, care, and resources in first-born and earlier-born siblings relative to later-borns, both during pregnancy and during childhood. Mothers are more likely to seek prenatal care for first-born children (Buckles and Kolka, 2014), they are more likely to breast feed first-borns (Buckles and Kolka, 2014), 
and they take longer periods of parental leave to spend with first-borns (Sundström and Duvander, 2002). Research in the United States indicates that parents regulate the television watching and monitor the school performance of first-borns to a greater extent than they do for later-born children (Hotz and Pantano, 2015). Studies also indicate that, particularly in middle class families, younger children can be hostages to the activities and schedules of older children, whose cultivation is prioritised by the parents over that of the younger children (Lareau, 2011).

Parents also spend more time with first-borns than later-borns, with some estimates suggesting that parents spend 20-30 minutes more quality time per day with first-borns than second-borns of the same age (Price, 2008). An important factor explaining this difference in quality time is structural change in the sibling group attributable to changes in family size, which leads to the dilution of parental resources (Blake, 1989). By definition parents have relatively more time for their first-born child during the early years of life than they have for later-born children, as parental time is finite, and family size is a time-varying factor during the life course. According to the resource dilution hypothesis, first-borns will typically be the most advantaged amongst a group of siblings precisely because they spend a period of time with exclusive access to parental attention and various other parental resources. Studies indicate that these early years can be crucial for child development. Although this has been shown most dramatically by examining severely deprived children (Rutter, 1998), it is also clear that early life investment has an important impact on reading ability and numeracy even amongst children who are not deprived (Stanovich, 1986; Bast and Reitsma, 1998; Sénéchal and LeFevre, 2002; Cheadle, 2008).

A second theory concerned with structural changes to the sibling group is the confluence hypothesis (Zajonc and Markus, 1975; Zajonc, 1976). The confluence hypothesis also posits that earlier-born siblings should be advantaged over later-born siblings, but argues that this is due to the average degree of intellectual stimulation in the household. First-borns interact exclusively with their parents, which is highly cognitively stimulating, until the birth of any later siblings. This is presumed to be beneficial for cognitive development. Later-borns, however, interact not only with the parents, but will also spend much time interacting with their other infant siblings, who offer much less cognitive stimulation. This in turn may have negative long-term consequences. 
Indeed, studies show that later-born children have lower cognitive ability and educational attainment than first-borns (Black, Devereux, and Salvanes, 2005a; Bjerkedal, Kristensen, Skjeret, and Brevik, 2007; Barclay, 2015b).

As this body of theoretical and empirical research would suggest, there are also consistent birth order differences in academic achievement. Studies that have compared siblings within the same family have consistently shown that later-borns have a lower GPA than first- and earlier-born siblings (Kalmijn and Kraaykamp, 2005), are less likely to graduate from high school (Härkönen, 2014), or to go to university (Barclay, 2018), and have lower completed educational attainment (Black, Devereux, and Salvanes, 2005a). In Sweden second-borns, third-borns and fourth-borns typically achieve around $30 \%, 40 \%$, and $50 \%$ of a year less education than first-borns by age 30 , respectively (Barclay, 2015a). Past work strongly suggests that these birth order differences in attainment are attributable to differences in how children are raised rather than any biological differences between siblings or differences in the in utero environment by parity. Studies on sibling groups where social and biological birth order differ, such as sibling groups where a child has died, or sibling groups of adopted children, show that it is social birth order that explains differences in attainment rather than biological order (Kristensen and Bjerkedal, 2007; Barclay, 2015a). Furthermore, it is worth noting that biomedical factors actually predict worse long-term outcomes for first-born children, who are more likely to be born with low birth weight (Kramer, 1987), and to be born pre-term (Astolfi and Zonta, 1999), both of which typically lead to worse long-term socioeconomic outcomes (Conley and Bennett, 2000; Black, Devereux, and Salvanes, 2007). Studies on birth order and academic attainment therefore not only suggests that the first-born and earlier-born advantage is attributable to differences in how children are raised, but also that these differences in nurture are sufficiently great to overcome physiological disadvantages amongst first-borns at the time of birth.

Family size is also assumed to have a negative effect on attainment, with each additional child leading to further dilution of resources and the attendant tradeoff between number of children and how much attention and resources parents can devote to each one (Becker and Lewis, 1973; Becker and Tomes, 1976; Blake, 1981). Indeed, most research correlating completed family size with the 
attainment of children has shown that growing up in a larger family is negatively correlated with educational and labor market success (Blake, 1989; Steelman et al., 2002). However, although the effect of family size on attainment has been an object of substantial research attention, completed family size is a rather poor way of capturing resource dilution within the family, because it assumes that each child in a family of a given size has access to a similar pool of resources. Family size is rather experienced as a time-varying factor, increasing as more children are born, decreasing as others leave the home. Birth order captures this time-varying nature of resource dilution within the family, though it does so most effectively for the first years of life, which is when parental investment is likely to matter the most (Stanovich, 1986; Bast and Reitsma, 1998; Sénéchal and LeFevre, 2002; Cheadle, 2008). Nevertheless, contemporary studies that have used a twin birth as an exogenous shock on family size are still able to capture the importance of the introduction of an additional, unexpected, sibling on resource dilution for those children that are born before the twin birth (Rosenzweig and Wolpin, 1980).

Past research on birth order and educational attainment not only accounts for why later-born children should achieve lower educational attainment than first- and earlier-born siblings, but also suggests that a child's later-born parents should have lower educational attainment than their firstand earlier-born aunts and uncles. If parental educational attainment has an effect on the attainment of their children, then we would expect that the birth order of the index person's parents should matter for educational attainment even net of the index person's own birth order. For example, the first-born child of a first-born mother should achieve higher levels of educational attainment than the first-born child of a third-born mother. We would also expect that a larger family size in the parental generation should have a negative effect on parental attainment, which should in turn have a negative effect on the attainment of their own children. Given that we expect that the effect of parental birth order on offspring educational attainment is driven by later-born parents having lower educational and occupational attainment, we expect that after we adjust for parental attained education and social class the effect of parental birth order on offspring educational attainment will be substantially or completely attenuated. If this is indeed the case, this would suggest that the effect of parental birth order follows a two-generation Markovian process. 


\section{DATA AND METHODS}

Data. In this study we use Swedish population register data with multigenerational linkages to examine how birth order and sibling group size in the parental generation is related to educational attainment amongst their children at age 30. We examine educational attainment amongst Swedish men and women born between 1960 and 1982, whose parents were born between 1938 and 1969. In our analyses we focus on families where both the parents and children were born in Sweden. In Sweden each individual has a personal identity number (PIN) that enables records to be linked across a variety of administrative registers. The Swedish multigenerational register also contains information on the PIN of the mother and father of any given individual. Information on the PIN of the mother and father allows any given individual to be linked to any biological kin, including siblings, cousins, and grandparents.

To examine the relationship between the birth order of parents and the educational attainment of their offspring, it is essential to have three generations of data. Information on the identity of the grandmother and grandfather (Generation 1 [G1]) is needed to identify the birth order of the parents (G2), while information on the fertility of the parents (G2) is need to identify the birth order of the grandchildren (G3). We classify a sibling group (G2 and G3) as a set of individuals who share a biological mother and father. A cousin group (G3) is based upon sharing a biological grandmother and grandfather. Figure 1 provides a graphical illustration of our data structure. Although we describe this in greater detail below, in the 'Statistical Analyses' section, a key dimension of our study is the use of a cousin fixed effects design, which has implications for our sample selection. We compare cousins in order to reduce confounding from factors shared amongst parents, aunts, and uncles. These factors include grandparental socioeconomic status, which might affect both fertility behaviour as well as the educational attainment of the parental generation (G2), and which are unmeasured because of the early time period. This means that we exclude 'only cousins' from our analysis. An 'only cousin' might have multiple siblings, but not have any cousins within their own generation, either because their parents were only children, or because their aunts and uncles did not have any children of their own. In our analyses focusing upon birth order we also exclude 
sibling groups at the G2 and G3 level which experienced a multiple birth such as twins, as this confuses the measurement of birth order. However, in our analyses of how sibling group size in the parental generation $(\mathrm{G} 2)$ affects offspring (G3) attainment, we utilize those sibling groups to take advantage of the exogenous increase in family size stemming from a twin birth.

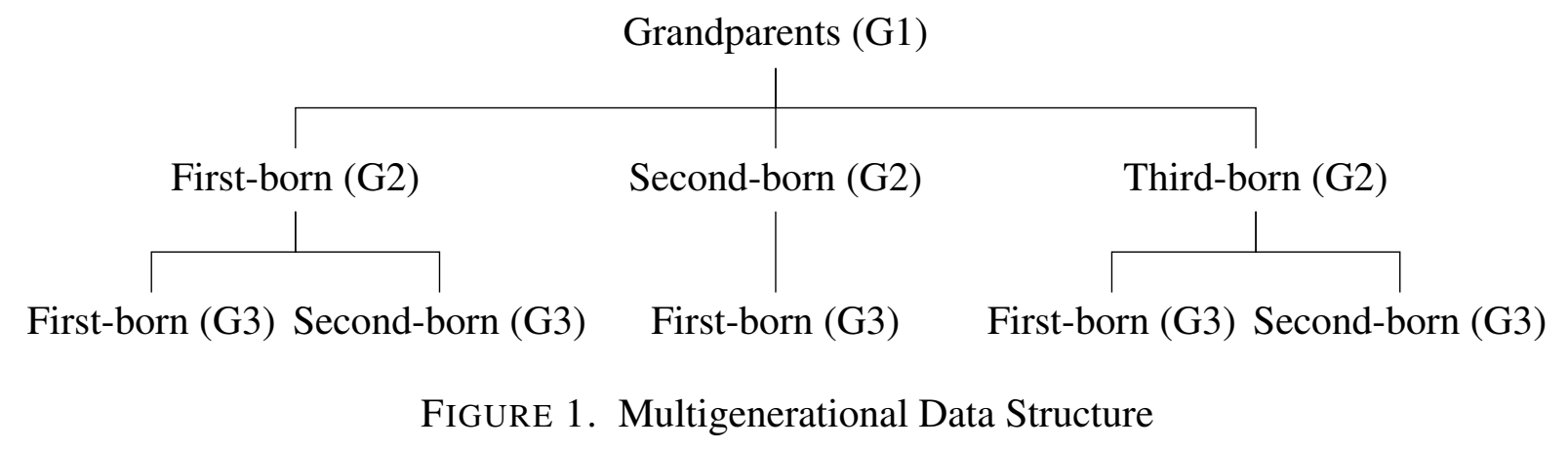

The Swedish Educational Context. Education in Sweden is state funded at all levels, and tertiary education is free for Swedish citizens (Halldén, 2008; Högskoleverket, 2012). In Sweden family resources are therefore less important for the transition to tertiary education than in other contexts, such as the United States. The Swedish education system is divided into three sections: (1) 9 years of compulsory schooling (grundskolan); (2) three additional years of secondary school (gymnasium); and, (3) the tertiary section (Halldén, 2008). Tertiary education in Sweden today consists of two parts. The first is a traditional university education, with degrees at the Bachelors (kandidatexamen), Magister (magisterexamen), Masters, Licentiate, and Doctoral levels. The second part is a vocational tertiary education (högre yrkesutbildning/högskolor) (Halldén, 2008). Students in tertiary education are eligible for financial support from the Swedish state for living costs in the form of study grants and student loans with low interest rates (Högskoleverket, 2012), minimising the need for reliance on family resources for maintenance. In 2012 approximately 33\% of the Swedish population had undergone post-secondary education, which was slightly higher than the OECD average (Högskoleverket, 2012).

Outcome Variable. The primary outcome variable in this study is educational attainment in years, measured in the year that the index person turned 30. This measure is based upon the number 
of years that correspond to the specific level of education achieved by age 30, and may not in all cases reflect that actual number of years that an individual spent in the educational system. We also conduct a number of additional analyses, using high school grade point average (GPA) and inflation-adjusted (CPI) logged earnings averaged between ages 29 to 31. The detailed results from those analyses are included in the supplementary section of our paper, but we also describe the results briefly in the results section below.

TABLE 1. Variables included in statistical models

\begin{tabular}{lllll}
\hline & & & Variables & \\
\cline { 2 - 4 } Variable Category & Model 1 & Models 2, 5, 8 & Models 3, 6, & Models 4, 7, 10 \\
\hline Explanatory & Maternal birth order & Maternal birth order & Maternal birth order & Maternal birth order \\
Explanatory & Paternal birth order & $\begin{array}{l}\text { Paternal birth order } \\
\text { (Maternal sibling group size) }\end{array}$ & $\begin{array}{l}\text { Paternal birth order } \\
\text { (Maternal sibling group size) }\end{array}$ & $\begin{array}{l}\text { Paternal birth order } \\
\text { G2 Control }\end{array}$ \\
G2 Control & (Paternal sibling group size) & (Paternal sibling group size) & (Paternal sibling group size) \\
G2 Control & Maternal grandmother age & Maternal grandmother age & Maternal grandmother age \\
G2 Control & Paternal grandmother age & Paternal grandmother age & Paternal grandmother age \\
G2 Control & Maternal birth year & Maternal birth year & Maternal birth year \\
G2 Control & Paternal birth year & Paternal birth year & Paternal birth year \\
G3 Mediator & & Index birth order & Index birth order \\
G3 Mediator & & Sex & Sex \\
G3 Mediator & & Sibling group size & Sibling group size \\
G3 Mediator & & Birth year & Birth year \\
G3 Mediator & & Maternal age & Maternal age \\
G3 Mediator & & Paternal age & Paternal age \\
G2 SES Mediator & & & Maternal educational attainment \\
G2 SES Mediator & & & Maternal social class (EGP) \\
G2 SES Mediator & & & Paternal educational attainment \\
G2 SES Mediator & & & Paternal social class (EGP) \\
\hline
\end{tabular}

Control Variables. In our analyses focusing on the effects of parental birth order we adjust for a number of different factors that may be linked to both parental (G2) and offspring (G3) birth order, and educational attainment. We adjust our analyses for maternal sibling group size $(\mathrm{G} 2)$, paternal sibling group size (G2), grandmaternal age at the time of birth of the mother $(\mathrm{G} 2)$, grandmaternal age at the time of birth of the father (G2), and maternal and paternal birth year (G2). These variables capture conditions at the time of birth, with the exception of parental sibling group size, which may be not settle until later childhood. We adjust for the completed sibling group size of the parents as there is a correlation between sibling group size and educational attainment (Black et al., 2005a), and higher birth order siblings will be drawn from larger sibling groups. We adjust for grandparental age at the time of birth as later-born siblings are typically born to older mother 
and fathers, and advanced parental age may be associated with educational outcomes (Barclay and Myrskylä, 2016). We control for birth year in order to adjust for educational expansion over time (Breen et al., 2009; Breen, 2010), which is likely to benefit later-born siblings and cousins (Barclay, 2018).

Mediator Variables. We consider two groups of variables that mediate the relationship between parental birth order and offspring educational attainment. The first group of mediating variables refers to sociodemographic characteristics of the grandchild generation (G3), including the birth order of the index person (G3), the sex of the index person (G3), the sibling group size of the index person (G3), the birth year of the index person (G3), and maternal and paternal age at the time of the birth of the index person (G3). These factors may well be influenced by parental birth order, and are also known to influence educational attainment. Most important amongst these is the birth year of the index person (G3), as being born in a later calendar year during a period of rapid educational expansion is known to be associated with a higher average educational attainment (Breen et al., 2009; Breen, 2010).

Our second group of mediator variables pertain to educational and socioeconomic attainment of the parents. Our expectation is that the association between parental birth order and offspring educational attainment operates entirely through the educational and socioeconomic attainment of the parents. We evaluate this mechanism by adjusting for the attained education and social class of the mother and father $(\mathrm{G} 2)$. Maternal and paternal educational attainment is based upon the highest attained level of educational attainment. Highest maternal and paternal educational attainment is grouped into eight categories, which are: primary ( $<9$ years); primary (9 years); secondary (10-11 years); secondary (12 years); tertiary (13-15 years); tertiary (15+ years); graduate school; and, missing. Maternal and paternal social class is based upon the Erikson, Goldthorpe and Portocarero occupational class scheme (EGP) (Erikson et al., 1979), measured between ages 30 and 40 using information on occupation from the Swedish censuses in 1960, 1970, 1980, and 1990. 
Table 2: Descriptive statistics for birth order and educational attainment at age 30 for generation 3 (G3), Swedish men and women born $1960-1982$.

\begin{tabular}{|c|c|c|c|c|c|c|c|c|c|c|c|c|c|c|c|c|}
\hline & & \multicolumn{5}{|c|}{ Index Birth Order } & \multicolumn{5}{|c|}{ Mother Birth Order } & \multicolumn{5}{|c|}{ Father Birth Order } \\
\hline & & 1 & 2 & 3 & 4 & $5+$ & 1 & 2 & 3 & 4 & $5+$ & 1 & 2 & 3 & 4 & $5+$ \\
\hline $\mathrm{N}$ & & 515,405 & 308,554 & 72,293 & 9,709 & 1,947 & 434,579 & 276,745 & 116,856 & 45,989 & 33,739 & 446,386 & 277,305 & 112,833 & 42,479 & 28,905 \\
\hline \multirow[t]{2}{*}{ Years of Education } & Mean & 12.9 & 13.0 & 12.9 & 12.6 & 12.3 & 12.9 & 13.0 & 12.9 & 12.7 & 12.6 & 12.9 & 13.0 & 12.9 & 12.7 & 12.6 \\
\hline & SD & 2.3 & 2.3 & 2.3 & 2.3 & 2.3 & 2.3 & 2.3 & 2.3 & 2.3 & 2.2 & 2.3 & 2.3 & 2.3 & 2.3 & 2.2 \\
\hline \multirow[t]{2}{*}{ Mother Birth Order } & Mean & 1.9 & 1.9 & 1.9 & 2.0 & 2.0 & 1.0 & 2.0 & 3.0 & 4.0 & 5.8 & 1.8 & 1.9 & 2.0 & 2.0 & 2.1 \\
\hline & $\mathrm{SD}$ & 1.2 & 1.2 & 1.2 & 1.3 & 1.3 & 0.0 & 0.0 & 0.0 & 0.0 & 1.2 & 1.1 & 1.2 & 1.2 & 1.3 & 1.4 \\
\hline \multirow[t]{2}{*}{ Father Birth Order } & Mean & 1.8 & 1.8 & 1.9 & 1.9 & 1.9 & 1.8 & 1.9 & 1.9 & 1.9 & 2.1 & 1.0 & 2.0 & 3.0 & 4.0 & 5.7 \\
\hline & SD & 1.1 & 1.1 & 1.1 & 1.2 & 1.2 & 1.1 & 1.1 & 1.2 & 1.2 & 1.3 & 0.0 & 0.0 & 0.0 & 0.0 & 1.1 \\
\hline \multirow[t]{2}{*}{ Index Birth Order } & Mean & 1.0 & 2.0 & 3.0 & 4.0 & 5.4 & 1.5 & 1.5 & 1.6 & 1.6 & 1.6 & 1.5 & 1.5 & 1.6 & 1.6 & 1.6 \\
\hline & SD & 0.0 & 0.0 & 0.0 & 0.0 & 0.8 & 0.7 & 0.7 & 0.7 & 0.7 & 0.7 & 0.7 & 0.7 & 0.7 & 0.7 & 0.7 \\
\hline \multirow[t]{2}{*}{ Index Sibling Group Size } & Mean & 2.0 & 2.4 & 3.3 & 4.4 & 6.1 & 2.3 & 2.3 & 2.4 & 2.4 & 2.4 & 2.3 & 2.3 & 2.4 & 2.4 & 2.5 \\
\hline & $\mathrm{SD}$ & 0.9 & 0.7 & 0.7 & 0.9 & 1.6 & 0.9 & 0.9 & 0.9 & 1.0 & 1.0 & 0.9 & 0.9 & 1.0 & 1.0 & 1.1 \\
\hline \multirow[t]{2}{*}{ Index Birth Year } & Mean & 1973.1 & 1974.6 & 1975.9 & 1976.5 & 1977.1 & 1973.7 & 1974.0 & 1974.1 & 1974.2 & 1974.4 & 1973.6 & 1974.0 & 1974.3 & 1974.5 & 1975.0 \\
\hline & $\mathrm{SD}$ & 5.6 & 5.0 & 4.6 & 4.5 & 4.4 & 5.5 & 5.4 & 5.3 & 5.3 & 5.1 & 5.5 & 5.4 & 5.3 & 5.3 & 4.9 \\
\hline \multirow[t]{2}{*}{ Index Mother Age } & Mean & 23.8 & 26.6 & 29.2 & 30.9 & 32.4 & 25.5 & 25.3 & 25.0 & 24.7 & 24.3 & 25.4 & 25.3 & 25.0 & 24.7 & 24.2 \\
\hline & $\mathrm{SD}$ & 4.1 & 3.8 & 3.8 & 4.0 & 4.1 & 4.4 & 4.4 & 4.4 & 4.3 & 4.2 & 4.4 & 4.4 & 4.4 & 4.4 & 4.2 \\
\hline \multirow[t]{2}{*}{ Index Father Age } & Mean & 26.0 & 28.7 & 31.3 & 33.0 & 34.5 & 27.4 & 27.5 & 27.4 & 27.2 & 27.0 & 27.6 & 27.4 & 27.1 & 26.9 & 26.5 \\
\hline & $\mathrm{SD}$ & 4.2 & 3.8 & 3.8 & 3.9 & 4.2 & 4.4 & 4.4 & 4.4 & 4.4 & 4.4 & 4.5 & 4.4 & 4.4 & 4.4 & 4.2 \\
\hline \multirow[t]{2}{*}{ Mother Sibling Group Size } & Mean & 2.8 & 2.9 & 3.1 & 3.3 & 3.6 & 2.2 & 2.8 & 3.8 & 4.9 & 6.9 & 2.8 & 2.9 & 3.0 & 3.1 & 3.2 \\
\hline & SD & 1.6 & 1.6 & 1.7 & 1.9 & 2.2 & 1.2 & 1.1 & 1.2 & 1.2 & 1.8 & 1.6 & 1.6 & 1.7 & 1.8 & 1.9 \\
\hline \multirow[t]{2}{*}{ Father Sibling Group Size } & Mean & 2.8 & 2.9 & 3.1 & 3.3 & 3.6 & 2.8 & 2.9 & 2.9 & 3.0 & 3.2 & 2.2 & 2.8 & 3.9 & 5.0 & 6.9 \\
\hline & $\mathrm{SD}$ & 1.6 & 1.6 & 1.7 & 1.9 & 2.1 & 1.6 & 1.6 & 1.7 & 1.7 & 1.9 & 1.2 & 1.2 & 1.2 & 1.4 & 1.8 \\
\hline \multirow[t]{2}{*}{ Mother Birth Year } & Mean & 1949.3 & 1948.0 & 1946.7 & 1945.6 & 1944.6 & 1948.2 & 1948.7 & 1949.2 & 1949.5 & 1950.1 & 1948.1 & 1948.7 & 1949.3 & 1949.8 & 1950.8 \\
\hline & $\mathrm{SD}$ & 5.4 & 4.8 & 4.3 & 4.0 & 3.7 & 5.3 & 5.1 & 5.1 & 5.1 & 4.8 & 5.2 & 5.2 & 5.1 & 5.1 & 4.9 \\
\hline \multirow[t]{2}{*}{ Father Birth Year } & Mean & 1947.1 & 1945.9 & 1944.6 & 1943.5 & 1942.6 & 1946.2 & 1946.5 & 1946.8 & 1947.0 & 1947.4 & 1946.0 & 1946.6 & 1947.1 & 1947.6 & 1948.6 \\
\hline & SD & 5.3 & 4.6 & 4.1 & 3.8 & 3.6 & 5.1 & 5.0 & 5.0 & 5.0 & 4.8 & 5.0 & 5.0 & 5.0 & 4.9 & 4.6 \\
\hline Maternal Grandmother & Mean & 28.2 & 28.4 & 28.5 & 28.4 & 28.2 & 25.9 & 29.0 & 31.4 & 33.0 & 35.1 & 28.3 & 28.3 & 28.2 & 28.2 & 28.1 \\
\hline Age at Birth & $\mathrm{SD}$ & 6.1 & 6.1 & 6.1 & 6.2 & 6.4 & 5.7 & 5.4 & 5.3 & 5.2 & 4.9 & 6.1 & 6.1 & 6.2 & 6.2 & 6.3 \\
\hline Paternal Grandmother & Mean & 28.3 & 28.6 & 28.7 & 28.8 & 28.3 & 28.5 & 28.4 & 28.5 & 28.4 & 28.4 & 26.3 & 29.3 & 31.4 & 33.0 & 34.9 \\
\hline Age at Birth & SD & 6.1 & 6.0 & 6.1 & 6.2 & 6.3 & 6.0 & 6.0 & 6.1 & 6.2 & 6.2 & 5.7 & 5.4 & 5.3 & 5.1 & 4.8 \\
\hline \multirow[t]{8}{*}{ Mother Education (\%) } & Primary ( $<9$ years) & 9.4 & 10.7 & 14.5 & 21.0 & 31.5 & 9.2 & 10.5 & 12.1 & 14.0 & 15.3 & 10.5 & 10.2 & 10.5 & 11.2 & 10.3 \\
\hline & Primary (9 years) & 12.0 & 11.2 & 10.5 & 10.9 & 10.8 & 11.0 & 11.6 & 12.4 & 13.3 & 15.2 & 11.3 & 11.4 & 12.2 & 13.1 & 14.4 \\
\hline & Secondary (10-11 years) & 41.1 & 40.6 & 40.0 & 38.8 & 35.9 & 39.8 & 40.8 & 42.1 & 44.0 & 45.8 & 39.9 & 40.8 & 42.0 & 44.3 & 46.6 \\
\hline & Secondary (12 years) & 9.5 & 9.1 & 7.7 & 6.2 & 5.4 & 9.8 & 9.0 & 8.3 & 7.8 & 7.1 & 9.3 & 9.1 & 9.2 & 8.6 & 9.3 \\
\hline & Tertiary (13-15 years) & 12.6 & 12.5 & 11.3 & 9.3 & 7.3 & 13.1 & 12.6 & 11.5 & 10.1 & 8.8 & 12.7 & 12.7 & 11.9 & 10.5 & 9.6 \\
\hline & Tertiary $(15+$ years $)$ & 14.8 & 15.3 & 15.5 & 13.4 & 8.4 & 16.6 & 15.0 & 13.0 & 10.3 & 7.6 & 15.8 & 15.2 & 13.8 & 12.0 & 9.6 \\
\hline & Graduate school & 0.5 & 0.5 & 0.5 & 0.4 & 0.3 & 0.5 & 0.5 & 0.4 & 0.3 & 0.1 & 0.5 & 0.5 & 0.4 & 0.3 & 0.2 \\
\hline & Missing & 0.1 & 0.1 & 0.1 & 0.1 & 0.4 & 0.1 & 0.1 & 0.1 & 0.1 & 0.1 & 0.1 & 0.1 & 0.1 & 0.1 & 0.1 \\
\hline
\end{tabular}


Table 2 - Continued from previous page

\begin{tabular}{|c|c|c|c|c|c|c|c|c|c|c|c|c|c|c|c|c|}
\hline & & \multicolumn{5}{|c|}{ Index Birth Order } & \multicolumn{5}{|c|}{ Mother Birth Order } & \multicolumn{5}{|c|}{ Father Birth Order } \\
\hline & & 1 & 2 & 3 & 4 & $5+$ & 1 & 2 & 3 & 4 & $5+$ & 1 & 2 & 3 & 4 & $5+$ \\
\hline \multirow{6}{*}{ Mother EGP (\%) } & I & 1.0 & 0.8 & 0.7 & 0.6 & 0.7 & 1.0 & 0.9 & 0.8 & 0.7 & 0.5 & 1.0 & 1.0 & 0.8 & 0.7 & 0.5 \\
\hline & II & 35.4 & 38.7 & 36.7 & 31.5 & 25.1 & 39.4 & 36.7 & 32.5 & 28.4 & 24.2 & 39.4 & 36.3 & 32.1 & 28.4 & 23.3 \\
\hline & III & 9.8 & 7.8 & 5.8 & 5.4 & 5.7 & 8.5 & 8.8 & 9.2 & 9.4 & 8.7 & 8.5 & 8.9 & 9.2 & 9.2 & 9.0 \\
\hline & IV & 2.5 & 3.0 & 4.5 & 6.3 & 6.8 & 2.7 & 3.0 & 3.3 & 2.9 & 2.9 & 2.7 & 3.0 & 3.2 & 3.3 & 3.0 \\
\hline & VI-VII & 27.5 & 26.0 & 28.0 & 34.0 & 42.8 & 25.4 & 26.9 & 29.4 & 32.6 & 35.6 & 25.7 & 26.9 & 29.8 & 31.9 & 34.2 \\
\hline & Unknown & 23.8 & 23.7 & 24.3 & 22.3 & 18.9 & 23.0 & 23.6 & 24.9 & 25.9 & 28.1 & 22.7 & 24.0 & 25.0 & 26.5 & 30.0 \\
\hline \multirow[t]{8}{*}{ Father Education (\%) } & Primary ( $<9$ years) & 18.1 & 20.3 & 25.2 & 31.9 & 38.8 & 18.8 & 19.3 & 20.7 & 22.6 & 24.6 & 17.6 & 19.8 & 22.5 & 26.5 & 27.7 \\
\hline & Primary (9 years) & 12.4 & 10.5 & 8.6 & 7.4 & 7.5 & 11.0 & 11.3 & 12.0 & 12.8 & 13.7 & 10.5 & 11.4 & 12.8 & 13.7 & 16.4 \\
\hline & Secondary (10-11 years) & 29.1 & 26.8 & 25.6 & 26.6 & 28.2 & 27.2 & 27.9 & 29.3 & 30.6 & 32.4 & 27.1 & 28.0 & 29.4 & 30.7 & 32.6 \\
\hline & Secondary (12 years) & 16.3 & 17.4 & 16.0 & 12.7 & 10.1 & 17.2 & 16.7 & 15.7 & 14.9 & 13.8 & 18.0 & 16.6 & 14.3 & 12.4 & 10.3 \\
\hline & Tertiary (13-15 years) & 10.5 & 10.5 & 9.0 & 6.9 & 4.5 & 10.6 & 10.4 & 9.9 & 9.0 & 8.2 & 11.0 & 10.3 & 9.3 & 7.9 & 7.2 \\
\hline & Tertiary (15+ years) & 12.1 & 12.9 & 13.4 & 12.1 & 8.9 & 13.5 & 12.7 & 11.0 & 8.9 & 6.6 & 13.8 & 12.5 & 10.4 & 8.0 & 5.1 \\
\hline & Graduate school & 1.3 & 1.5 & 2.0 & 2.2 & 1.8 & 1.6 & 1.4 & 1.2 & 0.9 & 0.5 & 1.7 & 1.3 & 1.1 & 0.7 & 0.5 \\
\hline & Missing & 0.3 & 0.2 & 0.1 & 0.2 & 0.3 & 0.3 & 0.2 & 0.3 & 0.3 & 0.2 & 0.3 & 0.2 & 0.2 & 0.2 & 0.2 \\
\hline \multirow[t]{6}{*}{ Father EGP $(\%)$} & I & 1.8 & 1.5 & 1.1 & 0.8 & 0.9 & 1.7 & 1.7 & 1.5 & 1.2 & 1.1 & 1.7 & 1.7 & 1.4 & 1.2 & 1.0 \\
\hline & II & 21.3 & 23.7 & 22.7 & 18.9 & 15.3 & 23.6 & 22.4 & 20.1 & 17.9 & 15.3 & 24.9 & 21.9 & 18.1 & 14.5 & 10.9 \\
\hline & III & 3.1 & 2.2 & 1.3 & 1.0 & 1.1 & 2.6 & 2.7 & 2.7 & 2.5 & 2.5 & 2.5 & 2.7 & 2.7 & 2.8 & 2.6 \\
\hline & IV & 5.2 & 5.4 & 6.7 & 8.5 & 7.6 & 5.2 & 5.4 & 6.0 & 5.9 & 6.2 & 4.9 & 5.6 & 6.2 & 6.6 & 6.4 \\
\hline & VI-VII & 47.4 & 46.3 & 47.2 & 50.5 & 55.0 & 45.3 & 46.4 & 49.5 & 52.9 & 57.7 & 44.0 & 47.1 & 51.7 & 56.3 & 61.8 \\
\hline & Unknown & 21.3 & 21.0 & 21.1 & 20.3 & 20.2 & 21.7 & 21.5 & 20.2 & 19.6 & 17.2 & 22.0 & 21.0 & 20.0 & 18.7 & 17.3 \\
\hline
\end{tabular}


The EGP variable used in this study is divided into the following categories: upper service class, including self-employed professionals (EGP=I); lower service class (EGP=II); routine nonmanual (EGP=III); self-employed non-professionals, farmers, and fishermen (EGP=IV); skilled and unskilled workers (EGP=VI-VII); and, unknown/other.

\section{Statistical Analyses.}

Parental Birth Order. To examine the relationship between birth order and educational attainment at age 30 we use linear regression with and without the application of fixed effects. We first estimate the association between parental birth order and offspring educational attainment using the full sample, without implementing fixed effects:

$$
\begin{aligned}
& y=\beta_{0}+\beta_{l} B O_{l}+\varepsilon \\
& y=\beta_{0}+\beta_{l} B O_{l}+\beta_{m} G 2-\text { Controls }_{m}+\varepsilon \\
& y=\beta_{0}+\beta_{l} B O_{l}+\beta_{m} G 2 \text {-Controls } s_{m}+\beta_{n} G 3 \text {-Mediator } s_{n}+\varepsilon \\
& y=\beta_{0}+\beta_{l} B O_{l}+\beta_{m} G 2 \text {-Control } s_{m}+\beta_{n} \text { G3-Mediators }{ }_{n}+\beta_{o} \text { G2-Mediators } \text { Me }_{o}+\varepsilon
\end{aligned}
$$

where $y$ refers to years of educational attainment at age $30, B O$ refers to a vector of the birth order of the mother (G2) and father (G2), G3-Controls refers to a vector of the control variables at the level of the third-generation, G2-Controls refers to a vector of the control variables at the level of the second-generation, and G2-Mediators refers to a vector of the G2 mediating variables, i.e. attained socioeconomic status and educational attainment of the parents. Model 1 estimates the total effect of maternal and paternal birth order on offspring educational attainment. Model 2 adjusts for confounding factors measured at the time of the parents birth, and Models 3 and 4 successively introduce control variables for mediating variables at the G3 and G2 level, respectively. Models 1, 2, 3, and 4 are OLS models that use the full population. Descriptive statistics for the population used to estimate Models 1, 2, 3, and 4 are shown in Table 2. 
Our fixed effects analyses are based upon a shared grandparental ID, meaning that we compare full biological cousins. Since an individual can have two sets of cousins, we have two analytical samples: maternal cousin groups, and paternal cousin groups. Our cousin fixed effects analyses are therefore based upon the following six models:

$$
\begin{aligned}
& y_{i j}=\beta_{0}+\beta_{l} B O_{l, i j}+\beta_{m} G 2-\text { Controls }_{m, i j}+\alpha_{j}+\varepsilon_{i j} \\
& y_{i j}=\beta_{0}+\beta_{l} B O_{l, i j}+\beta_{m} G 2 \text {-Controls } s_{m, i j}+\beta_{n} G 3 \text {-Mediators }{ }_{n, i j}+\alpha_{j}+\varepsilon_{i j} \\
& y_{i j}=\beta_{0}+\beta_{l} B O_{l, i j}+\beta_{m} G 2 \text {-Controls } s_{m, i j}+\beta_{n} G 3 \text {-Mediators }{ }_{n, i j}+\beta_{o} G 2 \text {-Mediators } \text { M }, i j+\alpha_{j}+\varepsilon_{i j} \\
& y_{i k}=\beta_{0}+\beta_{l} B O_{l, i k}+\beta_{m} G 2-\text { Controls }_{m, i k}+\delta_{k}+\varepsilon_{i k} \\
& y_{i k}=\beta_{0}+\beta_{l} B O_{l, i k}+\beta_{m} G 2-\text { Controls }_{m, i k}+\beta_{n} G 3 \text {-Mediators } \text { M }, i k+\delta_{k}+\varepsilon_{i k}
\end{aligned}
$$

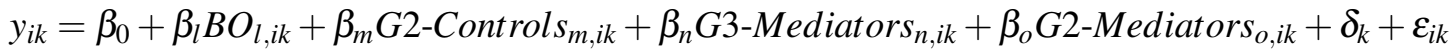

where $y$ refers to years of educational attainment at age 30, the indexes $i, j$, and $k$ refer to individual $i$ in maternal cousin group $j$, and paternal cousin group $k, \alpha$ is the fixed effect for maternal cousin group $j, \delta$ is the fixed effect for paternal cousin group $k$, and $\varepsilon$ is the residual. Models 5,6 , and 7 are linear regressions estimated on the maternal cousin analytical sample, implementing cousin fixed effects. Models 8, 9, and 10 are linear regressions estimated on the paternal cousin analytical sample, implementing cousin fixed effects. As with the OLS models without cousin fixed effects (Models 1 to 4), we control for confounding variables measured at the time of the parents birth in Models 5 and 8, and introduce control variables for mediating variables at the G3 and G2 level, respectively in Models 6, 7, 9, and 10. Further descriptive statistics for the maternal cousin and paternal cousin group samples are shown in the Supplementary Information, in Tables S1 and S2.

We also run a number of additional analyses to examine the extent to which parental and child birth order (and gender) moderate each other (i.e. interact) in predicting the educational attainment of the children. For example, we examine whether sharing the same birth order has any effect on educational attainment above and beyond the main effects of parent and child birth order. We operationalise birth order three ways to examine these interactions. We first examine whether 
the parents and child share the same ordinal birth order, we then examine whether they share a similarity in being a first-, middle-, or last-born child, and finally we examine whether they are similar in being either the first- or a later-born child. In further analyses we also examine whether parent-child birth order and gender homophily interacts with the educational level of the parent to influence educational attainment, and so examine whether this homophily is particularly important when the parents have greater human capital at their disposal.

Parental Sibling Group Size. Another objective of our study is to examine how resource dilution in the parental generation, related to family size, affects the attainment of the subsequent generation. Since family size is endogenous, we study twin births as an exogenous shock on family size (as first proposed by Rosenzweig and Wolpin, 1980), to examine the relationship between parental sibling group size and educational attainment amongst their children. The Swedish Multigenerational Register allows us to identify twins, and the parity at which the twin birth occurs. Although our focus is on the educational attainment of the grandchild generation (G3), who are born 1960-1982, we study how fertility and twinning in the grandparental generation (G1) affects the family size of the parental generation (G2). As the parental generation were born between the 1930s and early 1970s, this is before the first in vitro fertilisation (IVF) assisted birth took place in Sweden in 1982; consequently, twin births are a valid exogenous instrument for family size for the cohorts that we study.

To estimate these models we use a two-stage least squares (2SLS) estimation strategy (Angrist and Pischke, 2008, Chapter 4). We estimate the following equations:

$$
\begin{aligned}
\text { FAMILYSIZE } & =\alpha_{0}+\alpha_{1} \text { TWIN }_{G 2}+\alpha_{2} X+v \\
E D U_{G 3} & =\beta_{0}+\beta_{1} \text { FAMILYSIZE }_{G 2}+\beta_{2} X+\varepsilon
\end{aligned}
$$

where FAMILYSIZE $E_{G 2}$ is the final family size of the mother or father, TWIN is a binary indicator for a twin birth in the family, $X$ is a vector of control variables, and $E D U_{G 3}$ is the educational attainment of the offspring (G3) at age 30. Equation 11 is the first-stage estimation, and equation 
12 the second-stage. We estimate these 2SLS models separately for the mother and father. We control for the birth year of the mother or father, as well as the age of the grandmother (G1) at the time of birth, as maternal age at birth is related to the probability of twinning. To estimate these models we use what has been called the 'twin-first' approach (Black et al., 2009). The TWIN ${ }_{G 2}$ variable is a binary indicator denoting whether the $n$th birth was a twin or not, estimated on the population of children born before the $n$th birth in families with at least $n$ births. For example, we estimate these models on the population of first-born children in families with at least two children, whose mother may or may not have had a twin birth at parity 2. We estimate these models for mothers and father separately, for values of $n$ between 2 and 4 . To be clear, twins themselves are not included in the analysis, and the key variable pertains to whether or not an individual was exposed to a twin birth, implying exposure to a larger family size than would otherwise have been expected, as well as the potential consequences such as further resource dilution amongst siblings.

\section{RESULTS}

Parental Birth Order. We begin by presenting the results from our analyses of the relationship between parental birth order and the educational attainment of their children at age 30 . Figure 2 shows the results from models using the full population of individuals for whom it was possible to link three generations using the Swedish register data. The results shown in Figure 2 do not implement the cousin fixed effects approach. Figure 2 consists of four panels, successively displaying the results from Models 1 to 4 . These model numbers correspond to the equations detailed in the 'Statistical Analyses' section above. Full results tables for these models can be seen in the Supplementary Information, in Table S3.

Models 1 to 4 in Figure 2 show the correlation between maternal and paternal birth order and offspring educational attainment at age 30. The results from Model 1 are the total effects of parental birth order, capturing all intermediary mediating processes between parental birth and offspring educational attainment. The results from Model 1 show show that, relative to having a mother who was first-born, having a mother who was third-born is associated with 0.07 less years of education by age 30, and having a mother who was fifth-born is associated with 0.33 less years of education at age 30. Likewise, having a father who was third-born is associated with 0.03 less 
years of education by age 30, and having a father who was fifth-born is associated with 0.27 less years of education at age 30. Introducing additional controls for parental (G2) characteristics in Model 2 actually increases the size of the point estimates. We see that, relative to having a firstborn mother or father, having a mother or father who is second-born is associated with having approximately 0.20 years less education by age 30 , and having a mother or father who is fifth-born or later is associated with having over 0.40 years less education by age 30 . This change in the estimates between Models 1 and 2 is related to the fact that later-born parents were on average born into a later birth year, and as a consequence of educational expansion in Sweden they had more educational opportunities, with consequent benefits for their own educational achievement and subsequently the educational achievement of their children. By controlling for parental birth cohort in Model 2 we partially adjust for those period changes in educational opportunities.

In Models 3 and 4 we introduce additional covariates in order to control for mediating variables at the grandchild level and the parental level. Model 3 focuses on mediating variables at the grandchild level. The results from Model 3 are relatively similar to those from Model 2, and we see that, relative to having a mother who was first-born, having a mother who was second-born is associated with 0.14 less years of education by age 30, and having a mother who was fifthborn is associated with 0.33 less years of education at age 30. Likewise, having a father who was second-born is associated with 0.13 less years of education by age 30 , and having a father who was fifth-born is associated with 0.30 less years of education at age 30 . Thus, even net of the index person's own birth order and birth year, amongst other factors, having a later-born parent is associated with lower educational attainment at age 30. In relation to the summary statistics for this population, 0.30 years of education by age 30 is equivalent to $13 \%$ of a standard deviation, which is far from a trivial association.

As we discuss earlier in this manuscript, we not only want to examine the association between parental birth order and offspring educational attainment, but also to examine the pathway by which that association operates. One possibility is that the effects of grandparental fertility outcomes (the determinant of parental birth order) are fully channeled through parental socioeconomic attainment, corresponding to a memoryless Markov process. The second possibility is that there are 


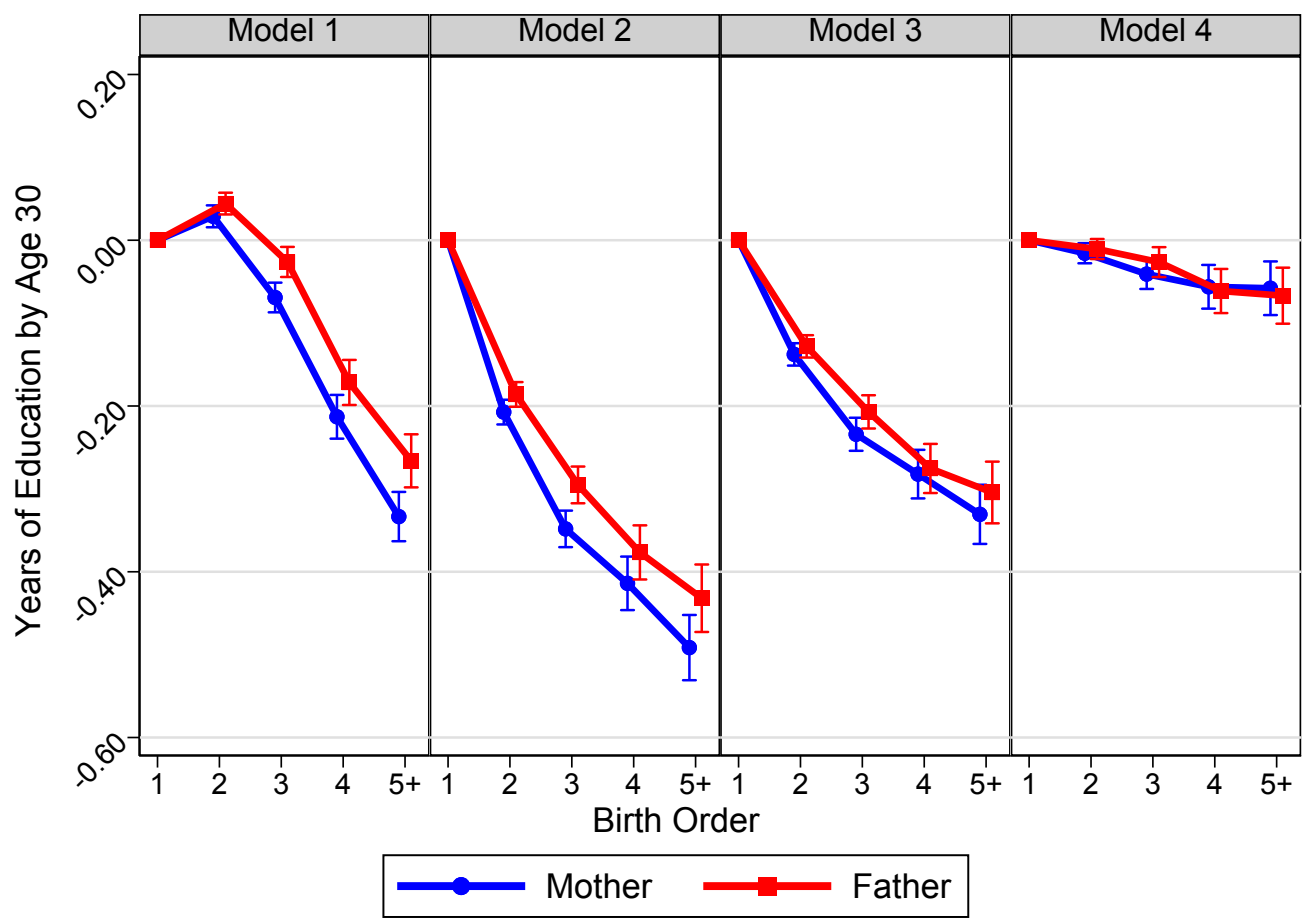

FIGURE 2. Educational attainment at age 30 amongst Swedish men and women born 1960 to 1982. Linear regression model, using maternal cousin sample. Error bars are $95 \%$ confidence intervals.

multigenerational effects above and beyond the two-generation dyad. To examine whether the association between grandparental fertility and grandchild educational attainment is a consequence of parental birth order, in Model 4 we also introduce additional covariates for the highest level of educational attainment of both the mother and father, as well as their attained social class position, measured between ages 40 and 50. As Figure 2 shows, when we control for parental educational and social class attainment, the association between parental birth order and offspring educational attainment is significantly attenuated. Relative to having a first-born mother or father, having a mother or father who is second-born is associated with having 0.01 years less education by age 30 , and having a mother or father who is fifth-born or later is associated with having over 0.06 years less education by age 30. Although these are very small differences, the differences are statistically significant. Nevertheless, since these models only control for observed confounding factors, there may be residual confounding. We now turn to our estimates using the cousin fixed effects approach that should help us to capture unobserved confounding from factors shared within the extended family. 
Figures 3 and 4 show the results from models where we implement a cousin fixed effects design, comparing cousins from generation 3 who share grandparents. Using this approach we attempt to control for background factors that are related to both the fertility outcomes of the grandparents as well as the attainment of the grandchildren many years later. Such background factors could include socioeconomic resources, as well as unobserved underlying health conditions within the family. Figure 3 shows the results from Models 5, 6, and 7, which are based on the maternal cousin group sample. Here we focus on the point estimates for maternal birth order, since it is unobserved maternal background characteristics that are being effectively controlled for by comparing maternal cousins to one another.

Model 5 in Figure 3, controlling for factors fixed at the time of the parents birth, illustrates that the relationship between maternal birth order and offspring educational attainment is somewhat mixed, but the differences are generally not statistically significant. The only exception is that having a fourth-born mother is positively associated with offspring educational attainment. In Model 6, we introduce additional covariates for mediating factors measured at the level of the index person (G3), or the grandchild generation. After controlling for G3 characteristics, most importantly birth year, we see that having a second-born mother relative to a first-born mother is associated with having 0.09 years less education at age 30. Furthermore, having a fifth- or laterborn mother relative to a first-born mother is associated with having 0.18 years less education at age 30. In Model 7 we again control for the attained educational and social class of the mother in order to examine whether effects of grandparental fertility flow only through their effects on parental educational and socioeconomic attainment. Here we find that the effects of maternal birth order are attenuated more severely, and the estimated effects for maternal birth order are also no longer statistically significant.

The reason for the difference in the estimates for maternal birth order between Models 5 and Models 6 and 7 is related to educational expansion as well as the cousin fixed effects approach. In the cousin fixed effects modeling approach we create a mechanical relationship between birth order and birth year, where later borns are almost always going to be born into a later birth year (this is completely deterministic in sibling FE model, but there is more potential for covariance in a cousin FE model focusing on parental birth order). When we control for G3 birth year, as 


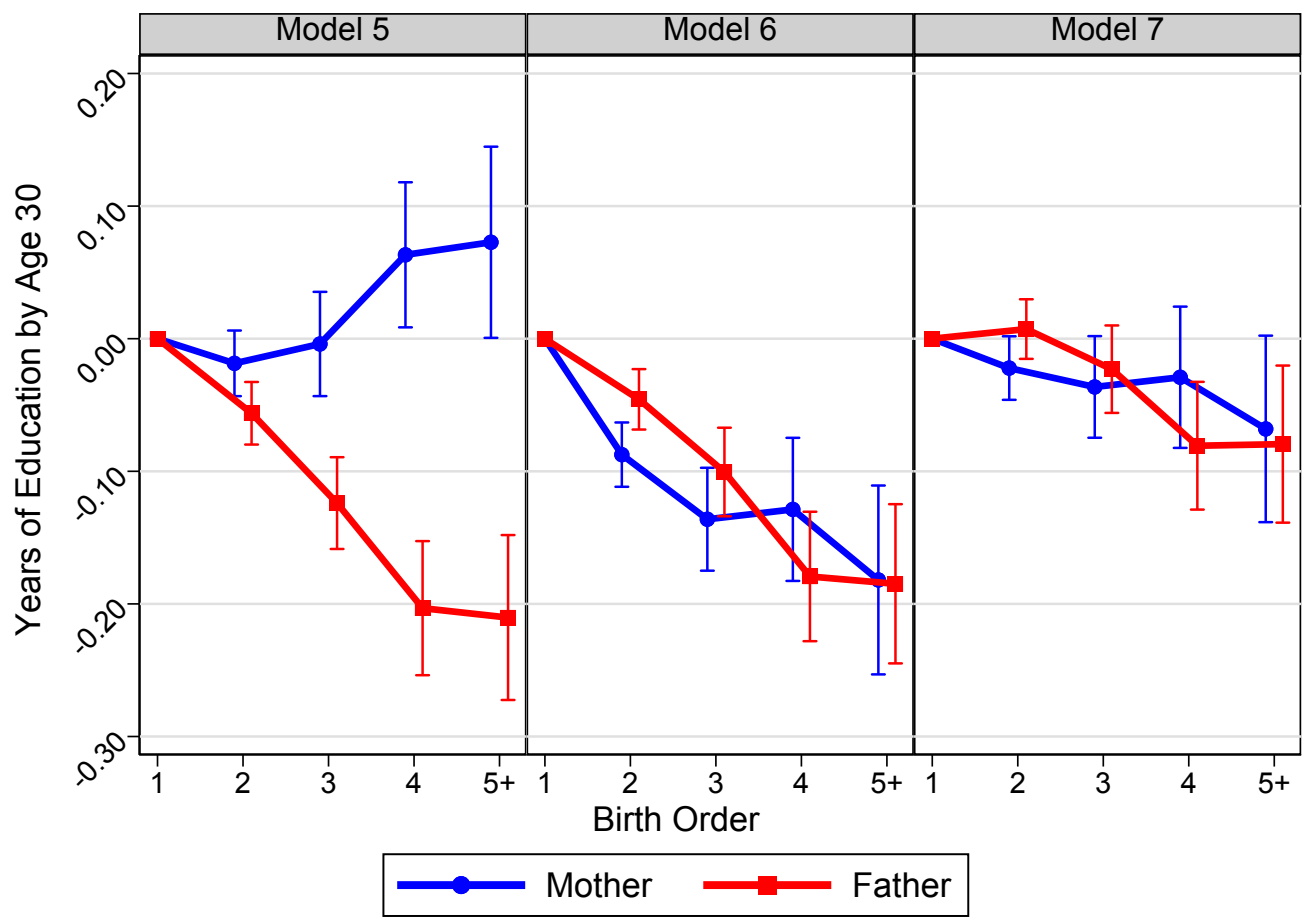

FIGURE 3. Educational attainment at age 30 amongst Swedish men and women born 1960 to 1982. Fixed effects linear regression model, using maternal cousin sample. Error bars are $95 \%$ confidence intervals.

we do in Model 6, we completely control away the benefits of educational expansion because G3 is the generation whose educational attainment we are actually measuring and who benefit directly from being born into a later birth year. By excluding a control for the birth year of G3 in Model 5 parental birth order unwittingly captures important intermediary processes, including secular trends in educational enrollment. As a result, the estimates from Model 5 indicate that later parental birth order tends to be associated with increasing educational attainment, but this is only because later-born parents are also more likely to give birth in a later calendar year than their older siblings, which then captures the increasing educational enrollment in Sweden in this period.

The results shown in Figure 4 repeat these analyses on the sample of paternal cousins, and here we focus on the association between the birth order of the father and offspring educational attainment. The results for paternal birth order from Models 8, 9, and 10 correspond relatively closely to the results for maternal birth order from Models 5, 6, and 7. In Model 8 we observe a positive, though non statistically significant, association between paternal birth order and offspring educational attainment. As explained above, this is primarily due to educational expansion and 


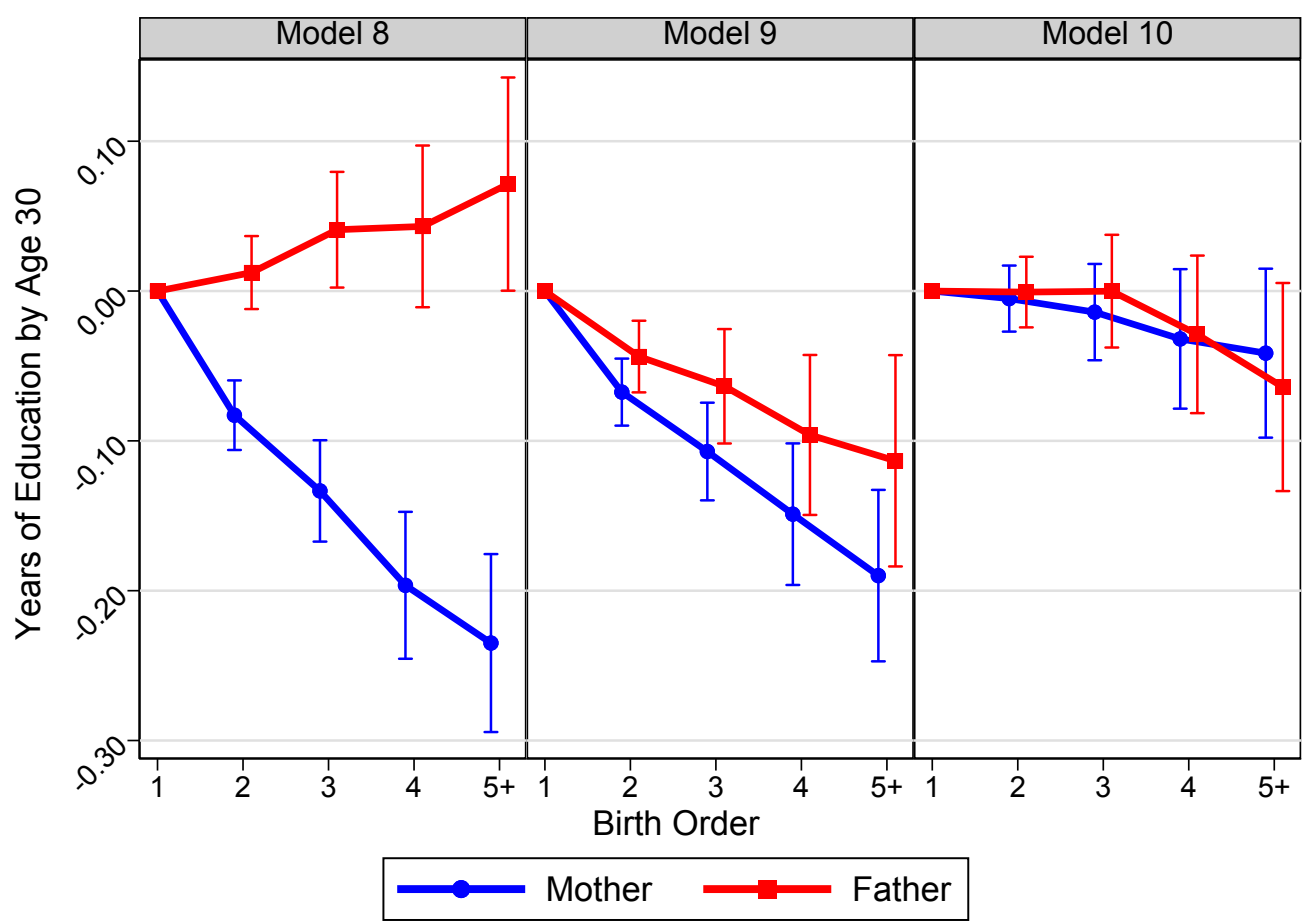

FIGURE 4. Educational attainment at age 30 amongst Swedish men and women born 1960 to 1982. Fixed effects linear regression model, using paternal cousin sample. Error bars are $95 \%$ confidence intervals.

the lack of a control for offspring birth year (G3). In Model 9 we find that having a secondborn father relative to a first-born father is associated with having 0.04 years less education at age 30, and having a fifth- or later-born father relative to a first-born father is associated with having 0.11 years less education at age 30. In Model 10 we introduce additional controls for the father's educational and social class attainment, and find that the effects of paternal birth order on offspring educational attainment are reduced almost to zero, and are no longer statistically significant. These results strongly suggest that the effects of grandparental fertility outcomes on grandchild attainment largely, if not completely, flow through the intermediary generation.

We have also conducted a number of robustness checks to examine the sensitivity of our results to our statistical modeling choices. We have checked whether coding birth order according to being first-, middle-, or last-born leads to meaningfully different results, and it does not. We have also recoded birth order according to a first- versus later-born dichotomy, and this does not affect the conclusions that we would draw either. We have also estimated models using a more detailed control for parental birth year, using individual-year dummy variables rather than the 
TABLE 3. The relationship between parent-child birth order homophily on offspring educational attainment at age 30, Swedish men and women born 1960-1982.

\begin{tabular}{lllllllll}
\hline Sample & Model & Birth Order Homophily & Gender Homophily & Parent & b & se & p & N \\
\hline Maternal Cousin & 7 & Ordinal & No & Mother & 0.015 & 0.007 & 0.029 & 509,739 \\
& 7 & Ordinal & No & Father & 0.014 & 0.006 & 0.028 & 509,739 \\
& 7 & First-Middle-Last & No & Mother & 0.009 & 0.007 & 0.157 & 509,739 \\
& 7 & First-Middle-Last & No & Father & 0.015 & 0.006 & 0.022 & 509,739 \\
& 7 & First-Later & No & Mother & 0.010 & 0.006 & 0.087 & 509,739 \\
& 7 & First-Later & No & Father & 0.019 & 0.006 & 0.001 & 509,739 \\
& 7 & Ordinal & Yes & Mother & -0.003 & 0.010 & 0.721 & 509,739 \\
& 7 & Ordinal & Yes & Father & 0.040 & 0.009 & 0.000 & 509,739 \\
& 7 & First-Middle-Last & Yes & Mother & 0.000 & 0.010 & 0.973 & 509,739 \\
& 7 & First-Middle-Last & Yes & Father & 0.031 & 0.009 & 0.001 & 509,739 \\
& 7 & First-Later & Yes & Mother & 0.025 & 0.009 & 0.004 & 509,739 \\
& 7 & First-Later & Yes & Father & 0.020 & 0.008 & 0.017 & 509,739 \\
& 10 & Ordinal & No & Mother & 0.017 & 0.006 & 0.007 & 514,222 \\
& 10 & Ordinal & No & Father & 0.011 & 0.007 & 0.108 & 514,222 \\
& 10 & First-Middle-Last & No & Mother & 0.011 & 0.006 & 0.084 & 514,222 \\
& 10 & First-Middle-Last & No & Father & 0.016 & 0.007 & 0.017 & 514,222 \\
& 10 & First-Later & No & Mother & 0.018 & 0.006 & 0.001 & 514,222 \\
& 10 & First-Later & No & Father & 0.015 & 0.006 & 0.008 & 514,222 \\
& 10 & Ordinal & Yes & Mother & 0.010 & 0.009 & 0.304 & 514,222 \\
& 10 & Ordinal & Yes & Father & 0.046 & 0.009 & 0.000 & 514,222 \\
10 & First-Middle-Last & Yes & Mother & 0.011 & 0.009 & 0.246 & 514,222 \\
10 & First-Middle-Last & Yes & Father & 0.045 & 0.009 & 0.000 & 514,222 \\
10 & First-Later & Yes & Mother & 0.033 & 0.009 & 0.000 & 514,222 \\
10 & First-Later & Yes & Father & 0.016 & 0.008 & 0.062 & 514,222 \\
\hline & & & & & & &
\end{tabular}

cohort groupings used in the main models above. Those models also produce extremely similar results to those presented above. The detailed output of all these additional analyses are available upon request from the authors.

Parent-Child Birth Order Interactions. The results from models examining whether there is an effect of parent-child birth order homophily on offspring educational attainment net of the main effects of parental birth order and child birth order are shown in Table 3. The results shown in Table 3 are based upon cousin fixed effects models applied to the same maternal cousin and paternal cousin group samples used in the analyses presented above in Figures 3 and 4 . These models include the same set of control variables as Models 7 and 10 for the maternal and paternal cousin group analyses respectively, along with an additional term for whether the parent and child shared the same birth order position.

We focus on displaying the point estimates for parent-child homophily, because the additional regression output is extremely large. These results are available in full upon request. Table 3 shows 
that we do observe an independent effect of parent-child birth order homophily, and that in most cases this independent effect is positive and statistically significant. However, we also observe that this effect is substantively negligible. A child who has the same birth order as the parent, whether that is defined as the same ordinal position, also being first-, middle- or last-born, or also being a first- versus a later-born, has 0.01 to 0.02 more years of education by age 30 relatively to his or her cousins who were not birth order homophilous with the parents.

Table 3 also shows the results from analyses where we examine whether there is an effect of parent-child birth order and gender homophily. Again, these models use the same samples and set of covariates, but include an additional term for whether the parent and child shared the same birth order position and gender (e.g. the first-born son of a first-born father). The results in Table 3 show that parent-child homophily on both birth order and gender is associated with a more meaningful increase in educational attainment for the child than if there is homophily on birth order alone. Nevertheless, even when parents and children share birth order position, however operationalised, as well as the same gender, the net increase in educational attainment is at most 0.05 years of education, and typically closer to 0.03 or 0.04 years of education by age 30 . It may be worth noting that parent-child birth order and gender homophily seems to be more beneficial for sons than it is for daughters, but these differences are extremely small in the context of educational attainment by age 30 .

We have also run additional analyses examining whether parental educational level interacts with parent-child birth order and gender homophily to influence educational attainment. For example, does a first-born son of a first-born father have a greater correlation in education than a secondborn son with a first-born father. Tables 4 and 5 examine this question using the maternal cousin and paternal cousin samples, respectively. We will focus on the results examining the interaction between parent-child homophily and maternal educational level in Table 4, as residual confounding in the maternal cousin group is most effectively controlled for in those analyses. Table 4 shows that when examining parent-child birth order homophily alone, we do not find that there is any statistically significant shift in the degree of parent-child educational similarity. However, when we examine parent-child homophily on both birth order and gender (i.e. a first-born mother and a first-born daughter rather than, say, a first-born mother and first-born son), then we do find a 
statistically significant interaction. In this case we find that the positive effect for the child of sharing the same birth order and gender position as the parent increases the higher the level of education of the mother. That is to say, sharing the same birth order and gender position as the mother is more beneficial for the child when the mother has higher levels of education. This is true whether we operationalise birth order according to ordinal position, first-middle-last, or a first- or later-born distinction. The pattern of results that we observe amongst the maternal cousin sample is also seen in Table 5, showing the results from the paternal cousin group analyses. Here we also see that parent-child birth order homophily alone does not interact significantly with paternal educational level, but when there is parent-child birth order and gender homophily, those whose fathers have higher levels of education benefit disproportionately. It seems that parent-child birth order and gender homophily shifts the slope of intergenerational transmission, where parents who share the same gender and birth order position are more similar in educational levels than the children who do not share those characteristics with the parents. Furthermore, we find that parentchild birth order and gender homophily is most beneficial when the parents have higher levels of human capital resources to transmit to their children.

In this study, we conduct a large number of statistical tests, which raises the multiple comparison problem. Overall we would emphasise that, since we use population data and the standard errors are generally very small, we should largely focus on the direction and substantive magnitude of the point estimates. Nevertheless, statistical testing can still be informative even when applied to population data because it tells us about the variance underlying the estimates: indeed, when an estimate does not reach even the conventional 5\% significance threshold with a very large N, that tells us something important about how noisy the underlying pattern is. In these analyses of the interaction between parent-child birth order homophily and parental education level, we perform a number of different tests, but find that the point estimates are relatively similar across comparable models, and we also find consistency in the patterns of statistical significance (e.g. across the different operationalisations of birth order when examining parent-child birth order and gender homophily). This suggests that we are not simply obtaining significant p-values at random as a result of running multiple different significance tests. 
Table 4: Interaction between parent-child birth order and gender homophily and parental education level, maternal cousin sample, Swedish men and women born 1960-1982.

\begin{tabular}{|c|c|c|c|c|c|c|c|}
\hline & & \multicolumn{3}{|c|}{ Birth Order Homophily } & \multicolumn{3}{|c|}{ Birth Order and Gender Homophily } \\
\hline & & Ordinal & FML & First-Later & Ordinal & FML & First-Later \\
\hline & & Model 7 & Model 7 & Model 7 & Model 7 & Model 7 & Model 7 \\
\hline & & $\mathrm{b}$ & $\mathrm{b}$ & $\mathrm{b}$ & $\mathrm{b}$ & $\mathrm{b}$ & $\mathrm{b}$ \\
\hline \multirow[t]{2}{*}{ Mother-Child Homophily } & Yes & 0.001 & 0.004 & -0.018 & $-0.073 * *$ & $-0.058 *$ & $-0.050^{*}$ \\
\hline & No (ref) & 0.000 & 0.000 & 0.000 & 0.000 & 0.000 & 0.000 \\
\hline \multirow[t]{8}{*}{ Maternal Education } & Primary $<9$ years & $-0.161 * * *$ & $-0.151 * * *$ & $-0.167 * * *$ & $-0.154 * * *$ & $-0.148 * * *$ & $-0.149 * * *$ \\
\hline & Primary - 9 years (ref) & 0.000 & 0.000 & 0.000 & 0.000 & 0.000 & 0.000 \\
\hline & Secondary - 10-11 years & $0.113 * * *$ & $0.115 * * *$ & $0.101 * * *$ & $0.107 * * *$ & $0.107 * * *$ & $0.098 * * *$ \\
\hline & Secondary - 12 years & $0.356 * * *$ & $0.360 * * *$ & $0.356 * * *$ & $0.353 * * *$ & $0.356 * * *$ & $0.349 * * *$ \\
\hline & Tertiary - $13-15$ years & $0.543 * * *$ & $0.539 * * *$ & $0.528 * * *$ & $0.534 * * *$ & $0.531 * * *$ & $0.517 * * *$ \\
\hline & Tertiary $-15+$ years & $0.749 * * *$ & $0.754 * * *$ & $0.738 * * *$ & $0.737 * * *$ & $0.741 * * *$ & $0.728 * * *$ \\
\hline & Post-graduate & $1.046^{* * *}$ & $1.040 * * *$ & $1.051 * * *$ & $1.010 * * *$ & $1.016^{* * *}$ & $1.008 * * *$ \\
\hline & Missing & 0.212 & 0.159 & 0.238 & 0.139 & 0.138 & 0.157 \\
\hline Mother-Child Homophily & Yes $*$ Primary $<9$ years & 0.011 & -0.023 & 0.021 & -0.014 & -0.062 & -0.030 \\
\hline Maternal Education & Yes $*$ Primary -9 years (ref) & 0.000 & 0.000 & 0.000 & 0.000 & 0.000 & 0.000 \\
\hline \multirow[t]{6}{*}{ Interaction } & Yes $*$ Secondary $-10-11$ years & 0.002 & -0.003 & 0.028 & $0.058 *$ & $0.056^{*}$ & $0.077 * *$ \\
\hline & Yes * Secondary -12 years & 0.050 & 0.035 & 0.032 & $0.131 * *$ & $0.100 * *$ & $0.100 * *$ \\
\hline & Yes $*$ Tertiary $-13-15$ years & 0.027 & 0.038 & $0.051 *$ & $0.123 * * *$ & $0.141 * * *$ & $0.157 * * *$ \\
\hline & Yes $*$ Tertiary $-15+$ years & 0.026 & 0.010 & 0.041 & $0.141 * * *$ & $0.110 * *$ & $0.135 * * *$ \\
\hline & Yes * Post-graduate & -0.009 & 0.006 & -0.021 & 0.227 & 0.180 & 0.162 \\
\hline & Yes $*$ Missing & -0.222 & -0.039 & -0.230 & 0.110 & 0.114 & -0.020 \\
\hline \multirow[t]{2}{*}{ Father-Child Homophily } & Yes & 0.018 & 0.021 & 0.021 & -0.041 & -0.041 & $-0.065 * *$ \\
\hline & No (ref) & 0.000 & 0.000 & 0.000 & 0.000 & 0.000 & 0.000 \\
\hline \multirow[t]{8}{*}{ Paternal Education } & Primary $<9$ years & $-0.135 * * *$ & $-0.138 * * *$ & $-0.137 * * *$ & $-0.152 * * *$ & $-0.153 * * *$ & $-0.154 * * *$ \\
\hline & Primary - 9 years (ref) & 0.000 & 0.000 & 0.000 & 0.000 & 0.000 & 0.000 \\
\hline & Secondary - $10-11$ years & $0.062 * * *$ & $0.066 * * *$ & $0.061 * * *$ & $0.051 * *$ & $0.054 * *$ & $0.047 * *$ \\
\hline & Secondary - 12 years & $0.422 * * *$ & $0.421 * * *$ & $0.429 * * *$ & $0.392 * * *$ & $0.395 * * *$ & $0.388 * * *$ \\
\hline & Tertiary - $13-15$ years & $0.619 * * *$ & $0.628 * * *$ & $0.614 * * *$ & $0.592 * * *$ & $0.600 * * *$ & $0.584 * * *$ \\
\hline & Tertiary $-15+$ years & $0.965 * * *$ & $0.967 * * *$ & $0.965 * * *$ & $0.938 * * *$ & $0.943 * * *$ & $0.928 * * *$ \\
\hline & Post-graduate & $1.332 * * *$ & $1.310 * * *$ & $1.328 * * *$ & $1.267 * * *$ & $1.262 * * *$ & $1.249 * * *$ \\
\hline & Missing & -0.095 & -0.135 & -0.079 & -0.075 & -0.096 & -0.069 \\
\hline Father-Child Homophily & Yes $*$ Primary $<9$ years & -0.012 & -0.004 & -0.005 & $0.062 *$ & $0.068 *$ & $0.060 *$ \\
\hline Paternal Education & Yes $*$ Primary -9 years (ref) & 0.000 & 0.000 & 0.000 & 0.000 & 0.000 & 0.000 \\
\hline
\end{tabular}


Table 4 - Continued from previous page

\begin{tabular}{|c|c|c|c|c|c|c|c|}
\hline & & \multicolumn{3}{|c|}{ Birth Order Homophily } & \multicolumn{3}{|c|}{ Birth Order and Gender Homophily } \\
\hline & & Ordinal & FML & First-Later & Ordinal & FML & First-Later \\
\hline & & Model 7 & Model 7 & Model 7 & Model 7 & Model 7 & Model 7 \\
\hline & & $\mathrm{b}$ & $\mathrm{b}$ & $\mathrm{b}$ & $\mathrm{b}$ & $\mathrm{b}$ & $\mathrm{b}$ \\
\hline \multirow[t]{6}{*}{ Interaction } & Yes * Secondary - 10-11 years & 0.004 & -0.007 & 0.004 & $0.061 *$ & 0.050 & $0.068 * *$ \\
\hline & Yes $*$ Secondary -12 years & -0.012 & -0.009 & -0.022 & $0.120 * * *$ & $0.110 * * *$ & $0.117 * * *$ \\
\hline & Yes $*$ Tertiary $-13-15$ years & -0.009 & -0.030 & 0.003 & $0.111 * *$ & $0.075^{*}$ & $0.123 * * *$ \\
\hline & Yes $*$ Tertiary $-15+$ years & 0.010 & 0.007 & 0.010 & $0.152 * * *$ & $0.130 * * *$ & $0.166^{* * *}$ \\
\hline & Yes * Post-graduate & -0.063 & -0.013 & -0.046 & $0.171 *$ & $0.196 * *$ & $0.213 * *$ \\
\hline & Yes $*$ Missing & 0.146 & 0.230 & 0.106 & 0.227 & $0.313^{*}$ & 0.184 \\
\hline \multirow[t]{5}{*}{ Paternal Sibling Group Size (G2) } & 1 & $-0.063 * * *$ & $-0.062 * * *$ & $-0.063 * * *$ & $-0.062 * * *$ & $-0.062 * * *$ & $-0.062 * * *$ \\
\hline & 2 (ref) & 0.000 & 0.000 & 0.000 & 0.000 & 0.000 & 0.000 \\
\hline & 3 & 0.001 & 0.002 & 0.001 & 0.001 & 0.002 & 0.001 \\
\hline & 4 & -0.020 & -0.018 & -0.020 & -0.019 & -0.018 & -0.019 \\
\hline & $5+$ & -0.026 & -0.024 & -0.026 & -0.026 & -0.025 & -0.026 \\
\hline Maternal Grandmother's & $15-19$ & $0.108 * *$ & $0.108 * *$ & $0.108 * *$ & $0.110 * *$ & $0.110 * *$ & $0.108 * *$ \\
\hline \multirow[t]{5}{*}{ Age at Birth (G2) } & $20-24$ & $0.066 * * *$ & $0.066 * * *$ & $0.066 * * *$ & $0.067 * * *$ & $0.066^{* * *}$ & $0.066^{* * *}$ \\
\hline & $25-29$ (ref) & 0.000 & 0.000 & 0.000 & 0.000 & 0.000 & 0.000 \\
\hline & $30-34$ & $-0.074 * * *$ & $-0.074 * * *$ & $-0.074 * * *$ & $-0.074 * * *$ & $-0.074 * * *$ & $-0.074 * * *$ \\
\hline & $35-39$ & $-0.143 * * *$ & $-0.143 * * *$ & $-0.144 * * *$ & $-0.143 * * *$ & $-0.143 * * *$ & $-0.143 * * *$ \\
\hline & $40+$ & $-0.238 * * *$ & $-0.239 * * *$ & $-0.239 * * *$ & $-0.237 * * *$ & $-0.238 * * *$ & $-0.238 * * *$ \\
\hline Paternal Grandmother's & $15-19$ & $-0.157 * * *$ & $-0.157 * * *$ & $-0.157 * * *$ & $-0.154 * * *$ & $-0.155 * * *$ & $-0.155 * * *$ \\
\hline \multirow[t]{5}{*}{ Age at Birth (G2) } & $20-24$ & $-0.097 * * *$ & $-0.097 * * *$ & $-0.097 * * *$ & $-0.096 * * *$ & $-0.096 * * *$ & $-0.096 * * *$ \\
\hline & $25-29$ (ref) & 0.000 & 0.000 & 0.000 & 0.000 & 0.000 & 0.000 \\
\hline & $30-34$ & $0.039 * *$ & $0.039 * *$ & $0.039 * *$ & $0.040 * *$ & $0.039 * *$ & $0.039 * *$ \\
\hline & $35-39$ & $0.033 *$ & $0.033 *$ & $0.033 *$ & $0.034 *$ & $0.033 *$ & $0.034 *$ \\
\hline & $40+$ & $0.046 *$ & $0.046^{*}$ & $0.046^{*}$ & $0.047 *$ & $0.046 *$ & $0.046^{*}$ \\
\hline \multirow[t]{6}{*}{ Maternal Birth Year (G2) } & 1938-1945 & $0.082 * *$ & $0.083 * *$ & $0.082 * *$ & $0.083 * *$ & $0.083 * *$ & $0.083 * *$ \\
\hline & 1946-1949 & $0.051 * *$ & $0.051 * *$ & $0.051 * *$ & $0.051 * *$ & $0.051 * *$ & $0.051 * *$ \\
\hline & 1950-1954 (ref) & 0.000 & 0.000 & 0.000 & 0.000 & 0.000 & 0.000 \\
\hline & 1955-1959 & $-0.089 * * *$ & $-0.089 * * *$ & $-0.089 * * *$ & $-0.090 * * *$ & $-0.090 * * *$ & $-0.088 * * *$ \\
\hline & 1960-1964 & $-0.155 * *$ & $-0.153 * *$ & $-0.153 * *$ & $-0.157 * *$ & $-0.155^{* *}$ & $-0.152 * *$ \\
\hline & 1965-1969 & -0.184 & -0.178 & -0.181 & -0.186 & -0.182 & -0.179 \\
\hline \multirow[t]{3}{*}{ Paternal Birth Year (G2) } & $1938-1945$ & $0.093 * * *$ & $0.093 * * *$ & $0.093 * * *$ & $0.093 * * *$ & $0.093 * * *$ & $0.093 * * *$ \\
\hline & 1946-1949 & $0.062 * * *$ & $0.062 * * *$ & $0.062 * * *$ & $0.062 * * *$ & $0.062 * * *$ & $0.061 * * *$ \\
\hline & $1950-1954$ (ref) & 0.000 & 0.000 & 0.000 & 0.000 & 0.000 & 0.000 \\
\hline
\end{tabular}


Table 4 - Continued from previous page

\begin{tabular}{|c|c|c|c|c|c|c|c|}
\hline & & \multicolumn{3}{|c|}{ Birth Order Homophily } & \multicolumn{3}{|c|}{ Birth Order and Gender Homophily } \\
\hline & & Ordinal & FML & First-Later & Ordinal & FML & First-Later \\
\hline & & Model 7 & Model 7 & Model 7 & Model 7 & Model 7 & Model 7 \\
\hline & & $\mathrm{b}$ & $\mathrm{b}$ & $\mathrm{b}$ & $\mathrm{b}$ & $\mathrm{b}$ & $\mathrm{b}$ \\
\hline & $1955-1959$ & $-0.085 * * *$ & $-0.085 * * *$ & $-0.085 * * *$ & $-0.086 * * *$ & $-0.085 * * *$ & $-0.084 * * *$ \\
\hline & $1960-1964$ & $-0.230 * *$ & $-0.229 * *$ & $-0.229 * *$ & $-0.232 * *$ & $-0.230 * *$ & $-0.229 * *$ \\
\hline & $1965-1969$ & -0.357 & -0.353 & -0.356 & -0.358 & -0.355 & -0.354 \\
\hline \multirow[t]{5}{*}{ Index Birth Order (G3) } & 1 (ref) & 0.000 & 0.000 & 0.000 & 0.000 & 0.000 & 0.000 \\
\hline & 2 & $-0.294 * * *$ & $-0.294 * * *$ & $-0.301 * * *$ & $-0.293 * * *$ & $-0.293 * * *$ & $-0.298 * * *$ \\
\hline & 3 & $-0.462 * * *$ & $-0.466 * * *$ & $-0.473 * * *$ & $-0.462 * * *$ & $-0.465 * * *$ & $-0.470 * * *$ \\
\hline & 4 & $-0.554 * * *$ & $-0.558 * * *$ & $-0.567 * * *$ & $-0.556 * * *$ & $-0.560 * * *$ & $-0.563 * * *$ \\
\hline & 5 & $-0.657 * * *$ & $-0.662 * * *$ & $-0.670 * * *$ & $-0.661 * * *$ & $-0.664 * * *$ & $-0.664 * * *$ \\
\hline \multirow[t]{5}{*}{ Mother Birth Order (G2) } & 1 (ref) & 0.000 & 0.000 & 0.000 & 0.000 & 0.000 & 0.000 \\
\hline & 2 & -0.022 & -0.022 & $-0.025^{*}$ & $-0.026 *$ & $-0.025^{*}$ & -0.024 \\
\hline & 3 & -0.036 & $-0.040 *$ & $-0.042 *$ & $-0.044 *$ & $-0.043^{*}$ & $-0.041 *$ \\
\hline & 4 & -0.028 & -0.033 & -0.034 & -0.037 & -0.035 & -0.033 \\
\hline & 5 & -0.070 & $-0.074 *$ & $-0.076^{*}$ & $-0.079 *$ & $-0.076^{*}$ & $-0.076^{*}$ \\
\hline \multirow{5}{*}{ Father Birth Order (G2) } & 1 (ref) & 0.000 & 0.000 & 0.000 & 0.000 & 0.000 & 0.000 \\
\hline & 2 & 0.007 & 0.008 & 0.007 & 0.008 & 0.008 & 0.004 \\
\hline & 3 & -0.023 & -0.025 & -0.026 & -0.021 & -0.026 & -0.030 \\
\hline & 4 & $-0.077 * *$ & $-0.080 * *$ & $-0.081 * *$ & $-0.076 * *$ & $-0.081 * *$ & $-0.085^{* *}$ \\
\hline & 5 & $-0.077 *$ & $-0.081 * *$ & $-0.081 * *$ & $-0.077 *$ & $-0.081 * *$ & $-0.085^{* *}$ \\
\hline \multirow[t]{2}{*}{ Sex (G3) } & Male (ref) & 0.000 & 0.000 & 0.000 & 0.000 & 0.000 & 0.000 \\
\hline & Female & $0.529 * * *$ & $0.529 * * *$ & $0.528 * * *$ & $0.545 * * *$ & $0.540 * * *$ & $0.527 * * *$ \\
\hline \multirow[t]{5}{*}{ Sibling Group Size (G3) } & 1 & $-0.222 * * *$ & $-0.222 * * *$ & $-0.222 * * *$ & $-0.222 * * *$ & $-0.221 * * *$ & $-0.222 * * *$ \\
\hline & 2 (ref) & 0.000 & 0.000 & 0.000 & 0.000 & 0.000 & 0.000 \\
\hline & 3 & 0.018 & 0.018 & 0.018 & 0.018 & 0.019 & 0.018 \\
\hline & 4 & -0.027 & -0.028 & -0.027 & -0.026 & -0.025 & -0.026 \\
\hline & $5+$ & $-0.173 * * *$ & $-0.174 * * *$ & $-0.172 * * *$ & $-0.173 * * *$ & $-0.170 * * *$ & $-0.172 * * *$ \\
\hline \multirow[t]{7}{*}{ Birth Year (G3) } & 1960 & $-0.841 * * *$ & $-0.841 * * *$ & $-0.845 * * *$ & $-0.838 * * *$ & $-0.839 * * *$ & $-0.844 * * *$ \\
\hline & 1961 & $-0.724 * * *$ & $-0.725 * * *$ & $-0.727 * * *$ & $-0.721 * * *$ & $-0.721 * * *$ & $-0.726 * * *$ \\
\hline & 1962 & $-0.717 * * *$ & $-0.718 * * *$ & $-0.720 * * *$ & $-0.715^{* * *}$ & $-0.715 * * *$ & $-0.719 * * *$ \\
\hline & 1963 & $-0.634 * * *$ & $-0.634 * * *$ & $-0.636 * * *$ & $-0.633 * * *$ & $-0.633 * * *$ & $-0.636 * * *$ \\
\hline & 1964 & $-0.573 * * *$ & $-0.574 * * *$ & $-0.575 * * *$ & $-0.573 * * *$ & $-0.573 * * *$ & $-0.575 * * *$ \\
\hline & 1965 & $-0.517 * * *$ & $-0.517 * * *$ & $-0.518 * * *$ & $-0.517 * * *$ & $-0.517 * * *$ & $-0.519 * * *$ \\
\hline & 1966 & $-0.421 * * *$ & $-0.421 * * *$ & $-0.422 * * *$ & $-0.421 * * *$ & $-0.421 * * *$ & $-0.422 * * *$ \\
\hline
\end{tabular}


Table 4 - Continued from previous page

\begin{tabular}{|c|c|c|c|c|c|c|c|}
\hline & & \multicolumn{3}{|c|}{ Birth Order Homophily } & \multicolumn{3}{|c|}{ Birth Order and Gender Homophily } \\
\hline & & Ordinal & FML & First-Later & Ordinal & FML & First-Later \\
\hline & & Model 7 & Model 7 & Model 7 & Model 7 & Model 7 & Model 7 \\
\hline & & $\mathrm{b}$ & $\mathrm{b}$ & $\mathrm{b}$ & $\mathrm{b}$ & $\mathrm{b}$ & $\mathrm{b}$ \\
\hline & 1967 & $-0.381 * * *$ & $-0.381 * * *$ & $-0.382 * * *$ & $-0.381 * * *$ & $-0.381 * * *$ & $-0.382 * * *$ \\
\hline & 1968 & $-0.317 * * *$ & $-0.317 * * *$ & $-0.317 * * *$ & $-0.317 * * *$ & $-0.317 * * *$ & $-0.317 * * *$ \\
\hline & 1969 & $-0.276^{* * *}$ & $-0.276 * * *$ & $-0.276^{* * *}$ & $-0.276^{* * *}$ & $-0.276 * * *$ & $-0.276 * * *$ \\
\hline & 1970 (ref) & 0.000 & 0.000 & 0.000 & 0.000 & 0.000 & 0.000 \\
\hline & 1971 & $0.115 * * *$ & $0.115 * * *$ & $0.115 * * *$ & $0.115 * * *$ & $0.115 * * *$ & $0.115 * * *$ \\
\hline & 1972 & $0.269 * * *$ & $0.269 * * *$ & $0.269 * * *$ & $0.269 * * *$ & $0.269 * * *$ & $0.269 * * *$ \\
\hline & 1973 & $0.447 * * *$ & $0.447 * * *$ & $0.447 * * *$ & $0.447 * * *$ & $0.448 * * *$ & $0.448 * * *$ \\
\hline & 1974 & $0.642 * * *$ & $0.643 * * *$ & $0.642 * * *$ & $0.643 * * *$ & $0.643 * * *$ & $0.643 * * *$ \\
\hline & 1975 & $0.838 * * *$ & $0.838 * * *$ & $0.838 * * *$ & $0.839 * * *$ & $0.839 * * *$ & $0.839 * * *$ \\
\hline & 1976 & $0.949 * * *$ & $0.949 * * *$ & $0.949 * * *$ & $0.950 * * *$ & $0.950 * * *$ & $0.949 * * *$ \\
\hline & 1977 & $1.001 * * *$ & $1.001 * * *$ & $1.000 * * *$ & $1.001 * * *$ & $1.001 * * *$ & $1.001 * * *$ \\
\hline & 1978 & $0.902 * * *$ & $0.902 * * *$ & $0.902 * * *$ & $0.903 * * *$ & $0.903 * * *$ & $0.902 * * *$ \\
\hline & 1979 & $0.972 * * *$ & $0.972 * * *$ & $0.972 * * *$ & $0.973 * * *$ & $0.973 * * *$ & $0.972 * * *$ \\
\hline & 1980 & $1.079 * * *$ & $1.079 * * *$ & $1.078 * * *$ & $1.080 * * *$ & $1.080 * * *$ & $1.079 * * *$ \\
\hline & 1981 & $1.126 * * *$ & $1.126 * * *$ & $1.125 * * *$ & $1.128 * * *$ & $1.127 * * *$ & $1.126 * * *$ \\
\hline & 1982 & $1.129 * * *$ & $1.128 * * *$ & $1.128 * * *$ & $1.130 * * *$ & $1.130 * * *$ & $1.128 * * *$ \\
\hline \multirow[t]{6}{*}{ Maternal Age at Birth (G3) } & $15-19$ & $-0.056^{*}$ & $-0.056 * *$ & $-0.056^{*}$ & $-0.054 *$ & $-0.055^{*}$ & $-0.055^{*}$ \\
\hline & $20-24$ & $-0.031 *$ & $-0.031 *$ & $-0.031 *$ & $-0.030 *$ & $-0.030 *$ & $-0.030 *$ \\
\hline & $25-29$ (ref) & 0.000 & 0.000 & 0.000 & 0.000 & 0.000 & 0.000 \\
\hline & $30-34$ & -0.016 & -0.016 & -0.016 & -0.016 & -0.016 & -0.017 \\
\hline & $35-39$ & $-0.085 * *$ & $-0.085^{* *}$ & $-0.085^{* *}$ & $-0.084 * *$ & $-0.085^{* *}$ & $-0.086^{* *}$ \\
\hline & $40+$ & 0.032 & 0.032 & 0.032 & 0.031 & 0.030 & 0.029 \\
\hline \multirow[t]{6}{*}{ Paternal Age at Birth (G3) } & $15-19$ & $-0.072 *$ & $-0.071 *$ & $-0.071 *$ & $-0.070 *$ & $-0.070 *$ & $-0.072 * *$ \\
\hline & $20-24$ & $-0.055 * * *$ & $-0.055 * * *$ & $-0.055 * * *$ & $-0.055 * * *$ & $-0.055 * * *$ & $-0.056 * * *$ \\
\hline & $25-29$ (ref) & 0.000 & 0.000 & 0.000 & 0.000 & 0.000 & 0.000 \\
\hline & $30-34$ & 0.019 & 0.019 & 0.019 & 0.020 & 0.019 & 0.019 \\
\hline & $35-39$ & 0.031 & 0.032 & 0.032 & 0.032 & 0.032 & 0.031 \\
\hline & $40+$ & 0.000 & 0.001 & 0.001 & 0.001 & 0.001 & 0.000 \\
\hline $\mathrm{N}$ & & 509,739 & 509,739 & 509,739 & 509,739 & 509,739 & 509,739 \\
\hline
\end{tabular}


Table 5: Interaction between parent-child birth order and gender homophily and parental education level, paternal cousin sample, Swedish men and women born 1960-1982.

\begin{tabular}{|c|c|c|c|c|c|c|c|}
\hline & & \multicolumn{3}{|c|}{ Birth Order Homophily } & \multicolumn{3}{|c|}{ Birth Order and Gender Homophily } \\
\hline & & Ordinal & FML & First-Later & Ordinal & FML & First-Later \\
\hline & & Model 10 & Model 10 & Model 10 & Model 10 & Model 10 & Model 10 \\
\hline & & $\mathrm{b}$ & $\mathrm{b}$ & $\mathrm{b}$ & $\mathrm{b}$ & $\mathrm{b}$ & $\mathrm{b}$ \\
\hline \multirow[t]{2}{*}{ Mother-Child Homophily } & Yes & 0.016 & 0.001 & -0.008 & $-0.046^{*}$ & -0.041 & -0.032 \\
\hline & No (ref) & 0.000 & 0.000 & 0.000 & 0.000 & 0.000 & 0.000 \\
\hline \multirow[t]{8}{*}{ Maternal Education } & Primary $<9$ years & $-0.217 * * *$ & $-0.218 * * *$ & $-0.223 * * *$ & $-0.218 * * *$ & $-0.215 * * *$ & $-0.214 * * *$ \\
\hline & Primary - 9 years (ref) & 0.000 & 0.000 & 0.000 & 0.000 & 0.000 & 0.000 \\
\hline & Secondary - $10-11$ years & $0.196 * * *$ & $0.189 * * *$ & $0.178 * * *$ & $0.184 * * *$ & $0.183 * * *$ & $0.176 * * *$ \\
\hline & Secondary - 12 years & $0.460 * * *$ & $0.462 * * *$ & $0.451 * * *$ & $0.452 * * *$ & $0.457 * * *$ & $0.449 * * *$ \\
\hline & Tertiary - $13-15$ years & $0.733 * * *$ & $0.723 * * *$ & $0.718 * * *$ & $0.714 * * *$ & $0.712 * * *$ & $0.705 * * *$ \\
\hline & Tertiary $-15+$ years & $0.983 * * *$ & $0.986 * * *$ & $0.973 * * *$ & $0.970 * * *$ & $0.973 * * *$ & $0.965 * * *$ \\
\hline & Post-graduate & $1.152 * * *$ & $1.157 * * *$ & $1.156^{* * *}$ & $1.171 * * *$ & $1.167 * * *$ & $1.177 * * *$ \\
\hline & Missing & $0.340 *$ & 0.235 & 0.252 & $0.300 *$ & $0.298 *$ & $0.290 *$ \\
\hline Mother-Child Homophily & Yes $*$ Primary $<9$ years & -0.009 & -0.007 & 0.007 & -0.013 & -0.028 & -0.021 \\
\hline Maternal Education & Yes $*$ Primary -9 years (ref) & 0.000 & 0.000 & 0.000 & 0.000 & 0.000 & 0.000 \\
\hline \multirow[t]{6}{*}{ Interaction } & Yes * Secondary - $10-11$ years & -0.009 & 0.007 & 0.028 & 0.045 & 0.049 & $0.069 * *$ \\
\hline & Yes * Secondary - 12 years & 0.026 & 0.023 & 0.042 & $0.097 * *$ & $0.073 *$ & $0.093 * *$ \\
\hline & Yes $*$ Tertiary $-13-15$ years & -0.001 & 0.023 & 0.030 & $0.100 * *$ & $0.108 * *$ & $0.117 * * *$ \\
\hline & Yes $*$ Tertiary $-15+$ years & 0.024 & 0.019 & 0.041 & $0.118 * * *$ & $0.101 * *$ & $0.119 * * *$ \\
\hline & Yes $*$ Post-graduate & 0.055 & 0.045 & 0.038 & 0.025 & 0.045 & 0.000 \\
\hline & Yes * Missing & -0.216 & 0.009 & -0.025 & -0.269 & -0.254 & -0.211 \\
\hline \multirow[t]{2}{*}{ Father-Child Homophily } & Yes & -0.005 & 0.013 & 0.005 & -0.028 & -0.009 & $-0.058 * *$ \\
\hline & No (ref) & 0.000 & 0.000 & 0.000 & 0.000 & 0.000 & 0.000 \\
\hline \multirow[t]{8}{*}{ Paternal Education } & Primary $<9$ years & $-0.110 * * *$ & $-0.107 * * *$ & $-0.117 * * *$ & $-0.112 * * *$ & $-0.112 * * *$ & $-0.117 * * *$ \\
\hline & Primary - 9 years (ref) & 0.000 & 0.000 & 0.000 & 0.000 & 0.000 & 0.000 \\
\hline & Secondary - 10-11 years & $0.037^{*}$ & $0.040^{*}$ & 0.034 & $0.036^{*}$ & $0.038 *$ & 0.030 \\
\hline & Secondary - 12 years & $0.362 * * *$ & $0.362 * * *$ & $0.369 * * *$ & $0.352 * * *$ & $0.351 * * *$ & $0.343 * * *$ \\
\hline & Tertiary - $13-15$ years & $0.511 * * *$ & $0.521 * * *$ & $0.510 * * *$ & $0.505 * * *$ & $0.510 * * *$ & $0.494 * * *$ \\
\hline & Tertiary $-15+$ years & $0.810 * * *$ & $0.814 * * *$ & $0.815 * * *$ & $0.795 * * *$ & $0.799 * * *$ & $0.781 * * *$ \\
\hline & Post-graduate & $1.103 * * *$ & $1.111 * * *$ & $1.117 * * *$ & $1.068 * * *$ & $1.074 * * *$ & $1.054 * * *$ \\
\hline & Missing & -0.134 & -0.139 & -0.145 & -0.108 & -0.112 & -0.107 \\
\hline Father-Child Homophily & Yes $*$ Primary $<9$ years & 0.011 & 0.000 & 0.021 & 0.052 & 0.034 & 0.048 \\
\hline Paternal Education & Yes $*$ Primary -9 years (ref) & 0.000 & 0.000 & 0.000 & 0.000 & 0.000 & 0.000 \\
\hline
\end{tabular}


Table 5 - Continued from previous page

\begin{tabular}{|c|c|c|c|c|c|c|c|}
\hline & & \multicolumn{3}{|c|}{ Birth Order Homophily } & \multicolumn{3}{|c|}{ Birth Order and Gender Homophily } \\
\hline & & Ordinal & FML & First-Later & Ordinal & FML & First-Later \\
\hline & & Model 10 & Model 10 & Model 10 & Model 10 & Model 10 & Model 10 \\
\hline & & $\mathrm{b}$ & $\mathrm{b}$ & $\mathrm{b}$ & $\mathrm{b}$ & $\mathrm{b}$ & $\mathrm{b}$ \\
\hline \multirow[t]{6}{*}{ Interaction } & Yes * Secondary - 10-11 years & 0.018 & 0.006 & 0.018 & 0.054 & 0.030 & $0.055^{*}$ \\
\hline & Yes $*$ Secondary - 12 years & 0.015 & 0.011 & -0.006 & $0.102 * *$ & $0.097 * *$ & $0.103 * * *$ \\
\hline & Yes $*$ Tertiary $-13-15$ years & 0.026 & -0.011 & 0.017 & $0.098 * *$ & 0.056 & $0.107 * * *$ \\
\hline & Yes $*$ Tertiary $-15+$ years & 0.021 & 0.005 & 0.002 & $0.143 * * *$ & $0.109 * *$ & $0.152 * * *$ \\
\hline & Yes * Post-graduate & 0.009 & -0.018 & -0.025 & $0.224 * *$ & $0.192 * *$ & $0.213 * *$ \\
\hline & Yes $*$ Missing & 0.177 & 0.186 & 0.161 & 0.201 & 0.215 & 0.148 \\
\hline \multirow[t]{5}{*}{ Paternal Sibling Group Size (G2) } & 1 & $-0.070 * * *$ & $-0.070 * * *$ & $-0.071 * * *$ & $-0.070 * * *$ & $-0.070 * * *$ & $-0.071 * * *$ \\
\hline & 2 (ref) & 0.000 & 0.000 & 0.000 & 0.000 & 0.000 & 0.000 \\
\hline & 3 & $-0.024 *$ & $-0.024^{*}$ & $-0.024 *$ & $-0.024 *$ & $-0.024^{*}$ & $-0.024 *$ \\
\hline & 4 & $-0.071 * * *$ & $-0.070 * * *$ & $-0.071 * * *$ & $-0.071 * * *$ & $-0.071 * * *$ & $-0.071 * * *$ \\
\hline & $5+$ & $-0.079 * * *$ & $-0.078 * * *$ & $-0.079 * * *$ & $-0.079 * * *$ & $-0.079 * * *$ & $-0.079 * * *$ \\
\hline Maternal Grandmother's & $15-19$ & $-0.163 * * *$ & $-0.163 * * *$ & $-0.163 * * *$ & $-0.162 * * *$ & $-0.162 * * *$ & $-0.163 * * *$ \\
\hline \multirow[t]{5}{*}{ Age at Birth (G2) } & $20-24$ & $-0.068 * * *$ & $-0.068 * * *$ & $-0.068 * * *$ & $-0.068 * * *$ & $-0.068 * * *$ & $-0.068 * * *$ \\
\hline & $25-29$ (ref) & 0.000 & 0.000 & 0.000 & 0.000 & 0.000 & 0.000 \\
\hline & $30-34$ & $0.058 * * *$ & $0.058 * * *$ & $0.058 * * *$ & $0.058 * * *$ & $0.058 * * *$ & $0.058 * * *$ \\
\hline & $35-39$ & $0.072 * * *$ & $0.072 * * *$ & $0.072 * * *$ & $0.072 * * *$ & $0.072 * * *$ & $0.072 * * *$ \\
\hline & $40+$ & $0.119 * * *$ & $0.119 * * *$ & $0.119 * * *$ & $0.120 * * *$ & $0.119 * * *$ & $0.120 * * *$ \\
\hline Paternal Grandmother's & $15-19$ & 0.050 & 0.050 & 0.050 & 0.053 & 0.052 & 0.052 \\
\hline \multirow[t]{5}{*}{ Age at Birth (G2) } & $20-24$ & 0.001 & 0.001 & 0.001 & 0.001 & 0.001 & 0.001 \\
\hline & $25-29$ (ref) & 0.000 & 0.000 & 0.000 & 0.000 & 0.000 & 0.000 \\
\hline & $30-34$ & $-0.038 *$ & $-0.038^{*}$ & $-0.038^{*}$ & $-0.037 *$ & $-0.037 *$ & $-0.038^{*}$ \\
\hline & $35-39$ & $-0.059 *$ & $-0.060 *$ & $-0.060 *$ & $-0.058 *$ & $-0.059 *$ & $-0.059 *$ \\
\hline & $40+$ & $-0.155 * * *$ & $-0.156 * * *$ & $-0.156 * * *$ & $-0.153 * * *$ & $-0.155 * * *$ & $-0.154 * * *$ \\
\hline \multirow[t]{6}{*}{ Maternal Birth Year (G2) } & 1938-1945 & $0.223^{* * *} *$ & $0.224 * * *$ & $0.224 * * *$ & $0.223 * * *$ & $0.224 * * *$ & $0.223 * * *$ \\
\hline & 1946-1949 & $0.143 * * *$ & $0.143 * * *$ & $0.143 * * *$ & $0.143 * * *$ & $0.143 * * *$ & $0.143 * * *$ \\
\hline & $1950-1954$ (ref) & 0.000 & 0.000 & 0.000 & 0.000 & 0.000 & 0.000 \\
\hline & 1955-1959 & $-0.173 * * *$ & $-0.173 * * *$ & $-0.173 * * *$ & $-0.174 * * *$ & $-0.173 * * *$ & $-0.173 * * *$ \\
\hline & 1960-1964 & $-0.367 * * *$ & $-0.365 * * *$ & $-0.364 * * *$ & $-0.368 * * *$ & $-0.366 * * *$ & $-0.368 * * *$ \\
\hline & 1965-1969 & $-0.853 * *$ & $-0.850 * *$ & $-0.850 * *$ & $-0.854 * *$ & $-0.851 * *$ & $-0.854 * *$ \\
\hline \multirow[t]{3}{*}{ Paternal Birth Year (G2) } & 1938-1945 & 0.024 & 0.024 & 0.023 & 0.024 & 0.024 & 0.024 \\
\hline & 1946-1949 & 0.025 & 0.025 & 0.025 & 0.025 & 0.025 & 0.025 \\
\hline & 1950-1954 (ref) & 0.000 & 0.000 & 0.000 & 0.000 & 0.000 & 0.000 \\
\hline
\end{tabular}


Table 5 - Continued from previous page

\begin{tabular}{|c|c|c|c|c|c|c|c|}
\hline & & \multicolumn{3}{|c|}{ Birth Order Homophily } & \multicolumn{3}{|c|}{ Birth Order and Gender Homophily } \\
\hline & & Ordinal & FML & First-Later & Ordinal & FML & First-Later \\
\hline & & Model 10 & Model 10 & Model 10 & Model 10 & Model 10 & Model 10 \\
\hline & & $\mathrm{b}$ & $\mathrm{b}$ & $\mathrm{b}$ & $\mathrm{b}$ & $\mathrm{b}$ & $\mathrm{b}$ \\
\hline & $1955-1959$ & -0.036 & -0.035 & -0.035 & -0.037 & -0.035 & -0.037 \\
\hline & 1960-1964 & $-0.221 * *$ & $-0.217 * *$ & $-0.216^{* *}$ & $-0.222 * *$ & $-0.219 * *$ & $-0.222 * *$ \\
\hline & $1965-1969$ & -0.568 & -0.565 & -0.567 & -0.574 & -0.564 & -0.560 \\
\hline \multirow[t]{5}{*}{ Index Birth Order (G3) } & 1 (ref) & 0.000 & 0.000 & 0.000 & 0.000 & 0.000 & 0.000 \\
\hline & 2 & $-0.314 * * *$ & $-0.314 * * *$ & $-0.322 * * *$ & $-0.314 * * *$ & $-0.313 * * *$ & $-0.318 * * *$ \\
\hline & 3 & $-0.484 * * *$ & $-0.488 * * *$ & $-0.497 * * *$ & $-0.485 * * *$ & $-0.487 * * *$ & $-0.493 * * *$ \\
\hline & 4 & $-0.614 * * *$ & $-0.618 * * *$ & $-0.628 * * *$ & $-0.615 * * *$ & $-0.617 * * *$ & $-0.623 * * *$ \\
\hline & 5 & $-0.665 * * *$ & $-0.669 * * *$ & $-0.680 * * *$ & $-0.667 * * *$ & $-0.669 * * *$ & $-0.673 * * *$ \\
\hline \multirow[t]{5}{*}{ Mother Birth Order (G2) } & 1 (ref) & 0.000 & 0.000 & 0.000 & 0.000 & 0.000 & 0.000 \\
\hline & 2 & -0.004 & -0.004 & -0.005 & -0.008 & -0.007 & -0.005 \\
\hline & 3 & -0.011 & -0.016 & -0.016 & -0.018 & -0.018 & -0.017 \\
\hline & 4 & -0.028 & -0.034 & -0.034 & -0.036 & -0.036 & -0.035 \\
\hline & 5 & -0.044 & -0.049 & -0.049 & -0.053 & -0.051 & -0.050 \\
\hline \multirow{5}{*}{ Father Birth Order (G2) } & 1 (ref) & 0.000 & 0.000 & 0.000 & 0.000 & 0.000 & 0.000 \\
\hline & 2 & -0.001 & 0.002 & -0.002 & 0.002 & 0.005 & -0.003 \\
\hline & 3 & 0.003 & 0.003 & 0.000 & 0.009 & 0.005 & -0.002 \\
\hline & 4 & -0.021 & -0.022 & -0.025 & -0.015 & -0.020 & -0.027 \\
\hline & 5 & -0.049 & -0.050 & -0.053 & -0.044 & -0.048 & -0.055 \\
\hline \multirow[t]{2}{*}{ Sex (G3) } & Male (ref) & 0.000 & 0.000 & 0.000 & 0.000 & 0.000 & 0.000 \\
\hline & Female & $0.528 * * *$ & $0.528 * * *$ & $0.528 * * *$ & $0.539 * * *$ & $0.539 * * *$ & $0.519 * * *$ \\
\hline \multirow[t]{5}{*}{ Sibling Group Size (G3) } & 1 & $-0.244 * * *$ & $-0.244 * * *$ & $-0.244 * * *$ & $-0.243 * * *$ & $-0.244 * * *$ & $-0.244 * * *$ \\
\hline & 2 (ref) & 0.000 & 0.000 & 0.000 & 0.000 & 0.000 & 0.000 \\
\hline & 3 & -0.005 & -0.006 & -0.005 & -0.005 & -0.006 & -0.005 \\
\hline & 4 & $-0.058 * *$ & $-0.060 * *$ & $-0.059 * *$ & $-0.059 * *$ & $-0.061 * *$ & $-0.058 * *$ \\
\hline & $5+$ & $-0.163 * * *$ & $-0.165 * * *$ & $-0.163 * * *$ & $-0.164 * * *$ & $-0.166^{* * *}$ & $-0.163 * * *$ \\
\hline \multirow[t]{7}{*}{ Birth Year (G3) } & 1960 & $-0.752 * * *$ & $-0.755 * * *$ & $-0.757 * * *$ & $-0.751 * * *$ & $-0.753 * * *$ & $-0.753 * * *$ \\
\hline & 1961 & $-0.690 * * *$ & $-0.692 * * *$ & $-0.694 * * *$ & $-0.689 * * *$ & $-0.690 * * *$ & $-0.690 * * *$ \\
\hline & 1962 & $-0.595 * * *$ & $-0.597 * * *$ & $-0.598 * * *$ & $-0.594 * * *$ & $-0.595 * * *$ & $-0.595 * * *$ \\
\hline & 1963 & $-0.609 * * *$ & $-0.610 * * *$ & $-0.611 * * *$ & $-0.609 * * *$ & $-0.610 * * *$ & $-0.610 * * *$ \\
\hline & 1964 & $-0.539 * * *$ & $-0.540 * * *$ & $-0.540 * * *$ & $-0.539 * * *$ & $-0.539 * * *$ & $-0.540 * * *$ \\
\hline & 1965 & $-0.470 * * *$ & $-0.471 * * *$ & $-0.471 * * *$ & $-0.471 * * *$ & $-0.471 * * *$ & $-0.472 * * *$ \\
\hline & 1966 & $-0.422 * * *$ & $-0.423 * * *$ & $-0.423 * * *$ & $-0.422 * * *$ & $-0.422 * * *$ & $-0.423 * * *$ \\
\hline
\end{tabular}


Table 5 - Continued from previous page

\begin{tabular}{|c|c|c|c|c|c|c|c|}
\hline & & \multicolumn{3}{|c|}{ Birth Order Homophily } & \multicolumn{3}{|c|}{ Birth Order and Gender Homophily } \\
\hline & & Ordinal & FML & First-Later & Ordinal & FML & First-Later \\
\hline & & Model 10 & Model 10 & Model 10 & Model 10 & Model 10 & Model 10 \\
\hline & & $\mathrm{b}$ & $\mathrm{b}$ & $\mathrm{b}$ & $\mathrm{b}$ & $\mathrm{b}$ & $\mathrm{b}$ \\
\hline & 1967 & $-0.364 * * *$ & $-0.365 * * *$ & $-0.365 * * *$ & $-0.365 * * *$ & $-0.365 * * *$ & $-0.365 * * *$ \\
\hline & 1968 & $-0.341 * * *$ & $-0.342 * * *$ & $-0.342 * * *$ & $-0.341 * * *$ & $-0.342 * * *$ & $-0.342 * * *$ \\
\hline & 1969 & $-0.276 * * *$ & $-0.276^{* * *}$ & $-0.276^{* * *}$ & $-0.276 * * *$ & $-0.276^{* * *}$ & $-0.276 * * *$ \\
\hline & 1970 (ref) & 0.000 & 0.000 & 0.000 & 0.000 & 0.000 & 0.000 \\
\hline & 1971 & $0.114 * * *$ & $0.114 * * *$ & $0.114 * * *$ & $0.114 * * *$ & $0.114 * * *$ & $0.114 * * *$ \\
\hline & 1972 & $0.284 * * *$ & $0.284 * * *$ & $0.283 * * *$ & $0.284 * * *$ & $0.284 * * *$ & $0.284 * * *$ \\
\hline & 1973 & $0.453 * * *$ & $0.453 * * *$ & $0.453 * * *$ & $0.453 * * *$ & $0.454 * * *$ & $0.454 * * *$ \\
\hline & 1974 & $0.612 * * *$ & $0.612 * * *$ & $0.612 * * *$ & $0.613 * * *$ & $0.613 * * *$ & $0.613 * * *$ \\
\hline & 1975 & $0.826 * * *$ & $0.826 * * *$ & $0.826 * * *$ & $0.827 * * *$ & $0.827 * * *$ & $0.826 * * *$ \\
\hline & 1976 & $0.922 * * *$ & $0.922 * * *$ & $0.922 * * *$ & $0.922 * * *$ & $0.923 * * *$ & $0.923 * * *$ \\
\hline & 1977 & $0.971 * * *$ & $0.971 * * *$ & $0.970 * * *$ & $0.971 * * *$ & $0.971 * * *$ & $0.971 * * *$ \\
\hline & 1978 & $0.890 * * *$ & $0.890 * * *$ & $0.889 * * *$ & $0.891 * * *$ & $0.890 * * *$ & $0.891 * * *$ \\
\hline & 1979 & $0.930 * * *$ & $0.930 * * *$ & $0.930 * * *$ & $0.931 * * *$ & $0.930 * * *$ & $0.930 * * *$ \\
\hline & 1980 & $1.072 * * *$ & $1.071 * * *$ & $1.071 * * *$ & $1.073 * * *$ & $1.072 * * *$ & $1.072 * * *$ \\
\hline & 1981 & $1.115 * * *$ & $1.114 * * *$ & $1.114 * * *$ & $1.116 * * *$ & $1.114 * * *$ & $1.115 * * *$ \\
\hline & 1982 & $1.119 * * *$ & $1.118 * * *$ & $1.118 * * *$ & $1.120 * * *$ & $1.118 * * *$ & $1.119 * * *$ \\
\hline \multirow[t]{6}{*}{ Maternal Age at Birth (G3) } & $15-19$ & $-0.170 * * *$ & $-0.170 * * *$ & $-0.170 * * *$ & $-0.169 * * *$ & $-0.169 * * *$ & $-0.170 * * *$ \\
\hline & $20-24$ & $-0.080 * * *$ & $-0.080 * * *$ & $-0.080 * * *$ & $-0.079 * * *$ & $-0.080 * * *$ & $-0.080 * * *$ \\
\hline & $25-29$ (ref) & 0.000 & 0.000 & 0.000 & 0.000 & 0.000 & 0.000 \\
\hline & $30-34$ & 0.024 & 0.024 & 0.025 & 0.025 & 0.025 & 0.024 \\
\hline & $35-39$ & -0.009 & -0.010 & -0.009 & -0.008 & -0.008 & -0.010 \\
\hline & $40+$ & -0.172 & -0.172 & -0.172 & -0.172 & -0.172 & $-0.175^{*}$ \\
\hline \multirow[t]{6}{*}{ Paternal Age at Birth (G3) } & $15-19$ & -0.050 & -0.049 & -0.050 & -0.049 & -0.049 & -0.051 \\
\hline & $20-24$ & $-0.042 * *$ & $-0.042 * *$ & $-0.042 * *$ & $-0.041 * *$ & $-0.041 * *$ & $-0.042 * *$ \\
\hline & $25-29$ (ref) & 0.000 & 0.000 & 0.000 & 0.000 & 0.000 & 0.000 \\
\hline & $30-34$ & 0.005 & 0.005 & 0.005 & 0.005 & 0.006 & 0.005 \\
\hline & $35-39$ & -0.027 & -0.026 & -0.027 & -0.027 & -0.025 & -0.027 \\
\hline & $40+$ & -0.092 & -0.090 & -0.092 & -0.092 & -0.090 & -0.093 \\
\hline $\mathrm{N}$ & & 514,222 & 514,222 & 514,222 & 514,222 & 514,222 & 514,222 \\
\hline
\end{tabular}


TABLE 6. Effect of parental sibling group size on offspring educational attainment at age 30, using twin births as a measure of an exogenous increase in parental family size for Swedish men and women born 1960-1982. Controls for maternal age at birth and birth year (single-year categories) included in models.

\begin{tabular}{llcccc}
\hline Sample & Estimation & beta & se & $95 \%$ CI & N \\
\hline First-born mothers & First Stage & 0.771 & 0.014 & $0.743,0.799$ & 404,554 \\
First-born fathers & Second Stage & 0.007 & 0.046 & $-0.083,0.098$ & 404,554 \\
& First Stage & 0.769 & 0.015 & $0.740,0.799$ & 366,574 \\
First- and second-born mothers & Second Stage & -0.052 & 0.050 & $-0.150,0.046$ & 366,574 \\
& First Stage & 0.768 & 0.014 & $0.740,0.797$ & 372,580 \\
First- and second-born fathers & Second Stage & -0.018 & 0.046 & $-0.109,0.072$ & 372,580 \\
& First Stage & 0.761 & 0.014 & $0.734,0.788$ & 341,091 \\
First-, second- and third-born mothers & Second Stage & -0.041 & 0.047 & $-0.133,0.051$ & 341,091 \\
& First Stage & 0.770 & 0.018 & $0.735,0.806$ & 226,649 \\
First-, second- and third-born fathers & Second Stage & 0.005 & 0.056 & $-0.105,0.116$ & 226,649 \\
& First Stage & 0.759 & 0.019 & $0.721,0.796$ & 207,898 \\
& Second Stage & -0.178 & 0.060 & $-0.296,-0.059$ & 207,898 \\
\hline
\end{tabular}

Parental Sibling Group Size. In further analyses we examine in detail the relationship between sibling group size in the parents generation and whether that has any effect on offspring educational attainment. More specifically, we examine whether an exogenous shock to the sibling group size experienced by the parents through a twin birth has any consequence for the educational attainment of their own children. The results from those analyses are shown in Table 6. We estimate these models for six different samples. The first two samples are first-born mothers, and first-born fathers, whose parents may or may not have given birth to twins at parity two. The second two samples are first- and second-born mothers and fathers, whose parents may or may not have given birth to twins at parity three. The third two samples are first-, second-, and third-born mothers and fathers, whose parents may or may not have given birth to twins at parity four.

Table 6 shows the estimates resulting from both the first and second stages of the 2SLS estimation procedure. The first stage estimates in each case show that there is a very strong correlation between a twin birth and eventual family size, which is consistent with previous research using twins as an instrument for family size in the Nordic context (e.g. see Black et al., 2005a; BaranowskaRataj et al., 2017). The results from the second stage estimates, however, show that there is no statistically significant, nor substantively meaningful, association between sibling group size in the parental generation and offspring educational attainment, with one exception; the children of first-, second-, and third-born fathers who experienced a twin birth at parity 4 have significantly lower educational attainment. The estimate suggests that this exogenous shock to the sibling group 
size of the father leads to 0.18 years lower education at age 30 amongst the children. Although this may reflect a true negative effect, it is somewhat surprising that this is the only association that is significant or with a substantively meaningful effect size, suggesting that it should be interpreted with caution and in the context of the other negligible effects.

Overall we find that these results suggest that grandparental fertility outcomes, and its subsequent effect on resource dilution in the parental sibling group, has no multigenerational effect on grandchild educational attainment.

Additional Analyses of High School GPA and Long-term Earnings. In addition to the analyses presented above, we have conducted additional analyses examining high school grade point average, measured at age 16, as well as inflation-adjusted logged earnings averaged over ages 29 to 31 as outcome variables. The results from those analyses lead to same conclusions as those that we draw from our analyses of educational attainment. The results from these additional analyses of GPA and long-term earnings are shown in the Supplementary Information section of this article, in Tables S6 to S14.

\section{DISCUSSION}

In this study we have used a remarkable multigenerational population dataset in order to examine whether family demographic factors related to grandparental fertility, specifically birth order and family size, have any effect on the educational attainment of subsequent generations. In doing so, we are some of the first to explore the multigenerational effects of demographic processes and the complimentary processes of demographic and socioeconomic reproduction that have been underappreciated in the previous literature (Mare, 2011). We find that grandparental fertility behavior is indeed associated with grandchild educational attainment, but that this effect flows almost completely through the educational and socioeconomic attainment of the parents in the middle generation of the three generations that we study. That is to say, grandparental fertility influences the educational and socioeconomic attainment of the parents through the family size and birth order that they experience, but grandparental fertility has little to no effect on the grandchildren once we adjust for the educational and socioeconomic attainment of the parents. Indeed, to this end our 
study suggests that parental birth order could even be employed as an instrument for parental educational and socioeconomic attainment, since its effects on the subsequent generation flow clearly through that attainment channel.

While our study speaks directly to the multigenerational importance of demographic factors for the socioeconomic attainment of subsequent generations, it also offers an insight into the findings of the much larger literature that has sprung up in recent years examining social stratification and mobility from a multigenerational perspective. This body of research has grappled with the question of whether social reproduction follows a Markovian process, where the attainment of any generation is influenced only by the attainment of the directly preceding generation, or whether there is a residual effect of grandparental, and even great-grandparental, status and resources net of the socioeconomic status of the parents. Increasingly research in this tradition has drawn the conclusion that grandparents $d o$ matter above and beyond the parents (e.g. see Warren and Hauser, 1997; Chan and Boliver, 2013; Zeng and Xie, 2014; Anderson et al., 2018). However, measurement of socioeconomic status is typically subject to measurement error as educational level and occupational status have many sub-dimensions. For example, educational level subsumes subject specialisation as well as quality of the training institution and the training itself. Occupational status, and even specific occupation, subsumes information like status within the workplace, how many people an individual is supervising, and the nature of the organisation and industry in which an individual is employed. All of those factors, and others, mean that measuring the importance of grandparental socioeconomic status for grandchild attainment is complicated and error-prone.

Although the measurement of grandparental socioeconomic status is often subject to measurement error, the measurement of grandparental fertility is far less vulnerable to this criticism. Family size and birth order in the parents generation in our population register data are measured with great accuracy, and as we have described in detail earlier, both birth order and family size are related to educational and socioeconomic attainment. Since birth order can be considered a quasi-random assignment to parental investment, and a twin-birth in the parental generation can be seen as an exogenous shock to the sibling group size and therefore resource levels within the sibling group, our study is able to get at the causal effect of resource distribution in the parental generation and how this may or may not influence the subsequent generation. We do find that parental birth order, 
though not parental family size, is associated with the educational attainment of the grandchild generation, but that this association is wiped out after accounting for the attained education and socioeconomic status of the parents measured in later adulthood. In short, this study suggests that multigenerational demographic effects follow a Markovian process, and given that our measures are much less vulnerable to measurement error, and benefit from exogeneity, our findings suggest that if multigenerational social stratification and mobility studies were able to measure grandparental social status to the same high standard as we measure grandparental fertility, grandparental socioeconomic status would not be associated with grandchild outcomes either. Although our analyses of parent-child birth order and gender homophily do indicate that there are also nonMarkovian processes operating, these effects on offspring educational attainment are relatively small.

It is also worth noting that our findings present themselves in Sweden, which has comparably speaking, low levels of inequality, a strong welfare state that supports the most needy, and a free educational system, including tertiary education. Thus, we expect that the intergenerational birth order effect that we observe in this study would be at least as likely to present itself in other countries whose social and political architecture exacerbates intergenerational inequality to a greater extent than in Sweden, and where rates of social mobility may be lower. However, it is worth also mentioning the specificity of the macro-demographic conditions in the period over which we study these multigenerational effects. Many of the grandparents whose fertility we examine in this study were born during the fertility transition in Sweden. Although total fertility was declining during this period, it was higher than today, attributable to lower levels of fertility control. Even though birth order was clearly a notable determinant of educational attainment within each generation, it is possible that birth order effects will become stronger over time as parents spend more time with children, focus even greater attention on quality over quantity, and practice longer birth spacing, as parental investment during the earliest years of life seems to be an important factor driving the birth order effect.

A noteworthy finding in our study is that we observe that parent-child birth order and gender homophily exerts only a small positive influence on the educational attainment of the child, but that this influence is stronger when parental education levels are higher. It seems that parents 
with higher levels of human capital reserve a certain degree of favoritism for the child whose position within the family corresponds most closely to their own in childhood. That is, it seems that first-born fathers favor first-born sons, middle-born mothers favor middle-born daughters, and so on. That this favoritism should be observed at all is somewhat surprising, and even more so that it should be observed amongst parents with higher levels of education. It may be that a closer identification between parents and the child whose position in the family is reminiscent of their own is widespread, but that parents who have greater levels of education simply have more skills to pass on to them, hence the greater educational performance of the homophilous child in the long-run. Given that first-borns are the most common birth order in the general population, and increasingly so given declining fertility, this kind of parental favoritism may be a small part of the explanation for why first-borns are generally found to outperform later-born siblings; parent-child matches on being the first-born child are likely the most common pairings.

More generally, our study also has the potential to shed light on the literature on the intergenerational effects of parental education on offspring educational attainment. Studies have generally used one of three different study designs to estimate the causal impact of parental education on offspring education: twin studies, adoption studies, and instrumental variables. Twin studies on this topic exploit differences in educational attainment between identical (monozygotic) twins, and examine educational attainment amongst their children. These studies, using data from the United States, Denmark, and Norway, have consistently shown a positive effect of paternal education on offspring educational attainment, but rarely a positive effect of maternal education (Behrman and Rosenzweig, 2002; Antonovics and Goldberger, 2005; Bingley et al., 2009; Hægeland et al., 2010; Pronzato, 2012). Research examining how parental educational level influences the educational attainment of adopted children, using data from the United States, Norway, and Sweden, typically shows that both maternal and paternal levels of education matter for adoptee attainment (Dearden et al., 1997; Plug, 2004; Björklund et al., 2006; Sacerdote, 2007; Hægeland et al., 2010). Studies using compulsory school reforms as an instrument to investigate whether parental educational attainment effects offspring educational have shown that in the UK and Norway greater maternal education increases education amongst the offspring, while greater paternal education does not have a significant effect (Chevalier, 2004; Black et al., 2005b). However, a study using data 
on compulsory school reforms from the United States has shown that both maternal and paternal education matter for offspring attainment (Oreopoulos et al., 2006). While these studies do consistently find that parental educational level does exert a small effect on the educational attainment of their children, there are inconsistencies in whether it is the mother's or the father's education that matters the more. If, as we argue, parental birth order can be seen as an instrument for parental educational attainment, our study suggests that both maternal and paternal educational levels matters for offspring educational attainment, but that maternal educational level matters slightly more. This is consistent with a broader literature that demonstrates the importance of parental educational levels, but particularly maternal educational level, for the developmental trajectories of children (e.g. Kalil et al., 2012).

In conclusion, we do not find that family size in the parental generation matters for the subsequent generation, but we do find that parental birth order matters, albeit indirectly, for offspring educational and labor market attainment net of the child's own birth order. This intergenerational birth order pattern suggests that differences in grandparental investment between siblings in the parental generation matters not only for their own educational attainment, but that this also has spillover effects into the subsequent generation due to the effects on parental educational and socioeconomic attainment. Thus, we observe the production of inequalities within families and across generations, an all the more remarkable finding since we are able to adjust for unmeasured confounding by comparing full cousins who share the same biological grandparents. Differences in parental investment (or grandparental investment) within a family are naturally much smaller than the differences in parental investment that are observed between different families, and our study therefore highlights just how important parental investment is for offspring attainment, and how this has the potential to accumulate over subsequent generations. However, as we have detailed, these multigenerational patterns seem to be entirely, or almost entirely, explained by the effect that grandparental investment has on parental educational and labor market attainment. When we take account of the level of education and labor market success that parents have attained by age 40 or 50 , the differences in parental investment exercised by the grandparents no longer matter for the grandchildren; the effects of grandparental investment appear to flow entirely through the parental generation, and this process of multigenerational stratification thereby seems to approximate a 
memoryless Markovian process. Given these findings, we can speculate that multigenerational effects of grandparental socioeconomic resources on grandchildren may need to be re-evaluated.

\section{REFERENCES}

Anderson, Lewis, Paula Sheppard, and Christiaan W. S. Monden. 2018. "Grandparent effects on educational outcomes: a systematic review." Sociological Science 5:114-142.

Angrist, Joshua D and Alan B Keueger. 1991. "Does compulsory school attendance affect schooling and earnings?" Quarterly Journal of Economics 106:979-1014.

Angrist, Joshua D and Jörn-Steffen Pischke. 2008. Mostly Harmless Econometrics: An Empiricist's Companion. Princeton, NJ: Princeton University Press.

Antonovics, Kate L. and Arthur S. Goldberger. 2005. "Does increasing women's schooling raise the schooling of the next generation? Comment." American Economic Review 95:1738-1744.

Astolfi, Paola and Laura A. Zonta. 1999. "Risks of preterm delivery and association with maternal age, birth order, and fetal gender." Human Reproduction 14:2891-2894.

Baranowska-Rataj, Anna, Kieron Barclay, and Martin Kolk. 2017. "The effect of number of siblings on adult mortality: evidence from Swedish registers for cohorts born between 1938 and 1972.” Population Studies 71:43-63.

Barclay, Kieron. 2015a. "Birth order and educational attainment: evidence from fully adopted sibling groups." Intelligence 48:109-122.

Barclay, Kieron. 2015b. "A within-family analysis of birth order and intelligence using population conscription data on Swedish men." Intelligence 49:134-143.

Barclay, Kieron. 2018. "The birth order paradox: sibling differences in educational attainment." Research in Social Stratification and Mobility 54:56-65.

Barclay, Kieron and Mikko Myrskylä. 2016. "Advanced maternal age and offspring outcomes: reproductive aging and counterbalancing period trends." Population and Development Review 42:69-94.

Bast, Janwillem and Pieter Reitsma. 1998. "Analyzing the development of individual differences in terms of Matthew effects in reading: results from a Dutch longitudinal study." Developmental Psychology 34:1373.

Becker, Gary S and H Gregg Lewis. 1973. "On the interaction between the quantity and quality of children." Journal of Political Economy 81:S279-S288.

Becker, Gary S and Nigel Tomes. 1976. "Child endowments and the quantity and quality of children." Journal of Political Economy 84:S143-S162.

Behrman, Jere R. and Mark R. Rosenzweig. 2002. "Does increasing women's schooling raise the schooling of the next generation?" American Economic Review 92:323334.

Bingley, Paul, Kaare Christensen, and Vibeke Myrup Jensen. 2009. "Parental schooling and child development: learning from twin parents." Danish National Centre for Social Research Social Policy and Welfare Services Working Paper 07:2009.

Bjerkedal, Tor, Petter Kristensen, Geir A. Skjeret, and John I. Brevik. 2007. "Intelligence test scores and birth order among young Norwegian men (conscripts) analyzed within and between families." Intelligence 35:503-514.

Björklund, Anders and Markus Jäntti. 2012. "How important is family background for laboreconomic outcomes." Labor Economics 19:465-474.

Björklund, Anders, Mikael Lindahl, and Erik Plug. 2006. "The origins of intergenerational associations: lessons from Swedish adoption data." Quarterly Journal of Economics 121:999-1028. 
Björklund, Anders, Mikael Lindahl, and Krister Sund. 2003. "Family background and school performance during a turbulent era of school reforms." Swedish Economic Policy Review 10:111136.

Black, Sandra E., Paul J. Devereux, and Kjell G. Salvanes. 2005a. "The more the merrier? The effect of family size and birth order on children's education." Quarterly Journal of Economics 120:669-700.

Black, Sandra E, Paul J Devereux, and Kjell G Salvanes. 2005b. "Why the apple doesn't fall far: understanding intergenerational transmission of human capital." American Economic Review 95:437-449.

Black, Sandra E, Paul J Devereux, and Kjell G Salvanes. 2007. "From the cradle to the labor market? The effect of birth weight on adult outcomes." Quarterly Journal of Economics 122:409439.

Black, Sandra E, Paul J Devereux, and Kjell G Salvanes. 2009. "Like father, like son? A note on the intergenerational transmission of IQ scores." Economics Letters 105:138-140.

Blake, Judith. 1981. "Family size and the quality of children." Demography 18:421-442.

Blake, Judith. 1989. Family Size \& Achievement, volume 3. Berkeley: University of California Press.

Blau, Peter M and Otis Dudley Duncan. 1967. The American Occupational Structure. New York: John Wiley \& Sons.

Bound, John, David A Jaeger, and Regina M Baker. 1995. "Problems with instrumental variables estimation when the correlation between the instruments and the endogenous explanatory variable is weak." Journal of the American Statistical Association 90:443-450.

Breen, Richard. 2010. "Educational expansion and social mobility in the 20th century." Social Forces 89:365-388.

Breen, Richard, Ruud Luijkx, Walter Müller, and Reinhard Pollak. 2009. "Nonpersistent inequality in educational attainment: evidence from eight European countries." American Journal of Sociology 114:1475-1521.

Buckles, Kasey and Shawna Kolka. 2014. "Prenatal investments, breastfeeding, and birth order." Social Science \& Medicine 118:66-70.

Chan, Tak Wing and Vikki Boliver. 2013. "The grandparents effect in social mobility: evidence from British birth cohort studies." American Sociological Review 78:662-678.

Cheadle, Jacob E. 2008. "Educational investment, family context, and children's math and reading growth from kindergarten through the third grade." Sociology of Education 81:1-31.

Chevalier, Arnaud. 2004. "Parental education and child's education: a natural experiment." IZA Discussion Paper 1153.

Conley, Dalton. 2004. The Pecking Order: Which Siblings Succeed and Why. New York: Pantheon.

Conley, Dalton and Neil G Bennett. 2000. "Is biology destiny? Birth weight and life chances." American Sociological Review 65:458-467.

Daniels, Denise, Judy Dunn, Frank F Furstenberg Jr, and Robert Plomin. 1985. "Environmental differences within the family and adjustment differences within pairs of adolescent siblings." Child Development pp. 764-774.

Dearden, Lorraine, Stephen Machin, and Howard Reed. 1997. "Intergenerational mobility in Britain." The Economic Journal 107:47-66.

DiPrete, Thomas A and Gregory M Eirich. 2006. "Cumulative advantage as a mechanism for inequality: a review of theoretical and empirical developments." Annual Review of Sociology pp. 271-297.

Erikson, Robert and John H. Goldthorpe. 1992. The Constant Flux: A Study of Class Mobility in Industrial Societies. Oxford: Clarendon Press. 
Erikson, Robert, John H Goldthorpe, and Lucienne Portocarero. 1979. "Intergenerational class mobility in three Western European societies: England, France and Sweden." British Journal of Sociology 30:415-441.

Ermisch, John, Markus Jantti, and Timothy M Smeeding. 2012. From Parents to Children: The Intergenerational Transmission of Advantage. New York: Russell Sage Foundation.

Ferrie, Joseph, Catherine Massey, and Jonathan Rothbaum. 2016. "Do grandparents and greatgrandparents matter? Multigenerational mobility in the US, 1910-2013." NBER Working Paper 22635.

Grätz, Michael, Kieron Barclay, Øyvind Wiborg, Torkild Lyngstad, Aleksi Karhula, Jani Erola, Patrick Präg, Thomas Laidley, and Dalton Conley. 2016. "Comparing sibling similarity in education within and between countries." Annual Meeting of the Population Association of America (PAA) 2016, Washington DC .

Hægeland, Torbjørn, Lars J Kirkebøen, Oddbjørn Raaum, and Kjell G Salvanes. 2010. "Why children of college graduates outperform their schoolmates: a study of cousins and adoptees." NHH Dept. of Economics Discussion Paper.

Halldén, Karin. 2008. "The Swedish educational system and classifying education using the ISCED-97." In The International Standard Classification of Education (ISCED-97). An Evaluation of Content and Criterion Validity in 15 European Countries, edited by Silke Schneider, pp. 253-267. Mannheim: MZES.

Hällsten, Martin. 2014. "Inequality across three and four generations in egalitarian Sweden: 1st and 2nd cousin correlations in socio-economic outcomes." Research in Social Stratification and Mobility 35:19-33.

Hällsten, Martin and Fabian T Pfeffer. 2017. “Grand advantage: family wealth and grandchildren's educational achievement in Sweden." American Sociological Review 82:328-360.

Härkönen, Juho. 2014. "Birth order effects on educational attainment and educational transitions in West Germany." European Sociological Review 30:166-179.

Heckman, James J. 2006. "Skill formation and the economics of investing in disadvantaged children." Science 312:1900-1902.

Högskoleverket. 2012. Swedish Universities and University Colleges: Short Version of Annual Report 2012. Stockholm: Högskoleverket.

Holmlund, Helena, Mikael Lindahl, and Erik Plug. 2011. "The causal effect of parents' schooling on children's schooling: a comparison of estimation methods." Journal of Economic Literature 49:615-651.

Hotz, V Joseph and Juan Pantano. 2015. "Strategic parenting, birth order, and school performance." Journal of Population Economics 28:911-936.

Jæger, Mads Meier. 2012. "The extended family and children's educational success." American Sociological Review 77:903-922.

Kalil, Ariel, Rebecca Ryan, and Michael Corey. 2012. "Diverging destinies: maternal education and the developmental gradient in time with children." Demography 49:1361-1383.

Kalmijn, Matthijs and Gerbert Kraaykamp. 2005. "Late or later? A sibling analysis of the effect of maternal age on children's schooling." Social Science Research 34:634-650.

Kramer, Michael S. 1987. "Determinants of low birth weight: methodological assessment and meta-analysis." Bulletin of the World Health Organization 65:663-737.

Kristensen, Petter and Tor Bjerkedal. 2007. "Explaining the relation between birth order and intelligence." Science 316:1717.

Lareau, Annette. 2011. Unequal Childhoods: Class, Race, and Family Life. Berkeley, CA: University of California Press. 
Lindahl, Lena. 2008. "Do birth order and family size matter for intergenerational income mobility? Evidence from Sweden." Applied Economics 40:2239-2257.

Lleras-Muney, Adriana. 2005. "The relationship between education and adult mortality in the United States." The Review of Economic Studies 72:189-221.

Lundberg, Ian. 2018. "Measuring multigenerational mobility: what can we learn from cousin correlations?" Annual Meeting of the Population Association of America (PAA) 2018, Denver, CO.

Mare, Robert D. 2011. "A multigenerational view of inequality.” Demography 48:1-23.

Marmot, Michael. 2004. Status Syndrome: How Your Social Standing Directly Affects Your Health and Life Expectancy. London: Bloomsbury.

Merton, Robert K. 1968. "The Matthew effect in science." Science 159:56-63.

Oreopoulos, Philip, Marianne E Page, and Ann Huff Stevens. 2006. "The intergenerational effects of compulsory schooling." Journal of Labor Economics 24:729-760.

Plomin, Robert and Denise Daniels. 1987. "Why are children in the same family so different from one another?" Behavioral and Brain Sciences 10:1-16.

Plug, Erik. 2004. "Estimating the effect of mother's schooling on children's schooling using a sample of adoptees." American Economic Review 94:358-368.

Price, Joseph. 2008. "Parent-Child Quality Time Does Birth Order Matter?" Journal of Human Resources 43:240-265.

Pronzato, Chiara. 2012. "An examination of paternal and maternal intergenerational transmission of schooling." Journal of Population Economics 25:591-608.

Reiss, David, Jenae M Neiderhiser, E Mavis Hetherington, and Robert Plomin. 2009. The Relationship Code: Deciphering Genetic and Social Influences on Adolescent Development. Cambridge, MA: Harvard University Press.

Rosenzweig, Mark R and Kenneth I Wolpin. 1980. “Testing the quantity-quality fertility model: the use of twins as a natural experiment." Econometrica 48:227-240.

Rutter, Michael. 1998. "Developmental catch-up, and deficit, following adoption after severe global early privation." Journal of Child Psychology and Psychiatry 39:465-476.

Sacerdote, Bruce. 2007. "How large are the effects from changes in family environment? A study of Korean American adoptees." Quarterly Journal of Economics 122:119-157.

Sénéchal, Monique and Jo-Anne LeFevre. 2002. "Parental involvement in the development of childrens reading skill: a five-year longitudinal study." Child Development 73:445-460.

Sorokin, Pitirim A. 1927. Social and Cultural Mobility. New York: Harper.

Stanovich, Keith E. 1986. "Matthew effects in reading: some consequences of individual differences in the acquisition of literacy." Reading Research Quarterly pp. 360-407.

Steelman, Lala Carr, Brian Powell, Regina Werum, and Scott Carter. 2002. "Reconsidering the effects of sibling configuration: recent advances and challenges." Annual Review of Sociology 28:243-269.

Suitor, J Jill, Jori Sechrist, Mari Plikuhn, Seth T Pardo, and Karl Pillemer. 2008. "Within-family differences in parent-child relations across the life course." Current Directions in Psychological Science 17:334-338.

Sundström, Marianne and Ann-Zofie E Duvander. 2002. "Gender division of childcare and the sharing of parental leave among new parents in Sweden." European Sociological Review 18:433-447.

Warren, John Robert and Robert M Hauser. 1997. "Social stratification across three generations: new evidence from the Wisconsin Longitudinal Study." American Sociological Review pp. 561572.

Zajonc, Robert B. 1976. "Family configuration and intelligence.” Science 192:227-236. 
Zajonc, Robert B. and G. B. Markus. 1975. "Birth order and intellectual development." Psychological Review 82:74-88.

Zeng, Zhen and Yu Xie. 2014. "The effects of grandparents on childrens schooling: evidence from rural China." Demography 51:599-617. 
INTERGENERATIONAL EFFECTS OF BIRTH ORDER AND FAMILY SIZE ON EDUCATIONAL ATTAINMENT 47

\section{SUPPLEMENTARY INFORMATION}


Table S1: Descriptive statistics for birth order and educational attainment at age 30 for generation 3 (G3), based upon maternal cousin sample, Swedish men and women born 1960-1982.

\begin{tabular}{|c|c|c|c|c|c|c|c|c|c|c|c|c|c|c|c|c|}
\hline & & \multicolumn{5}{|c|}{ Index Birth Order } & \multicolumn{5}{|c|}{ Mother Birth Order } & \multicolumn{5}{|c|}{ Father Birth Order } \\
\hline & & 1 & 2 & 3 & 4 & $5+$ & 1 & 2 & 3 & 4 & $5+$ & 1 & 2 & 3 & 4 & $5+$ \\
\hline $\mathrm{N}$ & & 300,257 & 162,985 & 39,219 & 5,746 & 1,532 & 202,317 & 160,275 & 81,438 & 35,953 & 29,756 & 245,376 & 155,266 & 65,549 & 25,432 & 18,116 \\
\hline \multirow[t]{2}{*}{ Years of Education } & Mean & 12.7 & 12.8 & 12.8 & 12.5 & 12.1 & 12.7 & 12.8 & 12.8 & 12.7 & 12.5 & 12.7 & 12.8 & 12.7 & 12.6 & 12.5 \\
\hline & SD & 2.3 & 2.3 & 2.3 & 2.3 & 2.3 & 2.3 & 2.3 & 2.3 & 2.3 & 2.2 & 2.3 & 2.3 & 2.3 & 2.2 & 2.2 \\
\hline \multirow[t]{2}{*}{ Mother Birth Order } & Mean & 2.1 & 2.2 & 2.2 & 2.2 & 2.1 & 1.0 & 2.0 & 3.0 & 4.0 & 5.9 & 2.1 & 2.1 & 2.2 & 2.3 & 2.4 \\
\hline & SD & 1.3 & 1.3 & 1.4 & 1.4 & 1.4 & 0.0 & 0.0 & 0.0 & 0.0 & 1.2 & 1.3 & 1.3 & 1.4 & 1.5 & 1.6 \\
\hline \multirow[t]{2}{*}{ Father Birth Order } & Mean & 1.9 & 1.9 & 1.9 & 2.0 & 2.0 & 1.8 & 1.9 & 1.9 & 2.0 & 2.1 & 1.0 & 2.0 & 3.0 & 4.0 & 5.8 \\
\hline & SD & 1.2 & 1.2 & 1.2 & 1.2 & 1.2 & 1.1 & 1.2 & 1.2 & 1.2 & 1.3 & 0.0 & 0.0 & 0.0 & 0.0 & 1.2 \\
\hline \multirow[t]{2}{*}{ Index Birth Order } & Mean & 1.0 & 2.0 & 3.0 & 4.0 & 5.5 & 1.5 & 1.5 & 1.5 & 1.5 & 1.6 & 1.5 & 1.5 & 1.5 & 1.5 & 1.5 \\
\hline & SD & 0.0 & 0.0 & 0.0 & 0.0 & 0.8 & 0.7 & 0.7 & 0.7 & 0.7 & 0.7 & 0.7 & 0.7 & 0.7 & 0.7 & 0.7 \\
\hline \multirow[t]{2}{*}{ Index Sibling Group Size } & Mean & 2.0 & 2.5 & 3.4 & 4.6 & 6.4 & 2.2 & 2.3 & 2.3 & 2.4 & 2.4 & 2.2 & 2.3 & 2.4 & 2.4 & 2.4 \\
\hline & SD & 0.9 & 0.8 & 0.8 & 1.0 & 1.7 & 1.0 & 1.0 & 1.0 & 1.0 & 1.1 & 1.0 & 1.0 & 1.1 & 1.1 & 1.1 \\
\hline \multirow[t]{2}{*}{ Index Birth Year } & Mean & 1973.3 & 1974.7 & 1975.9 & 1976.4 & 1977.1 & 1973.7 & 1974.1 & 1974.4 & 1974.4 & 1974.5 & 1973.7 & 1974.2 & 1974.4 & 1974.5 & 1975.0 \\
\hline & SD & 5.6 & 5.0 & 4.7 & 4.6 & 4.4 & 5.6 & 5.4 & 5.3 & 5.3 & 5.1 & 5.5 & 5.4 & 5.3 & 5.3 & 5.0 \\
\hline \multirow[t]{2}{*}{ Index Mother Age } & Mean & 23.5 & 26.2 & 28.8 & 30.4 & 32.2 & 25.1 & 24.9 & 24.7 & 24.4 & 24.1 & 25.0 & 24.9 & 24.7 & 24.4 & 23.9 \\
\hline & SD & 4.2 & 3.8 & 3.8 & 4.0 & 4.1 & 4.6 & 4.4 & 4.4 & 4.3 & 4.2 & 4.5 & 4.4 & 4.4 & 4.4 & 4.3 \\
\hline \multirow[t]{2}{*}{ Index Father Age } & Mean & 25.7 & 28.4 & 31.0 & 32.6 & 34.3 & 27.0 & 27.2 & 27.1 & 27.1 & 26.9 & 27.3 & 27.1 & 26.9 & 26.6 & 26.2 \\
\hline & SD & 4.2 & 3.8 & 3.9 & 4.0 & 4.3 & 4.5 & 4.4 & 4.4 & 4.4 & 4.4 & 4.5 & 4.4 & 4.4 & 4.4 & 4.2 \\
\hline \multirow[t]{2}{*}{ Mother Sibling Group Size } & Mean & 3.4 & 3.5 & 3.8 & 4.0 & 3.9 & 2.7 & 3.1 & 4.0 & 5.0 & 7.0 & 3.4 & 3.5 & 3.6 & 3.7 & 3.8 \\
\hline & SD & 1.7 & 1.7 & 1.8 & 2.0 & 2.2 & 1.3 & 1.2 & 1.3 & 1.3 & 1.9 & 1.7 & 1.7 & 1.8 & 1.9 & 2.0 \\
\hline \multirow[t]{2}{*}{ Father Sibling Group Size } & Mean & 2.9 & 2.9 & 3.1 & 3.4 & 3.7 & 2.9 & 2.9 & 3.0 & 3.1 & 3.2 & 2.2 & 2.9 & 3.9 & 5.0 & 6.9 \\
\hline & SD & 1.6 & 1.7 & 1.8 & 1.9 & 2.2 & 1.6 & 1.6 & 1.7 & 1.8 & 1.9 & 1.2 & 1.2 & 1.3 & 1.4 & 1.9 \\
\hline \multirow[t]{2}{*}{ Mother Birth Year } & Mean & 1949.8 & 1948.5 & 1947.2 & 1946.0 & 1944.9 & 1948.6 & 1949.2 & 1949.7 & 1949.9 & 1950.3 & 1948.7 & 1949.2 & 1949.7 & 1950.1 & 1951.1 \\
\hline & SD & 5.5 & 4.9 & 4.4 & 4.1 & 3.8 & 5.4 & 5.2 & 5.1 & 5.1 & 4.8 & 5.3 & 5.2 & 5.2 & 5.1 & 5.0 \\
\hline \multirow[t]{2}{*}{ Father Birth Year } & Mean & 1947.6 & 1946.3 & 1944.9 & 1943.8 & 1942.8 & 1946.6 & 1946.9 & 1947.2 & 1947.3 & 1947.6 & 1946.4 & 1947.1 & 1947.5 & 1947.8 & 1948.8 \\
\hline & SD & 5.3 & 4.7 & 4.2 & 3.9 & 3.6 & 5.2 & 5.0 & 5.0 & 5.0 & 4.8 & 5.1 & 5.1 & 5.1 & 5.0 & 4.6 \\
\hline Maternal Grandmother & Mean & 27.7 & 27.9 & 27.8 & 27.7 & 28.0 & 24.6 & 28.0 & 30.6 & 32.4 & 34.9 & 27.7 & 27.8 & 27.8 & 27.9 & 27.8 \\
\hline Age at Birth & SD & 6.0 & 5.9 & 5.8 & 5.9 & 6.3 & 4.9 & 5.1 & 5.2 & 5.1 & 4.9 & 5.9 & 5.9 & 6.0 & 6.1 & 6.3 \\
\hline Paternal Grandmother & Mean & 28.2 & 28.5 & 28.7 & 28.7 & 28.3 & 28.3 & 28.3 & 28.4 & 28.3 & 28.4 & 26.1 & 29.1 & 31.3 & 32.9 & 34.9 \\
\hline Age at Birth & SD & 6.1 & 6.1 & 6.1 & 6.2 & 6.3 & 6.1 & 6.1 & 6.1 & 6.2 & 6.2 & 5.7 & 5.5 & 5.3 & 5.2 & 4.9 \\
\hline Mother Education & Primary (<9 years) & 9.9 & 11.4 & 15.7 & 22.6 & 33.8 & 9.8 & 10.7 & 12.2 & 13.5 & 15.1 & 11.1 & 10.8 & 11.2 & 11.6 & 10.9 \\
\hline \multirow[t]{7}{*}{$(\%)$} & Primary ( 9 years) & 13.1 & 12.0 & 11.3 & 11.8 & 11.0 & 11.6 & 12.5 & 13.3 & 14.0 & 15.7 & 12.1 & 12.3 & 13.4 & 14.3 & 15.2 \\
\hline & Secondary (10-11 years) & 42.6 & 41.8 & 41.2 & 39.5 & 34.5 & 41.1 & 41.9 & 42.8 & 44.9 & 46.0 & 41.5 & 42.2 & 42.6 & 45.1 & 47.1 \\
\hline & Secondary (12 years) & 8.9 & 8.5 & 7.3 & 5.7 & 5.4 & 9.2 & 8.6 & 8.1 & 7.8 & 7.1 & 8.7 & 8.4 & 8.7 & 7.9 & 8.9 \\
\hline & Tertiary (13-15 years) & 11.8 & 11.9 & 10.4 & 7.9 & 6.7 & 12.5 & 11.9 & 11.1 & 9.6 & 8.5 & 12.0 & 12.0 & 11.2 & 9.6 & 8.8 \\
\hline & Tertiary $(15+$ years $)$ & 13.3 & 13.9 & 13.7 & 12.2 & 7.8 & 15.3 & 13.9 & 12.1 & 9.7 & 7.3 & 14.1 & 13.8 & 12.6 & 11.2 & 9.0 \\
\hline & Graduate school & 0.4 & 0.4 & 0.4 & 0.4 & 0.3 & 0.5 & 0.4 & 0.4 & 0.3 & 0.1 & 0.5 & 0.4 & 0.3 & 0.3 & 0.1 \\
\hline & Missing & 0.1 & 0.1 & 0.0 & 0.1 & 0.5 & 0.1 & 0.1 & 0.1 & 0.2 & 0.1 & 0.1 & 0.1 & 0.1 & 0.1 & 0.1 \\
\hline
\end{tabular}


Table S1 - Continued from previous page

\begin{tabular}{|c|c|c|c|c|c|c|c|c|c|c|c|c|c|c|c|c|}
\hline & & \multicolumn{5}{|c|}{ Index Birth Order } & \multicolumn{5}{|c|}{ Mother Birth Order } & \multicolumn{5}{|c|}{ Father Birth Order } \\
\hline & & 1 & 2 & 3 & 4 & $5+$ & 1 & 2 & 3 & 4 & $5+$ & 1 & 2 & 3 & 4 & $5+$ \\
\hline Mother EGP & I & 0.9 & 0.8 & 0.7 & 0.6 & 0.9 & 0.9 & 0.9 & 0.8 & 0.7 & 0.5 & 0.9 & 0.9 & 0.7 & 0.6 & 0.4 \\
\hline \multirow[t]{5}{*}{$(\%)$} & II & 31.6 & 34.7 & 32.9 & 27.7 & 23.4 & 35.6 & 33.5 & 29.8 & 26.1 & 22.9 & 35.2 & 32.6 & 28.8 & 25.6 & 20.8 \\
\hline & III & 10.0 & 8.1 & 6.3 & 5.8 & 5.9 & 8.8 & 9.2 & 9.4 & 10.0 & 8.6 & 8.9 & 9.2 & 9.4 & 8.9 & 8.8 \\
\hline & IV & 2.4 & 3.0 & 4.5 & 6.6 & 6.8 & 2.7 & 2.9 & 3.1 & 2.7 & 2.9 & 2.7 & 2.9 & 3.0 & 3.3 & 3.1 \\
\hline & VI-VII & 29.8 & 28.2 & 29.6 & 35.2 & 42.7 & 27.6 & 28.7 & 30.8 & 33.8 & 36.2 & 28.1 & 29.1 & 31.9 & 33.2 & 35.2 \\
\hline & Unknown & 25.2 & 25.2 & 26.0 & 24.1 & 20.4 & 24.5 & 24.8 & 26.1 & 26.8 & 29.0 & 24.2 & 25.3 & 26.2 & 28.5 & 31.8 \\
\hline Father Education & Primary ( $<9$ years) & 18.5 & 21.1 & 26.5 & 33.2 & 38.9 & 19.6 & 19.4 & 20.8 & 22.0 & 24.4 & 18.2 & 20.3 & 22.9 & 26.4 & 27.8 \\
\hline \multirow[t]{7}{*}{$(\%)$} & Primary (9 years) & 13.6 & 11.4 & 9.3 & 7.9 & 7.8 & 12.0 & 12.4 & 12.8 & 13.6 & 14.1 & 11.6 & 12.4 & 13.8 & 14.8 & 16.8 \\
\hline & Secondary (10-11 years) & 30.9 & 28.3 & 27.0 & 28.0 & 28.8 & 28.9 & 29.3 & 30.4 & 31.3 & 32.8 & 29.0 & 29.6 & 30.7 & 31.6 & 33.2 \\
\hline & Secondary (12 years) & 15.3 & 16.5 & 15.3 & 12.2 & 10.1 & 16.0 & 16.0 & 15.1 & 14.8 & 13.6 & 17.0 & 15.7 & 13.4 & 11.8 & 10.2 \\
\hline & Tertiary (13-15 years) & 9.8 & 10.0 & 8.6 & 6.4 & 4.2 & 10.0 & 10.0 & 9.6 & 8.8 & 8.1 & 10.5 & 9.7 & 8.8 & 7.5 & 6.5 \\
\hline & Tertiary $(15+$ years $)$ & 10.4 & 11.3 & 11.5 & 10.4 & 8.0 & 11.8 & 11.3 & 9.9 & 8.3 & 6.3 & 12.0 & 10.8 & 9.3 & 7.2 & 4.8 \\
\hline & Graduate school & 1.0 & 1.2 & 1.7 & 1.8 & 2.0 & 1.4 & 1.2 & 1.0 & 0.9 & 0.5 & 1.4 & 1.1 & 1.0 & 0.5 & 0.3 \\
\hline & Missing & 0.4 & 0.2 & 0.2 & 0.2 & 0.3 & 0.4 & 0.3 & 0.3 & 0.3 & 0.2 & 0.4 & 0.3 & 0.3 & 0.3 & 0.3 \\
\hline Father EGP & I & 1.7 & 1.4 & 1.0 & 0.9 & 1.0 & 1.6 & 1.6 & 1.5 & 1.2 & 1.1 & 1.6 & 1.6 & 1.3 & 1.0 & 0.9 \\
\hline \multirow[t]{5}{*}{$(\%)$} & II & 19.1 & 21.3 & 20.5 & 17.2 & 15.1 & 21.1 & 20.7 & 18.5 & 16.7 & 14.8 & 22.3 & 19.7 & 16.2 & 13.4 & 10.1 \\
\hline & III & 3.2 & 2.4 & 1.4 & 1.1 & 1.2 & 2.7 & 2.8 & 2.9 & 2.7 & 2.6 & 2.7 & 2.8 & 2.8 & 2.7 & 2.5 \\
\hline & IV & 5.2 & 5.6 & 6.7 & 8.7 & 7.1 & 5.3 & 5.4 & 5.9 & 5.7 & 6.0 & 5.0 & 5.8 & 6.0 & 6.5 & 6.3 \\
\hline & VI-VII & 49.8 & 48.9 & 50.0 & 53.0 & 55.0 & 47.8 & 48.4 & 51.1 & 54.0 & 58.3 & 46.8 & 49.4 & 53.8 & 57.3 & 62.9 \\
\hline & Unknown & 21.2 & 20.4 & 20.3 & 19.2 & 20.6 & 21.6 & 21.2 & 20.1 & 19.8 & 17.2 & 21.6 & 20.7 & 19.9 & 19.0 & 17.3 \\
\hline
\end{tabular}


Table S2: Descriptive statistics for birth order and educational attainment at age 30 for generation 3 (G3), based upon paternal cousin sample,

Swedish men and women born 1960-1982.

\begin{tabular}{|c|c|c|c|c|c|c|c|c|c|c|c|c|c|c|c|c|}
\hline & & \multicolumn{5}{|c|}{ Index Birth Order } & \multicolumn{5}{|c|}{ Mother Birth Order } & \multicolumn{5}{|c|}{ Father Birth Order } \\
\hline & & 1 & 2 & 3 & 4 & $5+$ & 1 & 2 & 3 & 4 & $5+$ & 1 & 2 & 3 & 4 & $5+$ \\
\hline $\mathrm{N}$ & & 301,480 & 165,810 & 39,570 & 5,829 & 1,533 & \#\#\#\#\# & 156,373 & 67,726 & 27,265 & 20,763 & 212,282 & 162,831 & 79,943 & 33,649 & 25,517 \\
\hline \multirow[t]{2}{*}{ Years of Education } & Mean & 12.7 & 12.9 & 12.8 & 12.5 & 12.2 & 12.8 & 12.8 & 12.7 & 12.6 & 12.5 & 12.7 & 12.8 & 12.8 & 12.7 & 12.6 \\
\hline & SD & 2.3 & 2.3 & 2.3 & 2.3 & 2.3 & 2.3 & 2.3 & 2.3 & 2.3 & 2.2 & 2.3 & 2.3 & 2.3 & 2.3 & 2.2 \\
\hline \multirow[t]{2}{*}{ Mother Birth Order } & Mean & 1.9 & 1.9 & 2.0 & 2.0 & 2.1 & 1.0 & 2.0 & 3.0 & 4.0 & 5.9 & 1.9 & 1.9 & 2.0 & 2.0 & 2.1 \\
\hline & SD & 1.2 & 1.2 & 1.3 & 1.3 & 1.3 & 0.0 & 0.0 & 0.0 & 0.0 & 1.2 & 1.2 & 1.2 & 1.2 & 1.3 & 1.4 \\
\hline \multirow[t]{2}{*}{ Father Birth Order } & Mean & 2.0 & 2.1 & 2.1 & 2.1 & 2.0 & 2.0 & 2.1 & 2.1 & 2.2 & 2.3 & 1.0 & 2.0 & 3.0 & 4.0 & 5.8 \\
\hline & SD & 1.3 & 1.3 & 1.3 & 1.3 & 1.2 & 1.2 & 1.3 & 1.3 & 1.4 & 1.5 & 0.0 & 0.0 & 0.0 & 0.0 & 1.2 \\
\hline \multirow[t]{2}{*}{ Index Birth Order } & Mean & 1.0 & 2.0 & 3.0 & 4.0 & 5.5 & 1.5 & 1.5 & 1.5 & 1.5 & 1.6 & 1.5 & 1.5 & 1.5 & 1.5 & 1.5 \\
\hline & SD & 0.0 & 0.0 & 0.0 & 0.0 & 0.8 & 0.7 & 0.7 & 0.7 & 0.7 & 0.8 & 0.7 & 0.7 & 0.7 & 0.7 & 0.7 \\
\hline \multirow[t]{2}{*}{ Index Sibling Group Size } & Mean & 2.0 & 2.5 & 3.4 & 4.5 & 6.4 & 2.3 & 2.3 & 2.3 & 2.4 & 2.4 & 2.2 & 2.3 & 2.4 & 2.4 & 2.5 \\
\hline & SD & 0.9 & 0.8 & 0.8 & 1.0 & 1.7 & 1.0 & 1.0 & 1.0 & 1.1 & 1.2 & 1.0 & 1.0 & 1.0 & 1.0 & 1.1 \\
\hline \multirow[t]{2}{*}{ Index Birth Year } & Mean & 1973.3 & 1974.7 & 1975.9 & 1976.4 & 1976.9 & 1973.8 & 1974.1 & 1974.2 & 1974.2 & 1974.4 & 1973.4 & 1974.1 & 1974.5 & 1974.6 & 1975.1 \\
\hline & SD & 5.7 & 5.0 & 4.7 & 4.6 & 4.5 & 5.5 & 5.4 & 5.4 & 5.3 & 5.2 & 5.6 & 5.4 & 5.3 & 5.2 & 4.9 \\
\hline \multirow[t]{2}{*}{ Index Mother Age } & Mean & 23.5 & 26.2 & 28.8 & 30.5 & 32.2 & 25.0 & 24.9 & 24.6 & 24.3 & 24.0 & 25.0 & 25.0 & 24.8 & 24.5 & 24.1 \\
\hline & SD & 4.2 & 3.8 & 3.8 & 3.9 & 4.2 & 4.5 & 4.4 & 4.4 & 4.3 & 4.2 & 4.5 & 4.4 & 4.4 & 4.4 & 4.2 \\
\hline \multirow[t]{2}{*}{ Index Father Age } & Mean & 25.7 & 28.4 & 31.0 & 32.6 & 34.3 & 27.1 & 27.2 & 27.1 & 26.9 & 26.8 & 27.3 & 27.1 & 26.9 & 26.7 & 26.3 \\
\hline & SD & 4.3 & 3.9 & 3.8 & 3.9 & 4.2 & 4.5 & 4.5 & 4.5 & 4.5 & 4.5 & 4.7 & 4.5 & 4.4 & 4.4 & 4.1 \\
\hline \multirow[t]{2}{*}{ Mother Sibling Group Size } & Mean & 2.9 & 2.9 & 3.1 & 3.4 & 3.7 & 2.2 & 2.8 & 3.8 & 4.9 & 6.9 & 2.8 & 2.9 & 3.0 & 3.1 & 3.2 \\
\hline & SD & 1.6 & 1.6 & 1.8 & 2.0 & 2.2 & 1.2 & 1.1 & 1.2 & 1.3 & 1.9 & 1.6 & 1.6 & 1.7 & 1.8 & 1.9 \\
\hline \multirow[t]{2}{*}{ Father Sibling Group Size } & Mean & 3.4 & 3.5 & 3.8 & 4.0 & 3.9 & 3.4 & 3.4 & 3.5 & 3.6 & 3.8 & 2.7 & 3.2 & 4.1 & 5.1 & 7.0 \\
\hline & SD & 1.7 & 1.7 & 1.8 & 2.0 & 2.2 & 1.7 & 1.7 & 1.7 & 1.8 & 2.0 & 1.3 & 1.3 & 1.3 & 1.4 & 1.9 \\
\hline \multirow[t]{2}{*}{ Mother Birth Year } & Mean & 1949.8 & 1948.5 & 1947.1 & 1946.0 & 1944.7 & 1948.8 & 1949.1 & 1949.6 & 1949.9 & 1950.4 & 1948.4 & 1949.2 & 1949.7 & 1950.1 & 1951.1 \\
\hline & SD & 5.5 & 4.9 & 4.4 & 4.1 & 3.7 & 5.3 & 5.2 & 5.2 & 5.1 & 4.9 & 5.4 & 5.1 & 5.1 & 5.1 & 4.9 \\
\hline \multirow[t]{2}{*}{ Father Birth Year } & Mean & 1947.5 & 1946.3 & 1944.9 & 1943.8 & 1942.7 & 1946.7 & 1946.9 & 1947.1 & 1947.3 & 1947.6 & 1946.1 & 1947.0 & 1947.6 & 1947.9 & 1948.8 \\
\hline & SD & 5.3 & 4.7 & 4.2 & 3.9 & 3.6 & 5.1 & 5.0 & 5.0 & 5.0 & 4.9 & 5.2 & 5.0 & 5.0 & 4.9 & 4.6 \\
\hline Maternal Grandmother & Mean & 28.0 & 28.3 & 28.4 & 28.3 & 28.1 & 25.7 & 28.8 & 31.2 & 32.9 & 35.1 & 28.1 & 28.1 & 28.1 & 28.1 & 28.0 \\
\hline Age at Birth & SD & 6.1 & 6.1 & 6.1 & 6.3 & 6.5 & 5.7 & 5.4 & 5.4 & 5.2 & 4.9 & 6.1 & 6.1 & 6.2 & 6.2 & 6.4 \\
\hline Paternal Grandmother & Mean & 27.9 & 28.0 & 28.0 & 28.0 & 28.0 & 27.9 & 27.9 & 28.0 & 28.0 & 28.0 & 25.0 & 28.3 & 30.7 & 32.5 & 34.7 \\
\hline Age at Birth & SD & 5.9 & 5.8 & 5.8 & 5.9 & 6.2 & 5.8 & 5.8 & 5.9 & 6.0 & 6.0 & 5.0 & 5.2 & 5.1 & 5.0 & 4.8 \\
\hline Mother Education & Primary (<9 years) & 9.2 & 10.5 & 14.7 & 21.0 & 32.5 & 9.0 & 10.1 & 11.9 & 13.8 & 15.1 & 10.6 & 9.8 & 10.1 & 10.9 & 9.9 \\
\hline \multirow[t]{7}{*}{$(\%)$} & Primary (9 years) & 12.7 & 11.8 & 11.2 & 11.7 & 11.4 & 11.6 & 12.3 & 13.0 & 14.0 & 16.1 & 11.8 & 12.0 & 12.7 & 13.6 & 14.8 \\
\hline & Secondary (10-11 years) & 42.2 & 41.6 & 40.9 & 39.6 & 34.9 & 41.0 & 41.7 & 43.2 & 44.0 & 45.8 & 40.8 & 41.5 & 42.7 & 44.8 & 47.1 \\
\hline & Secondary (12 years) & 9.4 & 9.0 & 7.5 & 5.9 & 5.0 & 9.6 & 9.0 & 8.2 & 8.0 & 7.2 & 9.0 & 9.1 & 9.2 & 8.6 & 9.3 \\
\hline & Tertiary (13-15 years) & 12.2 & 12.1 & 10.9 & 8.6 & 7.2 & 12.7 & 12.1 & 11.0 & 9.9 & 8.4 & 12.2 & 12.6 & 11.6 & 10.4 & 9.5 \\
\hline & Tertiary (15+ years) & 13.9 & 14.4 & 14.3 & 12.9 & 8.4 & 15.5 & 14.2 & 12.2 & 9.8 & 7.2 & 15.0 & 14.6 & 13.3 & 11.4 & 9.2 \\
\hline & Graduate school & 0.4 & 0.5 & 0.4 & 0.3 & 0.3 & 0.5 & 0.5 & 0.4 & 0.3 & 0.1 & 0.5 & 0.5 & 0.4 & 0.3 & 0.2 \\
\hline & Missing & 0.2 & 0.1 & 0.1 & 0.1 & 0.5 & 0.1 & 0.1 & 0.1 & 0.2 & 0.1 & 0.1 & 0.1 & 0.1 & 0.1 & 0.1 \\
\hline
\end{tabular}


Table S2 - Continued from previous page

\begin{tabular}{|c|c|c|c|c|c|c|c|c|c|c|c|c|c|c|c|c|}
\hline & & \multicolumn{5}{|c|}{ Index Birth Order } & \multicolumn{5}{|c|}{ Mother Birth Order } & \multicolumn{5}{|c|}{ Father Birth Order } \\
\hline & & 1 & 2 & 3 & 4 & $5+$ & 1 & 2 & 3 & 4 & $5+$ & 1 & 2 & 3 & 4 & $5+$ \\
\hline Mother EGP & I & 0.9 & 0.8 & 0.7 & 0.6 & 0.9 & 1.0 & 0.8 & 0.7 & 0.7 & 0.4 & 1.0 & 0.9 & 0.7 & 0.7 & 0.5 \\
\hline \multirow[t]{5}{*}{$(\%)$} & II & 32.4 & 35.4 & 33.8 & 29.5 & 23.7 & 36.0 & 33.6 & 29.8 & 26.5 & 22.3 & 36.5 & 33.9 & 30.4 & 26.9 & 22.4 \\
\hline & III & 10.1 & 8.1 & 5.9 & 5.4 & 5.9 & 9.0 & 9.1 & 9.2 & 9.7 & 8.6 & 8.8 & 9.3 & 9.4 & 9.3 & 9.1 \\
\hline & IV & 2.4 & 2.9 & 4.3 & 5.7 & 6.4 & 2.6 & 2.9 & 3.1 & 2.7 & 2.6 & 2.7 & 2.8 & 2.7 & 2.9 & 2.9 \\
\hline & VI-VII & 29.0 & 27.5 & 29.4 & 34.2 & 43.3 & 27.0 & 28.4 & 30.8 & 33.4 & 36.3 & 27.0 & 27.9 & 30.7 & 32.5 & 34.6 \\
\hline & Unknown & 25.2 & 25.3 & 26.1 & 24.6 & 19.8 & 24.4 & 25.2 & 26.4 & 27.0 & 29.8 & 24.0 & 25.3 & 26.0 & 27.6 & 30.5 \\
\hline Father Education & Primary ( $<9$ years) & 18.8 & 21.4 & 26.6 & 33.3 & 39.7 & 19.6 & 20.2 & 21.5 & 22.8 & 25.5 & 18.6 & 19.8 & 22.3 & 26.2 & 27.3 \\
\hline \multirow[t]{7}{*}{$(\%)$} & Primary (9 years) & 13.6 & 11.4 & 9.2 & 8.0 & 7.5 & 12.1 & 12.3 & 12.8 & 14.0 & 14.4 & 11.3 & 12.3 & 13.7 & 14.4 & 17.0 \\
\hline & Secondary (10-11 years) & 30.3 & 27.7 & 26.5 & 27.3 & 27.8 & 28.5 & 28.9 & 30.1 & 31.3 & 32.7 & 28.1 & 29.1 & 30.1 & 31.2 & 33.0 \\
\hline & Secondary (12 years) & 15.0 & 16.1 & 15.0 & 11.9 & 9.5 & 15.8 & 15.4 & 14.5 & 14.2 & 12.8 & 16.7 & 15.7 & 13.8 & 12.2 & 10.1 \\
\hline & Tertiary (13-15 years) & 9.9 & 10.0 & 8.7 & 6.6 & 4.4 & 10.1 & 10.0 & 9.5 & 8.5 & 7.9 & 10.6 & 9.9 & 9.1 & 7.7 & 7.1 \\
\hline & Tertiary $(15+$ years $)$ & 10.9 & 11.8 & 12.1 & 10.8 & 8.9 & 12.2 & 11.6 & 10.2 & 7.9 & 6.1 & 12.9 & 11.7 & 9.7 & 7.6 & 5.0 \\
\hline & Graduate school & 1.2 & 1.4 & 1.8 & 1.9 & 2.0 & 1.4 & 1.4 & 1.1 & 0.9 & 0.5 & 1.6 & 1.3 & 1.1 & 0.6 & 0.4 \\
\hline & Missing & 0.4 & 0.2 & 0.1 & 0.2 & 0.3 & 0.3 & 0.3 & 0.3 & 0.3 & 0.2 & 0.4 & 0.3 & 0.2 & 0.2 & 0.2 \\
\hline Father EGP & I & 1.7 & 1.4 & 1.1 & 0.8 & 1.0 & 1.6 & 1.6 & 1.4 & 1.2 & 1.0 & 1.7 & 1.7 & 1.4 & 1.1 & 1.0 \\
\hline \multirow[t]{5}{*}{$(\%)$} & II & 19.3 & 21.5 & 20.7 & 17.7 & 15.1 & 21.4 & 20.4 & 18.3 & 16.3 & 13.8 & 22.9 & 20.7 & 17.2 & 13.9 & 10.4 \\
\hline & III & 3.2 & 2.4 & 1.5 & 1.0 & 1.0 & 2.8 & 2.8 & 2.9 & 2.7 & 2.6 & 2.6 & 2.9 & 2.9 & 2.9 & 2.7 \\
\hline & IV & 5.2 & 5.5 & 6.5 & 8.2 & 6.9 & 5.3 & 5.3 & 6.1 & 5.9 & 6.1 & 5.0 & 5.4 & 5.9 & 6.5 & 6.4 \\
\hline & VI-VII & 49.4 & 48.5 & 49.6 & 52.1 & 55.1 & 47.6 & 48.6 & 51.0 & 54.3 & 58.9 & 45.6 & 48.3 & 52.8 & 57.0 & 62.1 \\
\hline & Unknown & 21.3 & 20.6 & 20.7 & 20.2 & 20.9 & 21.4 & 21.3 & 20.3 & 19.6 & 17.7 & 22.3 & 21.0 & 19.8 & 18.6 & 17.4 \\
\hline
\end{tabular}


Table S3: Parental Birth Order and Offspring Educational Attainment at Age 30, Linear Regression Model on Full Population of Swedish Men and Women Born 1960-1982.

\begin{tabular}{|c|c|c|c|c|c|c|c|c|c|c|c|c|c|}
\hline & & \multicolumn{3}{|c|}{ Model 1} & \multicolumn{3}{|c|}{ Model 2} & \multicolumn{3}{|c|}{ Model 3} & \multicolumn{3}{|c|}{ Model 4} \\
\hline & & $\mathrm{b}$ & se & $95 \% \mathrm{CI}$ & $\mathrm{b}$ & se & $95 \% \mathrm{CI}$ & $\mathrm{b}$ & se & $95 \% \mathrm{CI}$ & $\mathrm{b}$ & se & $95 \% \mathrm{CI}$ \\
\hline \multirow{5}{*}{ Mother Birth Order (G2) } & 1 & 0.00 & & & 0.00 & & & 0.00 & & & 0.00 & & \\
\hline & 2 & 0.03 & 0.01 & $0.02,0.04$ & -0.21 & 0.01 & $-0.22,-0.19$ & -0.14 & 0.01 & $-0.15,-0.12$ & -0.02 & 0.01 & $-0.03,0.00$ \\
\hline & 3 & -0.07 & 0.01 & $-0.09,-0.05$ & -0.35 & 0.01 & $-0.37,-0.33$ & -0.23 & 0.01 & $-0.25,-0.21$ & -0.04 & 0.01 & $-0.06,-0.02$ \\
\hline & 4 & -0.21 & 0.01 & $-0.24,-0.19$ & -0.41 & 0.02 & $-0.45,-0.38$ & -0.28 & 0.01 & $-0.31,-0.25$ & -0.06 & 0.01 & $-0.08,-0.03$ \\
\hline & $5+$ & -0.33 & 0.02 & $-0.36,-0.30$ & -0.49 & 0.02 & $-0.53,-0.45$ & -0.33 & 0.02 & $-0.37,-0.30$ & -0.06 & 0.02 & $-0.09,-0.03$ \\
\hline \multirow[t]{5}{*}{ Father Birth Order (G2) } & 1 & 0.00 & & & 0.00 & & $0.00,0.00$ & 0.00 & & & 0.00 & & \\
\hline & 2 & 0.04 & 0.01 & $0.03,0.06$ & -0.19 & 0.01 & $-0.20,-0.17$ & -0.13 & 0.01 & $-0.14,-0.11$ & -0.01 & 0.01 & $-0.02,0.00$ \\
\hline & 3 & -0.03 & 0.01 & $-0.04,-0.01$ & -0.30 & 0.01 & $-0.32,-0.27$ & -0.21 & 0.01 & $-0.23,-0.19$ & -0.03 & 0.01 & $-0.04,-0.01$ \\
\hline & 4 & -0.17 & 0.01 & $-0.20,-0.14$ & -0.38 & 0.02 & $-0.41,-0.34$ & -0.28 & 0.02 & $-0.30,-0.25$ & -0.06 & 0.01 & $-0.09,-0.03$ \\
\hline & $5+$ & -0.27 & 0.02 & $-0.30,-0.23$ & -0.43 & 0.02 & $-0.47,-0.39$ & -0.30 & 0.02 & $-0.34,-0.27$ & -0.07 & 0.02 & $-0.10,-0.03$ \\
\hline \multirow[t]{5}{*}{ Maternal Sibling Group Size (G2) } & 1 & & & & -0.24 & 0.01 & $-0.26,-0.22$ & -0.16 & 0.01 & $-0.18,-0.15$ & -0.07 & 0.01 & $-0.09,-0.06$ \\
\hline & 2 & & & & 0.00 & & & 0.00 & & & 0.00 & & \\
\hline & 3 & & & & 0.01 & 0.01 & $-0.01,0.03$ & 0.02 & 0.01 & $0.01,0.04$ & 0.01 & 0.01 & $0.00,0.02$ \\
\hline & 4 & & & & -0.10 & 0.01 & $-0.12,-0.08$ & -0.06 & 0.01 & $-0.08,-0.04$ & -0.01 & 0.01 & $-0.03,0.00$ \\
\hline & $5+$ & & & & -0.29 & 0.01 & $-0.32,-0.27$ & -0.18 & 0.01 & $-0.20,-0.16$ & -0.05 & 0.01 & $-0.07,-0.03$ \\
\hline \multirow[t]{5}{*}{ Paternal Sibling Group Size (G2) } & 1 & & & & -0.24 & 0.01 & $-0.26,-0.23$ & -0.17 & 0.01 & $-0.19,-0.16$ & -0.09 & 0.01 & $-0.10,-0.08$ \\
\hline & 2 & & & & 0.00 & & & 0.00 & & & 0.00 & & \\
\hline & 3 & & & & 0.02 & 0.01 & $0.01,0.04$ & 0.03 & 0.01 & $0.02,0.05$ & 0.03 & 0.01 & $0.02,0.04$ \\
\hline & 4 & & & & -0.08 & 0.01 & $-0.10,-0.06$ & -0.02 & 0.01 & $-0.04,0.00$ & 0.03 & 0.01 & $0.02,0.05$ \\
\hline & $5+$ & & & & -0.27 & 0.01 & $-0.29,-0.24$ & -0.14 & 0.01 & $-0.16,-0.12$ & 0.02 & 0.01 & $0.00,0.04$ \\
\hline Maternal Grandmother's & $15-19$ & & & & -0.72 & 0.01 & $-0.74,-0.69$ & -0.47 & 0.01 & $-0.49,-0.45$ & -0.23 & 0.01 & $-0.25,-0.20$ \\
\hline \multirow[t]{5}{*}{ Age at Birth (G2) } & $20-24$ & & & & -0.37 & 0.01 & $-0.39,-0.36$ & -0.24 & 0.01 & $-0.26,-0.23$ & -0.11 & 0.01 & $-0.12,-0.10$ \\
\hline & $25-29$ & & & & 0.00 & & & 0.00 & & & 0.00 & & \\
\hline & $30-34$ & & & & 0.17 & 0.01 & $0.16,0.19$ & 0.11 & 0.01 & $0.09,0.12$ & 0.05 & 0.01 & $0.04,0.06$ \\
\hline & $35-39$ & & & & 0.21 & 0.01 & $0.19,0.23$ & 0.12 & 0.01 & $0.10,0.14$ & 0.08 & 0.01 & $0.06,0.09$ \\
\hline & $40+$ & & & & 0.20 & 0.01 & $0.17,0.23$ & 0.11 & 0.01 & $0.09,0.14$ & 0.11 & 0.01 & $0.09,0.14$ \\
\hline Paternal Grandmother's & $15-19$ & & & & -0.67 & 0.01 & $-0.70,-0.65$ & -0.43 & 0.01 & $-0.46,-0.41$ & -0.19 & 0.01 & $-0.21,-0.16$ \\
\hline Age at Birth (G2) & $20-24$ & & & & -0.36 & 0.01 & $-0.37,-0.34$ & -0.24 & 0.01 & $-0.25,-0.23$ & -0.11 & 0.01 & $-0.12,-0.10$ \\
\hline & $25-29$ & & & & 0.00 & & & 0.00 & & & 0.00 & & \\
\hline & $30-34$ & & & & 0.16 & 0.01 & $0.14,0.17$ & 0.10 & 0.01 & $0.08,0.11$ & 0.05 & 0.01 & $0.04,0.07$ \\
\hline & $35-39$ & & & & 0.19 & 0.01 & $0.17,0.21$ & 0.11 & 0.01 & $0.10,0.13$ & 0.08 & 0.01 & $0.07,0.10$ \\
\hline & $40+$ & & & & 0.14 & 0.01 & $0.11,0.17$ & 0.07 & 0.01 & $0.04,0.09$ & 0.09 & 0.01 & $0.07,0.12$ \\
\hline Maternal Birth Year (G2) & $1938-1945$ & & & & -0.19 & 0.01 & $-0.21,-0.17$ & 0.45 & 0.01 & $0.42,0.48$ & 0.19 & 0.01 & $0.16,0.21$ \\
\hline & 1946-1949 & & & & -0.02 & 0.01 & $-0.04,-0.01$ & 0.25 & 0.01 & $0.23,0.27$ & 0.08 & 0.01 & $0.06,0.09$ \\
\hline & $1950-1954$ & & & & 0.00 & & & 0.00 & & & 0.00 & & \\
\hline & 1955-1959 & & & & -0.24 & 0.01 & $-0.26,-0.22$ & -0.34 & 0.01 & $-0.36,-0.32$ & -0.16 & 0.01 & $-0.18,-0.14$ \\
\hline & 1960-1964 & & & & -0.61 & 0.02 & $-0.65,-0.57$ & -0.69 & 0.02 & $-0.73,-0.64$ & -0.40 & 0.02 & $-0.44,-0.36$ \\
\hline & 1965-1969 & & & & -1.10 & 0.12 & $-1.32,-0.87$ & -0.95 & 0.12 & $-1.18,-0.72$ & -0.66 & 0.11 & $-0.88,-0.45$ \\
\hline Paternal Birth Year (G2) & $1938-1945$ & & & & -0.52 & 0.01 & $-0.54,-0.50$ & 0.09 & 0.01 & $0.06,0.11$ & 0.04 & 0.01 & $0.02,0.07$ \\
\hline & 1946-1949 & & & & -0.17 & 0.01 & $-0.19,-0.15$ & 0.06 & 0.01 & $0.04,0.07$ & 0.02 & 0.01 & $0.00,0.04$ \\
\hline & $1950-1954$ & & & & 0.00 & & & 0.00 & & & 0.00 & & \\
\hline & 1955-1959 & & & & -0.08 & 0.01 & $-0.11,-0.05$ & -0.14 & 0.01 & $-0.16,-0.11$ & -0.04 & 0.01 & $-0.07,-0.02$ \\
\hline & $1960-1964$ & & & & -0.41 & 0.03 & $-0.48,-0.34$ & -0.39 & 0.03 & $-0.46,-0.32$ & -0.25 & 0.03 & $-0.32,-0.19$ \\
\hline & 1965-1969 & & & & -0.74 & 0.24 & $-1.22,-0.26$ & -0.44 & 0.25 & $-0.93,0.05$ & -0.33 & 0.24 & $-0.81,0.15$ \\
\hline Index Birth Order (G3) & 1 & & & & & & & 0.00 & & & 0.00 & & \\
\hline & 2 & & & & & & & -0.63 & 0.00 & $-0.64,-0.62$ & -0.40 & 0.00 & $-0.41,-0.39$ \\
\hline & 3 & & & & & & & -1.16 & 0.01 & $-1.18,-1.14$ & -0.67 & 0.01 & $-0.69,-0.65$ \\
\hline & 4 & & & & & & & -1.52 & 0.02 & $-1.56,-1.47$ & -0.84 & 0.02 & $-0.89,-0.80$ \\
\hline & $5+$ & & & & & & & -1.84 & 0.05 & $-1.94,-1.73$ & -0.98 & 0.05 & $-1.08,-0.89$ \\
\hline Sex (G3) & Male & & & & & & & 0.00 & & & 0.00 & & \\
\hline & Female & & & & & & & 0.54 & 0.00 & $0.53,0.54$ & 0.54 & 0.00 & $0.53,0.55$ \\
\hline Sibling Group Size (G3) & 1 & & & & & & & -0.58 & 0.01 & $-0.59,-0.56$ & -0.42 & 0.01 & $-0.43,-0.41$ \\
\hline & 2 & & & & & & & 0.00 & & & 0.00 & & \\
\hline & 3 & & & & & & & 0.20 & 0.01 & $0.19,0.21$ & 0.07 & 0.01 & $0.06,0.08$ \\
\hline & 4 & & & & & & & 0.15 & 0.01 & $0.13,0.18$ & 0.00 & 0.01 & $-0.02,0.02$ \\
\hline & $5+$ & & & & & & & -0.01 & 0.02 & $-0.06,0.03$ & -0.13 & 0.02 & $-0.17,-0.09$ \\
\hline Birth Year (G3) & 1960 & & & & & & & -1.09 & 0.04 & $-1.16,-1.02$ & -0.63 & 0.03 & $-0.69,-0.56$ \\
\hline & 1961 & & & & & & & -1.01 & 0.03 & $-1.06,-0.95$ & -0.60 & 0.03 & $-0.66,-0.55$ \\
\hline & 1962 & & & & & & & -0.87 & 0.03 & $-0.92,-0.82$ & -0.52 & 0.02 & $-0.56,-0.47$ \\
\hline & 1963 & & & & & & & -0.84 & 0.02 & $-0.88,-0.80$ & -0.53 & 0.02 & $-0.57,-0.49$ \\
\hline & 1964 & & & & & & & -0.76 & 0.02 & $-0.79,-0.72$ & -0.50 & 0.02 & $-0.54,-0.47$ \\
\hline & 1965 & & & & & & & -0.64 & 0.02 & $-0.68,-0.61$ & -0.43 & 0.02 & $-0.46,-0.40$ \\
\hline & 1966 & & & & & & & -0.52 & 0.02 & $-0.56,-0.49$ & -0.35 & 0.01 & $-0.38,-0.32$ \\
\hline & 1967 & & & & & & & -0.44 & 0.01 & $-0.47,-0.41$ & -0.31 & 0.01 & $-0.34,-0.29$ \\
\hline
\end{tabular}


Table S3 - Continued from previous page

\begin{tabular}{|c|c|c|c|c|c|c|c|c|c|c|c|c|c|}
\hline & & \multicolumn{3}{|c|}{ Model 1} & \multicolumn{3}{|c|}{ Model 2} & \multicolumn{3}{|c|}{ Model 3} & \multicolumn{3}{|c|}{ Model 4} \\
\hline & & $\mathrm{b}$ & se & $95 \% \mathrm{CI}$ & $\mathrm{b}$ & se & $95 \% \mathrm{CI}$ & $\mathrm{b}$ & se & $95 \% \mathrm{CI}$ & $\mathrm{b}$ & se & $95 \% \mathrm{CI}$ \\
\hline & 1968 & & & & & & & -0.37 & 0.01 & $-0.40,-0.34$ & -0.29 & 0.01 & $-0.31,-0.26$ \\
\hline & 1969 & & & & & & & -0.29 & 0.01 & $-0.32,-0.26$ & -0.25 & 0.01 & $-0.28,-0.23$ \\
\hline & 1970 & & & & & & & 0.00 & & & 0.00 & & \\
\hline & 1971 & & & & & & & 0.19 & 0.01 & $0.16,0.22$ & 0.09 & 0.01 & $0.07,0.12$ \\
\hline & 1972 & & & & & & & 0.39 & 0.01 & $0.36,0.41$ & 0.25 & 0.01 & $0.23,0.28$ \\
\hline & 1973 & & & & & & & 0.59 & 0.01 & $0.56,0.61$ & 0.42 & 0.01 & $0.40,0.45$ \\
\hline & 1974 & & & & & & & 0.79 & 0.01 & $0.76,0.82$ & 0.59 & 0.01 & $0.57,0.62$ \\
\hline & 1975 & & & & & & & 1.02 & 0.02 & $0.99,1.05$ & 0.79 & 0.01 & $0.77,0.82$ \\
\hline & 1976 & & & & & & & 1.16 & 0.02 & $1.13,1.19$ & 0.90 & 0.02 & $0.87,0.93$ \\
\hline & 1977 & & & & & & & 1.23 & 0.02 & $1.20,1.26$ & 0.93 & 0.02 & $0.90,0.96$ \\
\hline & 1978 & & & & & & & 1.17 & 0.02 & $1.13,1.21$ & 0.83 & 0.02 & $0.80,0.87$ \\
\hline & 1979 & & & & & & & 1.26 & 0.02 & $1.22,1.30$ & 0.88 & 0.02 & $0.84,0.91$ \\
\hline & 1980 & & & & & & & 1.44 & 0.02 & $1.40,1.48$ & 1.00 & 0.02 & $0.97,1.04$ \\
\hline & 1981 & & & & & & & 1.48 & 0.02 & $1.44,1.53$ & 1.00 & 0.02 & $0.96,1.04$ \\
\hline & 1982 & & & & & & & 1.52 & 0.02 & $1.47,1.56$ & 1.00 & 0.02 & $0.96,1.04$ \\
\hline \multirow[t]{6}{*}{ Maternal Age at Birth (G3) } & $15-19$ & & & & & & & -0.67 & 0.01 & $-0.69,-0.64$ & -0.40 & 0.01 & $-0.43,-0.38$ \\
\hline & $20-24$ & & & & & & & -0.41 & 0.01 & $-0.42,-0.39$ & -0.19 & 0.01 & $-0.21,-0.18$ \\
\hline & $25-29$ & & & & & & & 0.00 & & & 0.00 & & \\
\hline & $30-34$ & & & & & & & 0.14 & 0.01 & $0.12,0.15$ & 0.04 & 0.01 & $0.03,0.06$ \\
\hline & $35-39$ & & & & & & & 0.06 & 0.02 & $0.02,0.10$ & 0.01 & 0.02 & $-0.03,0.05$ \\
\hline & $40+$ & & & & & & & 0.04 & 0.06 & $-0.08,0.17$ & 0.07 & 0.06 & $-0.05,0.19$ \\
\hline \multirow[t]{6}{*}{ Paternal Age at Birth (G3) } & $15-19$ & & & & & & & -0.24 & 0.02 & $-0.27,-0.20$ & -0.27 & 0.02 & $-0.30,-0.24$ \\
\hline & $20-24$ & & & & & & & -0.21 & 0.01 & $-0.23,-0.20$ & -0.18 & 0.01 & $-0.19,-0.16$ \\
\hline & $25-29$ & & & & & & & 0.00 & & & 0.00 & & \\
\hline & $30-34$ & & & & & & & 0.03 & 0.01 & $0.01,0.05$ & 0.07 & 0.01 & $0.05,0.08$ \\
\hline & $35-39$ & & & & & & & -0.08 & 0.02 & $-0.11,-0.05$ & 0.05 & 0.01 & $0.02,0.08$ \\
\hline & $40+$ & & & & & & & -0.22 & 0.03 & $-0.29,-0.16$ & 0.02 & 0.03 & $-0.04,0.08$ \\
\hline \multirow{8}{*}{$\begin{array}{l}\text { Maternal Educational Attainment } \\
\text { (G2) }\end{array}$} & Primary $<9$ years & & & & & & & & & & -0.15 & 0.01 & $-0.17,-0.13$ \\
\hline & Primary - 9 years & & & & & & & & & & 0.00 & & \\
\hline & Secondary - 10-11 years & & & & & & & & & & 0.25 & 0.01 & $0.23,0.26$ \\
\hline & Secondary - 12 years & & & & & & & & & & 0.60 & 0.01 & $0.58,0.62$ \\
\hline & Tertiary - $13-15$ years & & & & & & & & & & 0.84 & 0.01 & $0.82,0.86$ \\
\hline & Tertiary $-15+$ years & & & & & & & & & & 1.17 & 0.01 & $1.15,1.18$ \\
\hline & Post-graduate & & & & & & & & & & 1.44 & 0.03 & $1.37,1.50$ \\
\hline & Missing & & & & & & & & & & 0.23 & 0.09 & $0.06,0.40$ \\
\hline \multirow{6}{*}{$\begin{array}{l}\text { Maternal Social Class (EGP) } \\
\text { (G2) }\end{array}$} & I & & & & & & & & & & 0.00 & 0.02 & $-0.04,0.05$ \\
\hline & II & & & & & & & & & & 0.00 & & \\
\hline & III & & & & & & & & & & -0.14 & 0.01 & $-0.16,-0.13$ \\
\hline & IV & & & & & & & & & & -0.22 & 0.02 & $-0.25,-0.19$ \\
\hline & VI-VII & & & & & & & & & & -0.29 & 0.01 & $-0.30,-0.28$ \\
\hline & Unknown & & & & & & & & & & -0.29 & 0.01 & $-0.30,-0.28$ \\
\hline \multirow{8}{*}{$\begin{array}{l}\text { Paternal Educational Attainment } \\
\text { (G2) }\end{array}$} & Primary $<9$ years & & & & & & & & & & -0.06 & 0.01 & $-0.07,-0.04$ \\
\hline & Primary - 9 years & & & & & & & & & & 0.00 & & \\
\hline & Secondary - 10-11 years & & & & & & & & & & 0.15 & 0.01 & $0.14,0.17$ \\
\hline & Secondary - 12 years & & & & & & & & & & 0.52 & 0.01 & $0.50,0.54$ \\
\hline & Tertiary - $13-15$ years & & & & & & & & & & 0.73 & 0.01 & $0.71,0.75$ \\
\hline & Tertiary $-15+$ years & & & & & & & & & & 1.16 & 0.01 & $1.14,1.18$ \\
\hline & Post-graduate & & & & & & & & & & 1.54 & 0.02 & $1.50,1.58$ \\
\hline & Missing & & & & & & & & & & -0.13 & 0.05 & $-0.22,-0.03$ \\
\hline \multirow{6}{*}{$\begin{array}{l}\text { Paternal Social Class (EGP) } \\
\text { (G2) }\end{array}$} & $\mathrm{I}$ & & & & & & & & & & 0.05 & 0.02 & $0.02,0.09$ \\
\hline & II & & & & & & & & & & 0.00 & & \\
\hline & III & & & & & & & & & & -0.16 & 0.02 & $-0.19,-0.13$ \\
\hline & IV & & & & & & & & & & -0.17 & 0.01 & $-0.19,-0.15$ \\
\hline & VI-VII & & & & & & & & & & -0.26 & 0.01 & $-0.27,-0.25$ \\
\hline & Unknown & & & & & & & & & & -0.15 & 0.01 & $-0.17,-0.14$ \\
\hline $\mathrm{N}$ & & & $90^{\circ}$ & & & $90^{\circ}$ & & & 907, & 08 & & 907 & 908 \\
\hline
\end{tabular}


Table S4: Parental Birth Order and Offspring Educational Attainment at Age 30, Fixed Effects Linear Regression on Maternal Cousin Sample of Swedish Men and Women Born 1960-1982.

\begin{tabular}{|c|c|c|c|c|c|c|c|c|c|c|}
\hline & & \multicolumn{3}{|c|}{ Model 5} & \multicolumn{3}{|c|}{ Model 6} & \multicolumn{3}{|c|}{ Model 7} \\
\hline & & $\mathrm{b}$ & $\mathrm{se}$ & $95 \% \mathrm{CI}$ & $\mathrm{b}$ & se & $95 \% \mathrm{CI}$ & $\mathrm{b}$ & se & $95 \% \mathrm{CI}$ \\
\hline \multirow{5}{*}{ Mother Birth Order (G2) } & 1 & 0.00 & & & 0.00 & & & 0.00 & & \\
\hline & 2 & -0.02 & 0.01 & $-0.04,0.01$ & -0.09 & 0.01 & $-0.11,-0.06$ & -0.02 & 0.01 & $-0.05,0.00$ \\
\hline & 3 & 0.00 & 0.02 & $-0.04,0.04$ & -0.14 & 0.02 & $-0.17,-0.10$ & -0.04 & 0.02 & $-0.07,0.00$ \\
\hline & 4 & 0.06 & 0.03 & $0.01,0.12$ & -0.13 & 0.03 & $-0.18,-0.07$ & -0.03 & 0.03 & $-0.08,0.02$ \\
\hline & $5+$ & 0.07 & 0.04 & $0.00,0.14$ & -0.18 & 0.04 & $-0.25,-0.11$ & -0.07 & 0.04 & $-0.14,0.00$ \\
\hline \multirow[t]{5}{*}{ Father Birth Order (G2) } & 1 & 0.00 & & $0.00,0.00$ & 0.00 & & & 0.00 & & \\
\hline & 2 & -0.06 & 0.01 & $-0.08,-0.03$ & -0.05 & 0.01 & $-0.07,-0.02$ & 0.01 & 0.01 & $-0.02,0.03$ \\
\hline & 3 & -0.12 & 0.02 & $-0.16,-0.09$ & -0.10 & 0.02 & $-0.13,-0.07$ & -0.02 & 0.02 & $-0.06,0.01$ \\
\hline & 4 & -0.20 & 0.03 & $-0.25,-0.15$ & -0.18 & 0.02 & $-0.23,-0.13$ & -0.08 & 0.02 & $-0.13,-0.03$ \\
\hline & $5+$ & -0.21 & 0.03 & $-0.27,-0.15$ & -0.18 & 0.03 & $-0.24,-0.12$ & -0.08 & 0.03 & $-0.14,-0.02$ \\
\hline \multirow[t]{5}{*}{ Maternal Sibling Group Size (G2) } & 1 & & & & & & & & & \\
\hline & 2 & & & & & & & & & \\
\hline & 3 & & & & & & & & & \\
\hline & 4 & & & & & & & & & \\
\hline & $5+$ & & & & & & & & & \\
\hline \multirow[t]{5}{*}{ Paternal Sibling Group Size (G2) } & 1 & -0.12 & 0.01 & $-0.15,-0.09$ & -0.10 & 0.01 & $-0.12,-0.07$ & -0.06 & 0.01 & $-0.09,-0.03$ \\
\hline & 2 & 0.00 & & & 0.00 & & & 0.00 & & \\
\hline & 3 & -0.01 & 0.01 & $-0.04,0.01$ & 0.00 & 0.01 & $-0.03,0.02$ & 0.00 & 0.01 & $-0.02,0.03$ \\
\hline & 4 & -0.06 & 0.02 & $-0.09,-0.03$ & -0.04 & 0.02 & $-0.07,-0.01$ & -0.02 & 0.02 & $-0.05,0.01$ \\
\hline & $5+$ & -0.13 & 0.02 & $-0.16,-0.09$ & -0.07 & 0.02 & $-0.11,-0.04$ & -0.02 & 0.02 & $-0.05,0.02$ \\
\hline Maternal Grandmother's & $15-19$ & -0.11 & 0.04 & $-0.18,-0.04$ & 0.09 & 0.04 & $0.02,0.15$ & 0.10 & 0.03 & $0.03,0.16$ \\
\hline \multirow[t]{5}{*}{ Age at Birth (G2) } & $20-24$ & -0.05 & 0.02 & $-0.08,-0.01$ & 0.06 & 0.02 & $0.03,0.10$ & 0.06 & 0.02 & $0.02,0.09$ \\
\hline & $25-29$ & 0.00 & & & 0.00 & & & 0.00 & & \\
\hline & $30-34$ & 0.05 & 0.02 & $0.02,0.09$ & -0.09 & 0.02 & $-0.12,-0.05$ & -0.07 & 0.02 & $-0.10,-0.03$ \\
\hline & $35-39$ & 0.11 & 0.03 & $0.05,0.17$ & -0.17 & 0.03 & $-0.23,-0.11$ & -0.13 & 0.03 & $-0.18,-0.07$ \\
\hline & $40+$ & 0.16 & 0.05 & $0.07,0.25$ & -0.27 & 0.05 & $-0.36,-0.18$ & -0.21 & 0.05 & $-0.30,-0.13$ \\
\hline Paternal Grandmother's & $15-19$ & -0.31 & 0.02 & $-0.36,-0.27$ & -0.23 & 0.02 & $-0.27,-0.19$ & -0.15 & 0.02 & $-0.19,-0.10$ \\
\hline \multirow[t]{5}{*}{ Age at Birth (G2) } & $20-24$ & -0.17 & 0.01 & $-0.20,-0.15$ & -0.13 & 0.01 & $-0.16,-0.11$ & -0.09 & 0.01 & $-0.12,-0.07$ \\
\hline & $25-29$ & 0.00 & & & 0.00 & & & 0.00 & & \\
\hline & $30-34$ & 0.08 & 0.01 & $0.06,0.11$ & 0.06 & 0.01 & $0.03,0.08$ & 0.04 & 0.01 & $0.01,0.06$ \\
\hline & $35-39$ & 0.08 & 0.02 & $0.05,0.11$ & 0.05 & 0.01 & $0.02,0.08$ & 0.03 & 0.01 & $0.00,0.06$ \\
\hline & $40+$ & 0.09 & 0.02 & $0.05,0.14$ & 0.04 & 0.02 & $0.00,0.08$ & 0.05 & 0.02 & $0.00,0.09$ \\
\hline \multirow[t]{6}{*}{ Maternal Birth Year (G2) } & $1938-1945$ & -0.24 & 0.03 & $-0.29,-0.19$ & 0.04 & 0.03 & $-0.01,0.09$ & 0.04 & 0.03 & $-0.01,0.09$ \\
\hline & 1946-1949 & -0.08 & 0.02 & $-0.11,-0.05$ & 0.03 & 0.02 & $0.00,0.07$ & 0.02 & 0.02 & $-0.02,0.05$ \\
\hline & $1950-1954$ & 0.00 & & & 0.00 & & & 0.00 & & \\
\hline & $1955-1959$ & -0.09 & 0.02 & $-0.13,-0.05$ & -0.12 & 0.02 & $-0.16,-0.08$ & -0.08 & 0.02 & $-0.12,-0.04$ \\
\hline & 1960-1964 & -0.21 & 0.05 & $-0.31,-0.12$ & -0.19 & 0.05 & $-0.28,-0.10$ & -0.15 & 0.05 & $-0.24,-0.06$ \\
\hline & 1965-1969 & -0.42 & 0.35 & $-1.11,0.26$ & -0.19 & 0.34 & $-0.85,0.47$ & -0.22 & 0.33 & $-0.87,0.43$ \\
\hline \multirow[t]{6}{*}{ Paternal Birth Year (G2) } & $1938-1945$ & -0.44 & 0.02 & $-0.47,-0.40$ & 0.05 & 0.02 & $0.00,0.09$ & 0.06 & 0.02 & $0.02,0.11$ \\
\hline & 1946-1949 & -0.15 & 0.01 & $-0.18,-0.12$ & 0.06 & 0.02 & $0.03,0.09$ & 0.05 & 0.02 & $0.02,0.08$ \\
\hline & $1950-1954$ & 0.00 & & & 0.00 & & & 0.00 & & \\
\hline & $1955-1959$ & 0.00 & 0.02 & $-0.04,0.05$ & -0.12 & 0.02 & $-0.16,-0.07$ & -0.08 & 0.02 & $-0.12,-0.04$ \\
\hline & $1960-1964$ & -0.13 & 0.07 & $-0.27,0.01$ & -0.30 & 0.07 & $-0.43,-0.16$ & -0.23 & 0.07 & $-0.36,-0.09$ \\
\hline & $1965-1969$ & -0.23 & 0.59 & $-1.39,0.93$ & -0.42 & 0.57 & $-1.54,0.70$ & -0.40 & 0.56 & $-1.50,0.70$ \\
\hline \multirow[t]{5}{*}{ Index Birth Order (G3) } & 1 & & & & 0.00 & & & 0.00 & & \\
\hline & 2 & & & & -0.34 & 0.01 & $-0.36,-0.33$ & -0.29 & 0.01 & $-0.31,-0.28$ \\
\hline & 3 & & & & -0.56 & 0.01 & $-0.59,-0.54$ & -0.46 & 0.01 & $-0.48,-0.43$ \\
\hline & 4 & & & & -0.69 & 0.03 & $-0.75,-0.64$ & -0.54 & 0.03 & $-0.60,-0.49$ \\
\hline & $5+$ & & & & -0.83 & 0.06 & $-0.94,-0.72$ & -0.64 & 0.06 & $-0.75,-0.53$ \\
\hline Sex (G3) & Male & & & & 0.00 & & & 0.00 & & \\
\hline & Female & & & & 0.53 & 0.01 & $0.51,0.54$ & 0.53 & 0.01 & $0.52,0.54$ \\
\hline Sibling Group Size (G3) & 1 & & & & -0.26 & 0.01 & $-0.28,-0.23$ & -0.22 & 0.01 & $-0.25,-0.20$ \\
\hline & 2 & & & & 0.00 & & & 0.00 & & \\
\hline & 3 & & & & 0.04 & 0.01 & $0.01,0.06$ & 0.03 & 0.01 & $0.00,0.05$ \\
\hline & 4 & & & & -0.01 & 0.02 & $-0.05,0.03$ & -0.01 & 0.02 & $-0.05,0.03$ \\
\hline & $5+$ & & & & -0.19 & 0.04 & $-0.26,-0.12$ & -0.16 & 0.03 & $-0.23,-0.09$ \\
\hline Birth Year (G3) & 1960 & & & & -1.00 & 0.06 & $-1.12,-0.88$ & -0.82 & 0.06 & $-0.93,-0.70$ \\
\hline & 1961 & & & & -0.88 & 0.05 & $-0.98,-0.79$ & -0.71 & 0.05 & $-0.81,-0.62$ \\
\hline & 1962 & & & & -0.85 & 0.04 & $-0.93,-0.77$ & -0.71 & 0.04 & $-0.79,-0.63$ \\
\hline & 1963 & & & & -0.75 & 0.04 & $-0.82,-0.68$ & -0.62 & 0.03 & $-0.69,-0.55$ \\
\hline & 1964 & & & & -0.67 & 0.03 & $-0.73,-0.61$ & -0.56 & 0.03 & $-0.62,-0.50$ \\
\hline
\end{tabular}


Table S4 - Continued from previous page

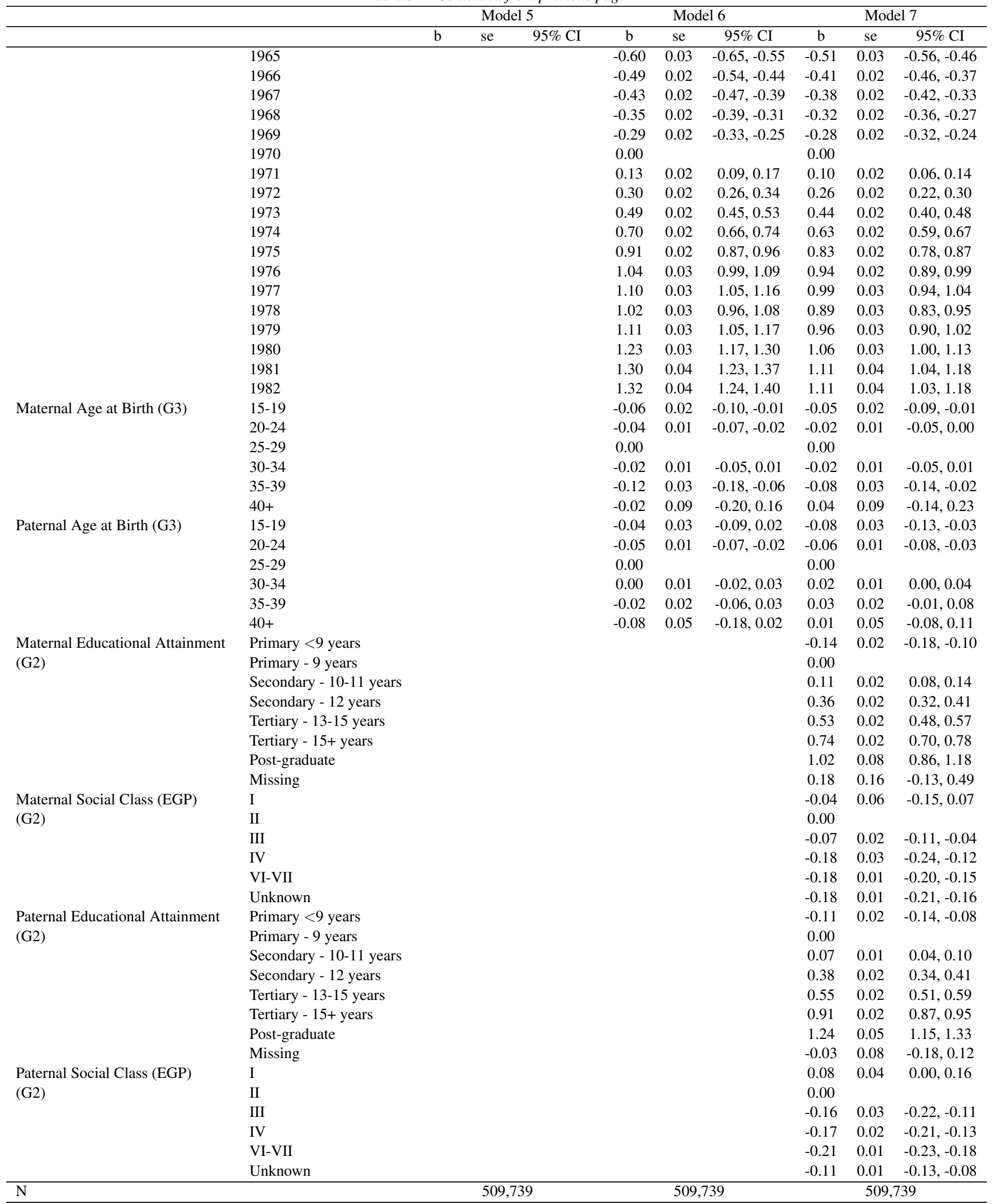


Table S5: Parental Birth Order and Offspring Educational Attainment at Age 30, Fixed Effects Linear Regression on Paternal Cousin Sample of Swedish Men and Women Born 1960-1982.

\begin{tabular}{|c|c|c|c|c|c|c|c|c|c|c|}
\hline & & \multicolumn{3}{|c|}{ Model 8} & \multicolumn{3}{|c|}{ Model 9} & \multicolumn{3}{|c|}{ Model 10} \\
\hline & & $\mathrm{b}$ & $\mathrm{se}$ & $95 \% \mathrm{CI}$ & $\mathrm{b}$ & $\mathrm{se}$ & $95 \% \mathrm{CI}$ & $\mathrm{b}$ & $\mathrm{se}$ & $95 \% \mathrm{CI}$ \\
\hline \multirow{5}{*}{ Mother Birth Order (G2) } & 1 & 0.00 & & & 0.00 & & & 0.00 & & \\
\hline & 2 & -0.08 & 0.01 & $-0.11,-0.06$ & -0.07 & 0.01 & $-0.09,-0.05$ & -0.01 & 0.01 & $-0.03,0.02$ \\
\hline & 3 & -0.13 & 0.02 & $-0.17,-0.10$ & -0.11 & 0.02 & $-0.14,-0.07$ & -0.01 & 0.02 & $-0.05,0.02$ \\
\hline & 4 & -0.20 & 0.03 & $-0.25,-0.15$ & -0.15 & 0.02 & $-0.20,-0.10$ & -0.03 & 0.02 & $-0.08,0.01$ \\
\hline & $5+$ & -0.23 & 0.03 & $-0.29,-0.18$ & -0.19 & 0.03 & $-0.25,-0.13$ & -0.04 & 0.03 & $-0.10,0.01$ \\
\hline \multirow{5}{*}{ Father Birth Order (G2) } & 1 & 0.00 & & $0.00,0.00$ & 0.00 & & & 0.00 & & \\
\hline & 2 & 0.01 & 0.01 & $-0.01,0.04$ & -0.04 & 0.01 & $-0.07,-0.02$ & 0.00 & 0.01 & $-0.02,0.02$ \\
\hline & 3 & 0.04 & 0.02 & $0.00,0.08$ & -0.06 & 0.02 & $-0.10,-0.03$ & 0.00 & 0.02 & $-0.04,0.04$ \\
\hline & 4 & 0.04 & 0.03 & $-0.01,0.10$ & -0.10 & 0.03 & $-0.15,-0.04$ & -0.03 & 0.03 & $-0.08,0.02$ \\
\hline & $5+$ & 0.07 & 0.04 & $0.00,0.14$ & -0.11 & 0.04 & $-0.18,-0.04$ & -0.06 & 0.04 & $-0.13,0.01$ \\
\hline \multirow{5}{*}{ Maternal Sibling Group Size (G2) } & 1 & -0.13 & 0.01 & $-0.16,-0.11$ & -0.11 & 0.01 & $-0.14,-0.08$ & -0.07 & 0.01 & $-0.10,-0.04$ \\
\hline & 2 & 0.00 & & & 0.00 & & & 0.00 & & \\
\hline & 3 & -0.04 & 0.01 & $-0.06,-0.01$ & -0.02 & 0.01 & $-0.05,0.00$ & -0.02 & 0.01 & $-0.05,0.00$ \\
\hline & 4 & -0.09 & 0.02 & $-0.12,-0.06$ & -0.08 & 0.02 & $-0.11,-0.05$ & -0.06 & 0.02 & $-0.09,-0.03$ \\
\hline & $5+$ & -0.15 & 0.02 & $-0.19,-0.12$ & -0.10 & 0.02 & $-0.14,-0.07$ & -0.07 & 0.02 & $-0.11,-0.04$ \\
\hline \multirow[t]{5}{*}{ Paternal Sibling Group Size (G2) } & 1 & & & & & & & & & \\
\hline & 2 & & & & & & & & & \\
\hline & 3 & & & & & & & & & \\
\hline & 4 & & & & & & & & & \\
\hline & $5+$ & & & & & & & & & \\
\hline Maternal Grandmother's & $15-19$ & -0.35 & 0.02 & $-0.39,-0.31$ & -0.25 & 0.02 & $-0.29,-0.21$ & -0.16 & 0.02 & $-0.19,-0.12$ \\
\hline \multirow[t]{5}{*}{ Age at Birth (G2) } & $20-24$ & -0.16 & 0.01 & $-0.18,-0.14$ & -0.11 & 0.01 & $-0.14,-0.09$ & -0.06 & 0.01 & $-0.08,-0.04$ \\
\hline & $25-29$ & 0.00 & & & 0.00 & & & 0.00 & & \\
\hline & $30-34$ & 0.11 & 0.01 & $0.08,0.13$ & 0.08 & 0.01 & $0.05,0.10$ & 0.06 & 0.01 & $0.03,0.08$ \\
\hline & $35-39$ & 0.13 & 0.02 & $0.10,0.16$ & 0.09 & 0.01 & $0.06,0.12$ & 0.07 & 0.01 & $0.04,0.10$ \\
\hline & $40+$ & 0.16 & 0.02 & $0.11,0.20$ & 0.13 & 0.02 & $0.08,0.17$ & 0.12 & 0.02 & $0.07,0.16$ \\
\hline Paternal Grandmother's & $15-19$ & -0.18 & 0.04 & $-0.26,-0.11$ & -0.01 & 0.04 & $-0.08,0.06$ & 0.05 & 0.03 & $-0.02,0.12$ \\
\hline \multirow[t]{5}{*}{ Age at Birth (G2) } & $20-24$ & -0.12 & 0.02 & $-0.15,-0.08$ & -0.03 & 0.02 & $-0.06,0.01$ & 0.00 & 0.02 & $-0.04,0.03$ \\
\hline & $25-29$ & 0.00 & & & 0.00 & & & 0.00 & & \\
\hline & $30-34$ & 0.10 & 0.02 & $0.06,0.13$ & -0.01 & 0.02 & $-0.05,0.02$ & -0.04 & 0.02 & $-0.07,0.00$ \\
\hline & $35-39$ & 0.22 & 0.03 & $0.16,0.27$ & -0.02 & 0.03 & $-0.07,0.04$ & -0.06 & 0.03 & $-0.11,0.00$ \\
\hline & $40+$ & 0.28 & 0.04 & $0.20,0.37$ & -0.08 & 0.04 & $-0.17,0.01$ & -0.15 & 0.04 & $-0.24,-0.07$ \\
\hline \multirow[t]{6}{*}{ Maternal Birth Year (G2) } & $1938-1945$ & -0.44 & 0.02 & $-0.47,-0.41$ & 0.22 & 0.02 & $0.18,0.27$ & 0.16 & 0.02 & $0.11,0.20$ \\
\hline & 1946-1949 & -0.20 & 0.01 & $-0.22,-0.17$ & 0.15 & 0.01 & $0.12,0.18$ & 0.09 & 0.01 & $0.06,0.12$ \\
\hline & $1950-1954$ & 0.00 & & & 0.00 & & & 0.00 & & \\
\hline & $1955-1959$ & 0.04 & 0.02 & $0.01,0.07$ & -0.22 & 0.02 & $-0.26,-0.18$ & -0.16 & 0.02 & $-0.19,-0.12$ \\
\hline & 1960-1964 & -0.05 & 0.04 & $-0.13,0.02$ & -0.44 & 0.04 & $-0.52,-0.37$ & -0.34 & 0.04 & $-0.42,-0.27$ \\
\hline & 1965-1969 & -0.50 & 0.27 & $-1.04,0.04$ & -0.92 & 0.27 & $-1.44,-0.40$ & -0.84 & 0.26 & $-1.35,-0.33$ \\
\hline \multirow[t]{6}{*}{ Paternal Birth Year (G2) } & $1938-1945$ & -0.09 & 0.03 & $-0.14,-0.04$ & 0.01 & 0.03 & $-0.04,0.06$ & -0.01 & 0.02 & $-0.06,0.04$ \\
\hline & 1946-1949 & 0.02 & 0.02 & $-0.02,0.05$ & 0.02 & 0.02 & $-0.01,0.06$ & 0.01 & 0.02 & $-0.03,0.04$ \\
\hline & $1950-1954$ & 0.00 & & & 0.00 & & & 0.00 & & \\
\hline & $1955-1959$ & -0.16 & 0.03 & $-0.21,-0.11$ & -0.08 & 0.03 & $-0.13,-0.03$ & -0.03 & 0.03 & $-0.08,0.02$ \\
\hline & $1960-1964$ & -0.50 & 0.09 & $-0.67,-0.33$ & -0.31 & 0.08 & $-0.47,-0.14$ & -0.21 & 0.08 & $-0.37,-0.05$ \\
\hline & 1965-1969 & -1.24 & 1.10 & $-3.38,0.91$ & -0.53 & 1.06 & $-2.60,1.54$ & -0.33 & 1.04 & $-2.37,1.70$ \\
\hline \multirow[t]{5}{*}{ Index Birth Order (G3) } & 1 & & & & 0.00 & & & 0.00 & & \\
\hline & 2 & & & & -0.37 & 0.01 & $-0.38,-0.36$ & -0.31 & 0.01 & $-0.32,-0.29$ \\
\hline & 3 & & & & -0.61 & 0.01 & $-0.63,-0.58$ & -0.47 & 0.01 & $-0.50,-0.45$ \\
\hline & 4 & & & & -0.78 & 0.03 & $-0.84,-0.72$ & -0.59 & 0.03 & $-0.65,-0.54$ \\
\hline & $5+$ & & & & -0.88 & 0.06 & $-0.99,-0.77$ & -0.64 & 0.06 & $-0.75,-0.53$ \\
\hline Sex (G3) & Male & & & & 0.00 & & & 0.00 & & \\
\hline & Female & & & & 0.53 & 0.01 & $0.51,0.54$ & 0.53 & 0.01 & $0.52,0.54$ \\
\hline Sibling Group Size (G3) & 1 & & & & -0.29 & 0.01 & $-0.31,-0.26$ & -0.25 & 0.01 & $-0.27,-0.22$ \\
\hline & 2 & & & & 0.00 & & & 0.00 & & \\
\hline & 3 & & & & 0.03 & 0.01 & $0.01,0.05$ & 0.00 & 0.01 & $-0.02,0.03$ \\
\hline & 4 & & & & -0.01 & 0.02 & $-0.05,0.03$ & -0.04 & 0.02 & $-0.08,0.00$ \\
\hline & $5+$ & & & & -0.17 & 0.03 & $-0.23,-0.10$ & -0.14 & 0.03 & $-0.21,-0.07$ \\
\hline Birth Year (G3) & 1960 & & & & -0.92 & 0.06 & $-1.04,-0.81$ & -0.74 & 0.06 & $-0.85,-0.62$ \\
\hline & 1961 & & & & -0.84 & 0.05 & $-0.94,-0.75$ & -0.69 & 0.05 & $-0.78,-0.60$ \\
\hline & 1962 & & & & -0.73 & 0.04 & $-0.81,-0.65$ & -0.59 & 0.04 & $-0.67,-0.51$ \\
\hline & 1963 & & & & -0.72 & 0.03 & $-0.79,-0.65$ & -0.61 & 0.03 & $-0.67,-0.54$ \\
\hline & 1964 & & & & -0.63 & 0.03 & $-0.69,-0.57$ & -0.54 & 0.03 & $-0.59,-0.48$ \\
\hline
\end{tabular}


Table S5 - Continued from previous page

\begin{tabular}{|c|c|c|c|c|c|c|c|c|c|c|}
\hline & & \multicolumn{3}{|c|}{ Model 8} & \multicolumn{3}{|c|}{ Model 9} & \multicolumn{3}{|c|}{ Model 10} \\
\hline & & $\mathrm{b}$ & se & $95 \% \mathrm{CI}$ & $\mathrm{b}$ & se & $95 \% \mathrm{CI}$ & $\mathrm{b}$ & se & $95 \% \mathrm{CI}$ \\
\hline & 1965 & & & & -0.55 & 0.03 & $-0.61,-0.50$ & -0.47 & 0.03 & $-0.52,-0.42$ \\
\hline & 1966 & & & & -0.49 & 0.02 & $-0.54,-0.44$ & -0.42 & 0.02 & $-0.47,-0.37$ \\
\hline & 1967 & & & & -0.41 & 0.02 & $-0.46,-0.37$ & -0.37 & 0.02 & $-0.41,-0.32$ \\
\hline & 1968 & & & & -0.38 & 0.02 & $-0.42,-0.33$ & -0.34 & 0.02 & $-0.39,-0.30$ \\
\hline & 1969 & & & & -0.29 & 0.02 & $-0.33,-0.25$ & -0.28 & 0.02 & $-0.32,-0.24$ \\
\hline & 1970 & & & & 0.00 & & & 0.00 & & \\
\hline & 1971 & & & & 0.13 & 0.02 & $0.09,0.17$ & 0.09 & 0.02 & $0.06,0.13$ \\
\hline & 1972 & & & & 0.32 & 0.02 & $0.28,0.36$ & 0.27 & 0.02 & $0.23,0.31$ \\
\hline & 1973 & & & & 0.50 & 0.02 & $0.46,0.54$ & 0.44 & 0.02 & $0.40,0.48$ \\
\hline & 1974 & & & & 0.68 & 0.02 & $0.63,0.72$ & 0.60 & 0.02 & $0.56,0.64$ \\
\hline & 1975 & & & & 0.91 & 0.02 & $0.86,0.95$ & 0.81 & 0.02 & $0.77,0.86$ \\
\hline & 1976 & & & & 1.02 & 0.03 & $0.97,1.07$ & 0.91 & 0.02 & $0.86,0.96$ \\
\hline & 1977 & & & & 1.08 & 0.03 & $1.03,1.13$ & 0.96 & 0.03 & $0.91,1.01$ \\
\hline & 1978 & & & & 1.01 & 0.03 & $0.96,1.07$ & 0.88 & 0.03 & $0.82,0.94$ \\
\hline & 1979 & & & & 1.07 & 0.03 & $1.01,1.13$ & 0.92 & 0.03 & $0.86,0.98$ \\
\hline & 1980 & & & & 1.24 & 0.03 & $1.17,1.30$ & 1.06 & 0.03 & $0.99,1.12$ \\
\hline & 1981 & & & & 1.29 & 0.04 & $1.22,1.36$ & 1.10 & 0.04 & $1.03,1.17$ \\
\hline & 1982 & & & & 1.31 & 0.04 & $1.24,1.39$ & 1.10 & 0.04 & $1.03,1.18$ \\
\hline \multirow[t]{6}{*}{ Maternal Age at Birth (G3) } & $15-19$ & & & & -0.17 & 0.02 & $-0.21,-0.13$ & -0.15 & 0.02 & $-0.19,-0.11$ \\
\hline & $20-24$ & & & & -0.10 & 0.01 & $-0.12,-0.07$ & -0.07 & 0.01 & $-0.09,-0.04$ \\
\hline & $25-29$ & & & & 0.00 & & & 0.00 & & \\
\hline & $30-34$ & & & & 0.03 & 0.01 & $0.00,0.06$ & 0.02 & 0.01 & $-0.01,0.04$ \\
\hline & $35-39$ & & & & -0.04 & 0.03 & $-0.09,0.02$ & -0.02 & 0.03 & $-0.08,0.04$ \\
\hline & $40+$ & & & & -0.22 & 0.09 & $-0.40,-0.04$ & -0.17 & 0.09 & $-0.35,0.00$ \\
\hline \multirow[t]{6}{*}{ Paternal Age at Birth (G3) } & $15-19$ & & & & -0.03 & 0.03 & $-0.09,0.02$ & -0.05 & 0.03 & $-0.11,0.00$ \\
\hline & $20-24$ & & & & -0.04 & 0.01 & $-0.07,-0.02$ & -0.04 & 0.01 & $-0.06,-0.02$ \\
\hline & $25-29$ & & & & 0.00 & & & 0.00 & & \\
\hline & $30-34$ & & & & -0.01 & 0.01 & $-0.03,0.02$ & 0.01 & 0.01 & $-0.02,0.03$ \\
\hline & $35-39$ & & & & -0.06 & 0.03 & $-0.11,-0.01$ & -0.02 & 0.02 & $-0.07,0.03$ \\
\hline & $40+$ & & & & -0.17 & 0.05 & $-0.26,-0.07$ & -0.08 & 0.05 & $-0.18,0.02$ \\
\hline \multirow{8}{*}{$\begin{array}{l}\text { Maternal Educational Attainment } \\
\text { (G2) }\end{array}$} & Primary $<9$ years & & & & & & & -0.19 & 0.02 & $-0.23,-0.16$ \\
\hline & Primary - 9 years & & & & & & & 0.00 & & \\
\hline & Secondary - 10-11 years & & & & & & & 0.19 & 0.01 & $0.16,0.21$ \\
\hline & Secondary - 12 years & & & & & & & 0.46 & 0.02 & $0.42,0.50$ \\
\hline & Tertiary - $13-15$ years & & & & & & & 0.70 & 0.02 & $0.66,0.73$ \\
\hline & Tertiary $-15+$ years & & & & & & & 0.97 & 0.02 & $0.94,1.01$ \\
\hline & Post-graduate & & & & & & & 1.17 & 0.07 & $1.03,1.30$ \\
\hline & Missing & & & & & & & 0.29 & 0.12 & $0.04,0.53$ \\
\hline \multirow{6}{*}{$\begin{array}{l}\text { Maternal Social Class (EGP) } \\
\text { (G2) }\end{array}$} & I & & & & & & & -0.05 & 0.05 & $-0.15,0.05$ \\
\hline & II & & & & & & & 0.00 & & \\
\hline & III & & & & & & & -0.10 & 0.02 & $-0.14,-0.07$ \\
\hline & IV & & & & & & & -0.22 & 0.03 & $-0.28,-0.17$ \\
\hline & VI-VII & & & & & & & -0.24 & 0.01 & $-0.27,-0.22$ \\
\hline & Unknown & & & & & & & -0.23 & 0.01 & $-0.25,-0.21$ \\
\hline \multirow{8}{*}{$\begin{array}{l}\text { Paternal Educational Attainment } \\
\text { (G2) }\end{array}$} & Primary $<9$ years & & & & & & & -0.08 & 0.02 & $-0.12,-0.05$ \\
\hline & Primary - 9 years & & & & & & & 0.00 & & \\
\hline & Secondary - 10-11 years & & & & & & & 0.05 & 0.02 & $0.01,0.08$ \\
\hline & Secondary - 12 years & & & & & & & 0.32 & 0.02 & $0.29,0.36$ \\
\hline & Tertiary - $13-15$ years & & & & & & & 0.45 & 0.02 & $0.41,0.49$ \\
\hline & Tertiary $-15+$ years & & & & & & & 0.77 & 0.02 & $0.72,0.81$ \\
\hline & Post-graduate & & & & & & & 1.06 & 0.05 & $0.96,1.15$ \\
\hline & Missing & & & & & & & -0.08 & 0.09 & $-0.25,0.10$ \\
\hline \multirow{6}{*}{$\begin{array}{l}\text { Paternal Social Class (EGP) } \\
\text { (G2) }\end{array}$} & I & & & & & & & -0.06 & 0.04 & $-0.14,0.03$ \\
\hline & II & & & & & & & 0.00 & & \\
\hline & III & & & & & & & -0.10 & 0.03 & $-0.16,-0.03$ \\
\hline & IV & & & & & & & -0.20 & 0.03 & $-0.25,-0.15$ \\
\hline & VI-VII & & & & & & & -0.20 & 0.01 & $-0.23,-0.17$ \\
\hline & Unknown & & & & & & & -0.10 & 0.02 & $-0.13,-0.07$ \\
\hline $\mathrm{N}$ & & & 512 & & & 514, & 22 & & 514 & \\
\hline
\end{tabular}


Table S6: Descriptive statistics for birth order and offspring inflation-adjusted (CPI) log earnings averaged over ages 29-30 for generation 3 (G3), Swedish men and women born 1960-1982.

\begin{tabular}{|c|c|c|c|c|c|c|c|c|c|c|c|c|c|c|c|c|}
\hline & & \multicolumn{5}{|c|}{ Index Birth Order } & \multicolumn{5}{|c|}{ Mother Birth Order } & \multicolumn{5}{|c|}{ Father Birth Order } \\
\hline & & 1 & 2 & 3 & 4 & $5+$ & 1 & 2 & 3 & 4 & $5+$ & 1 & 2 & 3 & 4 & $5+$ \\
\hline $\mathrm{N}$ & & 471,411 & 279,431 & 63,209 & 8,234 & 1,574 & 395,010 & 251,371 & 105,575 & 41,655 & 30,248 & 406,732 & 251,624 & 101,708 & 38,122 & 25,673 \\
\hline \multirow[t]{2}{*}{ Income $(, 000 \mathrm{~s})$} & Mean & 133.0 & 137.4 & 136.1 & 131.5 & 124.4 & 135.2 & 135.6 & 133.6 & 131.7 & 129.7 & 134.9 & 135.7 & 134.0 & 131.7 & 130.5 \\
\hline & SD & 74.4 & 71.8 & 69.8 & 68.9 & 67.8 & 74.6 & 73.4 & 70.3 & 69.9 & 66.2 & 75.1 & 72.5 & 70.2 & 68.4 & 67.1 \\
\hline \multirow[t]{2}{*}{ Mother Birth Order } & Mean & 1.9 & 1.9 & 1.9 & 2.0 & 2.0 & 1.0 & 2.0 & 3.0 & 4.0 & 5.8 & 1.8 & 1.9 & 2.0 & 2.0 & 2.1 \\
\hline & SD & 1.2 & 1.2 & 1.2 & 1.3 & 1.3 & 0.0 & 0.0 & 0.0 & 0.0 & 1.2 & 1.1 & 1.2 & 1.2 & 1.3 & 1.4 \\
\hline \multirow[t]{2}{*}{ Father Birth Order } & Mean & 1.8 & 1.8 & 1.9 & 1.9 & 1.9 & 1.8 & 1.8 & 1.9 & 1.9 & 2.1 & 1.0 & 2.0 & 3.0 & 4.0 & 5.7 \\
\hline & SD & 1.1 & 1.1 & 1.1 & 1.2 & 1.1 & 1.1 & 1.1 & 1.2 & 1.2 & 1.3 & 0.0 & 0.0 & 0.0 & 0.0 & 1.1 \\
\hline \multirow[t]{2}{*}{ Index Birth Order } & Mean & 1.0 & 2.0 & 3.0 & 4.0 & 5.3 & 1.5 & 1.5 & 1.5 & 1.5 & 1.6 & 1.5 & 1.5 & 1.5 & 1.5 & 1.5 \\
\hline & SD & 0.0 & 0.0 & 0.0 & 0.0 & 0.8 & 0.7 & 0.7 & 0.7 & 0.7 & 0.7 & 0.7 & 0.7 & 0.7 & 0.7 & 0.7 \\
\hline \multirow[t]{2}{*}{ Index Sibling Group Size } & Mean & 2.0 & 2.4 & 3.3 & 4.4 & 6.1 & 2.3 & 2.3 & 2.4 & 2.4 & 2.4 & 2.3 & 2.3 & 2.4 & 2.4 & 2.4 \\
\hline & SD & 0.9 & 0.7 & 0.7 & 0.9 & 1.5 & 0.9 & 0.9 & 0.9 & 1.0 & 1.0 & 0.9 & 0.9 & 1.0 & 1.0 & 1.0 \\
\hline \multirow[t]{2}{*}{ Index Birth Year } & Mean & 1972.6 & 1974.1 & 1975.2 & 1975.8 & 1976.3 & 1973.1 & 1973.4 & 1973.6 & 1973.7 & 1973.8 & 1973.0 & 1973.5 & 1973.7 & 1973.9 & 1974.4 \\
\hline & SD & 5.4 & 4.7 & 4.4 & 4.3 & 4.2 & 5.2 & 5.1 & 5.1 & 5.1 & 4.9 & 5.2 & 5.1 & 5.1 & 5.0 & 4.7 \\
\hline \multirow[t]{2}{*}{ Index Mother Age } & Mean & 23.7 & 26.5 & 29.0 & 30.7 & 32.1 & 25.3 & 25.1 & 24.8 & 24.5 & 24.1 & 25.3 & 25.1 & 24.9 & 24.5 & 24.0 \\
\hline & SD & 4.0 & 3.7 & 3.7 & 3.9 & 4.0 & 4.4 & 4.3 & 4.3 & 4.2 & 4.1 & 4.3 & 4.3 & 4.3 & 4.3 & 4.1 \\
\hline \multirow[t]{2}{*}{ Index Father Age } & Mean & 25.8 & 28.6 & 31.1 & 32.8 & 34.1 & 27.3 & 27.3 & 27.2 & 27.0 & 26.8 & 27.4 & 27.2 & 27.0 & 26.7 & 26.3 \\
\hline & SD & 4.0 & 3.7 & 3.7 & 3.8 & 4.1 & 4.3 & 4.3 & 4.3 & 4.3 & 4.3 & 4.4 & 4.3 & 4.3 & 4.2 & 4.0 \\
\hline \multirow[t]{2}{*}{ Mother Sibling Group Size } & Mean & 2.8 & 2.9 & 3.1 & 3.3 & 3.6 & 2.2 & 2.8 & 3.8 & 4.9 & 6.9 & 2.8 & 2.9 & 3.0 & 3.1 & 3.2 \\
\hline & SD & 1.6 & 1.6 & 1.7 & 1.9 & 2.1 & 1.2 & 1.1 & 1.2 & 1.2 & 1.8 & 1.6 & 1.6 & 1.7 & 1.8 & 1.9 \\
\hline \multirow[t]{2}{*}{ Father Sibling Group Size } & Mean & 2.8 & 2.9 & 3.1 & 3.3 & 3.6 & 2.8 & 2.9 & 2.9 & 3.0 & 3.2 & 2.2 & 2.9 & 3.9 & 5.0 & 6.9 \\
\hline & SD & 1.6 & 1.6 & 1.7 & 1.9 & 2.1 & 1.6 & 1.6 & 1.7 & 1.7 & 1.9 & 1.2 & 1.2 & 1.2 & 1.4 & 1.8 \\
\hline \multirow[t]{2}{*}{ Mother Birth Year } & Mean & 1948.9 & 1947.6 & 1946.2 & 1945.1 & 1944.1 & 1947.8 & 1948.3 & 1948.8 & 1949.2 & 1949.7 & 1947.7 & 1948.3 & 1948.9 & 1949.4 & 1950.4 \\
\hline & SD & 5.2 & 4.6 & 4.1 & 3.8 & 3.5 & 5.1 & 4.9 & 4.9 & 4.9 & 4.6 & 5.0 & 5.0 & 5.0 & 4.9 & 4.7 \\
\hline \multirow[t]{2}{*}{ Father Birth Year } & Mean & 1946.8 & 1945.5 & 1944.2 & 1943.0 & 1942.1 & 1945.9 & 1946.1 & 1946.4 & 1946.6 & 1947.0 & 1945.6 & 1946.3 & 1946.8 & 1947.2 & 1948.2 \\
\hline & SD & 5.0 & 4.4 & 3.9 & 3.6 & 3.3 & 4.9 & 4.8 & 4.8 & 4.8 & 4.6 & 4.8 & 4.8 & 4.8 & 4.7 & 4.4 \\
\hline Maternal Grandmother & Mean & 28.2 & 28.5 & 28.5 & 28.4 & 28.2 & 26.0 & 29.1 & 31.4 & 33.0 & 35.1 & 28.4 & 28.3 & 28.3 & 28.3 & 28.1 \\
\hline Age at Birth & SD & 6.1 & 6.1 & 6.1 & 6.2 & 6.4 & 5.7 & 5.4 & 5.3 & 5.2 & 4.9 & 6.1 & 6.1 & 6.2 & 6.2 & 6.4 \\
\hline Paternal Grandmother & Mean & 28.4 & 28.6 & 28.7 & 28.8 & 28.5 & 28.5 & 28.5 & 28.5 & 28.4 & 28.5 & 26.4 & 29.3 & 31.4 & 33.0 & 34.9 \\
\hline Age at Birth & SD & 6.0 & 6.0 & 6.1 & 6.2 & 6.3 & 6.0 & 6.0 & 6.1 & 6.2 & 6.2 & 5.7 & 5.4 & 5.3 & 5.1 & 4.8 \\
\hline Mother Education & Primary ( $¡ 9$ years) & 9.8 & 11.3 & 15.5 & 22.3 & 33.6 & 9.6 & 10.9 & 12.7 & 14.6 & 16.0 & 10.9 & 10.7 & 11.0 & 11.7 & 10.9 \\
\hline \multirow[t]{7}{*}{$(\%)$} & Primary ( 9 years) & 11.9 & 11.1 & 10.4 & 10.5 & 10.7 & 11.0 & 11.5 & 12.3 & 13.2 & 14.6 & 11.3 & 11.3 & 12.1 & 12.9 & 14.1 \\
\hline & Secondary (10-11 years) & 41.2 & 40.8 & 40.2 & 38.8 & 35.3 & 40.0 & 40.9 & 42.3 & 44.2 & 46.0 & 40.0 & 40.9 & 42.2 & 44.6 & 46.9 \\
\hline & Secondary ( 12 years) & 9.3 & 9.0 & 7.4 & 6.1 & 4.8 & 9.6 & 8.9 & 8.2 & 7.7 & 7.0 & 9.1 & 9.0 & 9.0 & 8.4 & 9.0 \\
\hline & Tertiary (13-15 years) & 12.5 & 12.3 & 11.1 & 9.2 & 7.2 & 13.0 & 12.4 & 11.3 & 10.0 & 8.8 & 12.6 & 12.6 & 11.7 & 10.3 & 9.5 \\
\hline & Tertiary (15+ years) & 14.7 & 15.0 & 15.0 & 12.8 & 8.2 & 16.4 & 14.8 & 12.8 & 10.0 & 7.4 & 15.6 & 15.0 & 13.5 & 11.8 & 9.5 \\
\hline & Graduate school & 0.5 & 0.5 & 0.5 & 0.4 & 0.3 & 0.5 & 0.5 & 0.4 & 0.3 & 0.1 & 0.5 & 0.5 & 0.4 & 0.3 & 0.2 \\
\hline & Missing & 0.1 & 0.1 & 0.0 & 0.0 & 0.1 & 0.1 & 0.1 & 0.1 & 0.1 & 0.1 & 0.1 & 0.1 & 0.1 & 0.1 & 0.1 \\
\hline
\end{tabular}


Table S6 - Continued from previous page

\begin{tabular}{|c|c|c|c|c|c|c|c|c|c|c|c|c|c|c|c|c|}
\hline & & \multicolumn{5}{|c|}{ Index Birth Order } & \multicolumn{5}{|c|}{ Mother Birth Order } & \multicolumn{5}{|c|}{ Father Birth Order } \\
\hline & & 1 & 2 & 3 & 4 & $5+$ & 1 & 2 & 3 & 4 & $5+$ & 1 & 2 & 3 & 4 & $5+$ \\
\hline Mother EGP & I & 0.9 & 0.7 & 0.7 & 0.7 & 0.8 & 0.9 & 0.8 & 0.8 & 0.7 & 0.5 & 0.9 & 0.9 & 0.7 & 0.6 & 0.4 \\
\hline \multirow[t]{5}{*}{$(\%)$} & II & 36.6 & 40.1 & 37.9 & 32.0 & 24.6 & 40.7 & 37.9 & 33.6 & 29.4 & 25.2 & 40.7 & 37.5 & 33.2 & 29.5 & 24.2 \\
\hline & III & 9.5 & 7.4 & 5.7 & 5.5 & 5.5 & 8.2 & 8.5 & 9.0 & 9.2 & 8.6 & 8.1 & 8.6 & 8.9 & 8.9 & 8.9 \\
\hline & IV & 2.6 & 3.1 & 4.8 & 6.7 & 7.1 & 2.8 & 3.1 & 3.4 & 3.0 & 3.0 & 2.8 & 3.1 & 3.3 & 3.4 & 3.2 \\
\hline & VI-VII & 26.9 & 25.7 & 28.6 & 35.4 & 46.6 & 25.0 & 26.5 & 29.0 & 32.3 & 35.2 & 25.3 & 26.5 & 29.4 & 31.5 & 33.7 \\
\hline & Unknown & 23.6 & 23.1 & 22.3 & 19.7 & 15.5 & 22.5 & 23.1 & 24.3 & 25.4 & 27.6 & 22.2 & 23.5 & 24.6 & 26.1 & 29.6 \\
\hline Father Education & Primary ( $i 9$ years) & 18.7 & 21.1 & 26.4 & 33.2 & 40.8 & 19.5 & 20.0 & 21.5 & 23.4 & 25.5 & 18.2 & 20.5 & 23.4 & 27.6 & 28.8 \\
\hline \multirow[t]{7}{*}{$(\%)$} & Primary (9 years) & 12.1 & 10.1 & 8.1 & 7.1 & 6.8 & 10.6 & 11.0 & 11.6 & 12.4 & 13.2 & 10.2 & 11.0 & 12.4 & 13.2 & 15.8 \\
\hline & Secondary (10-11 years) & 28.6 & 26.5 & 25.4 & 26.6 & 27.7 & 26.8 & 27.5 & 28.8 & 30.2 & 31.9 & 26.8 & 27.6 & 29.0 & 30.2 & 32.0 \\
\hline & Secondary (12 years) & 16.6 & 17.7 & 16.1 & 12.4 & 9.8 & 17.4 & 17.0 & 15.9 & 15.1 & 14.1 & 18.3 & 16.8 & 14.5 & 12.5 & 10.5 \\
\hline & Tertiary (13-15 years) & 10.4 & 10.3 & 8.8 & 6.8 & 4.5 & 10.5 & 10.3 & 9.8 & 8.9 & 8.2 & 10.9 & 10.1 & 9.2 & 7.8 & 7.2 \\
\hline & Tertiary $(15+$ years $)$ & 12.0 & 12.7 & 13.1 & 11.6 & 8.6 & 13.4 & 12.5 & 10.9 & 8.8 & 6.4 & 13.7 & 12.3 & 10.3 & 7.8 & 5.1 \\
\hline & Graduate school & 1.3 & 1.5 & 2.0 & 2.2 & 1.9 & 1.6 & 1.4 & 1.2 & 0.9 & 0.5 & 1.7 & 1.3 & 1.1 & 0.7 & 0.5 \\
\hline & Missing & 0.3 & 0.2 & 0.1 & 0.2 & 0.0 & 0.3 & 0.2 & 0.2 & 0.3 & 0.2 & 0.3 & 0.2 & 0.2 & 0.2 & 0.2 \\
\hline Father EGP & I & 1.7 & 1.3 & 1.0 & 0.8 & 0.9 & 1.6 & 1.5 & 1.4 & 1.1 & 1.0 & 1.6 & 1.5 & 1.2 & 1.0 & 0.9 \\
\hline \multirow[t]{5}{*}{$(\%)$} & II & 21.9 & 24.2 & 23.2 & 19.1 & 15.3 & 24.2 & 23.0 & 20.6 & 18.4 & 15.7 & 25.5 & 22.4 & 18.5 & 14.8 & 11.2 \\
\hline & III & 2.9 & 1.9 & 1.2 & 0.9 & 1.1 & 2.3 & 2.4 & 2.5 & 2.4 & 2.3 & 2.3 & 2.5 & 2.5 & 2.6 & 2.4 \\
\hline & IV & 5.2 & 5.5 & 6.7 & 8.7 & 8.1 & 5.2 & 5.5 & 6.1 & 5.9 & 6.2 & 4.9 & 5.7 & 6.2 & 6.7 & 6.5 \\
\hline & VI-VII & 47.2 & 46.3 & 47.6 & 51.1 & 56.2 & 45.2 & 46.3 & 49.4 & 52.8 & 57.8 & 43.9 & 47.0 & 51.7 & 56.4 & 61.9 \\
\hline & Unknown & 21.3 & 20.8 & 20.3 & 19.6 & 18.5 & 21.6 & 21.3 & 20.1 & 19.4 & 16.9 & 21.9 & 20.9 & 19.8 & 18.5 & 17.1 \\
\hline
\end{tabular}


Table S7: Parental Birth Order and Offspring Inflation-adjusted (CPI) Log Earnings Averaged Over Ages 29-30, Linear Regression Model on Full Population of Swedish Men and Women Born 1960-1981.

\begin{tabular}{|c|c|c|c|c|c|c|c|c|c|c|c|c|c|}
\hline & & \multicolumn{3}{|c|}{ Model 1} & \multicolumn{3}{|c|}{ Model 2} & \multicolumn{3}{|c|}{ Model 3} & \multicolumn{3}{|c|}{ Model 4} \\
\hline & & $\mathrm{b}$ & se & $95 \% \mathrm{CI}$ & $\mathrm{b}$ & se & $95 \% \mathrm{CI}$ & $\mathrm{b}$ & se & $95 \% \mathrm{CI}$ & $\mathrm{b}$ & se & $95 \% \mathrm{CI}$ \\
\hline \multirow[t]{5}{*}{ Mother Birth Order (G2) } & 1 & 0.000 & & & 0.000 & & & 0.000 & & & 0.000 & & \\
\hline & 2 & 0.006 & 0.002 & $0.001,0.011$ & -0.023 & 0.003 & $-0.028,-0.018$ & -0.012 & 0.003 & $-0.017,-0.007$ & -0.007 & 0.003 & $-0.012,-0.002$ \\
\hline & 3 & -0.011 & 0.003 & $-0.017,-0.005$ & -0.036 & 0.004 & $-0.044,-0.028$ & -0.020 & 0.004 & $-0.027,-0.012$ & -0.013 & 0.004 & $-0.020,-0.005$ \\
\hline & 4 & -0.026 & 0.005 & $-0.035,-0.016$ & -0.036 & 0.006 & $-0.047,-0.024$ & -0.020 & 0.006 & $-0.031,-0.008$ & -0.011 & 0.006 & $-0.022,0.000$ \\
\hline & $5+$ & -0.035 & 0.005 & $-0.046,-0.025$ & -0.042 & 0.007 & $-0.056,-0.027$ & -0.018 & 0.007 & $-0.031,-0.004$ & -0.008 & 0.007 & $-0.021,0.006$ \\
\hline \multirow[t]{4}{*}{ Father Birth Order (G2) } & 1 & 0.000 & & & 0.000 & & & 0.000 & & & 0.000 & & \\
\hline & 2 & 0.012 & 0.002 & $0.007,0.016$ & -0.018 & 0.003 & $-0.023,-0.013$ & -0.010 & 0.003 & $-0.015,-0.005$ & -0.005 & 0.003 & $-0.010,0.000$ \\
\hline & 4 & -0.021 & 0.005 & $-0.030,-0.011$ & -0.037 & 0.006 & $-0.049,-0.025$ & -0.023 & 0.006 & $-0.034,-0.011$ & -0.014 & 0.006 & $-0.026,-0.003$ \\
\hline & $5+$ & -0.026 & 0.006 & $-0.038,-0.015$ & -0.044 & 0.008 & $-0.058,-0.029$ & -0.027 & 0.007 & $-0.041,-0.013$ & -0.018 & 0.007 & $-0.032,-0.003$ \\
\hline \multirow[t]{5}{*}{ Maternal Sibling Group Size (G2) } & 1 & & & & -0.038 & 0.003 & $-0.045,-0.032$ & -0.025 & 0.003 & $-0.032,-0.019$ & -0.022 & 0.003 & $-0.028,-0.016$ \\
\hline & 2 & & & & 0.000 & & & 0.000 & & & 0.000 & & \\
\hline & 3 & & & & -0.015 & 0.003 & $-0.021,-0.009$ & -0.013 & 0.003 & $-0.018,-0.007$ & -0.012 & 0.003 & $-0.017,-0.006$ \\
\hline & 4 & & & & -0.039 & 0.004 & $-0.046,-0.032$ & -0.028 & 0.004 & $-0.035,-0.021$ & -0.023 & 0.004 & $-0.030,-0.016$ \\
\hline & $5+$ & & & & -0.067 & 0.004 & $-0.075,-0.058$ & -0.044 & 0.004 & $-0.052,-0.036$ & -0.035 & 0.004 & $-0.043,-0.027$ \\
\hline \multirow[t]{3}{*}{ Paternal Sibling Group Size (G2) } & 1 & & & & -0.032 & 0.003 & $-0.038,-0.025$ & -0.020 & 0.003 & $-0.026,-0.014$ & -0.016 & 0.003 & $-0.022,-0.010$ \\
\hline & 4 & & & & -0.032 & 0.004 & $-0.039,-0.025$ & -0.021 & 0.003 & $-0.028,-0.014$ & -0.016 & 0.003 & $-0.022,-0.009$ \\
\hline & $5+$ & & & & -0.060 & 0.004 & $-0.068,-0.051$ & -0.036 & 0.004 & $-0.044,-0.028$ & -0.025 & 0.004 & $-0.033,-0.017$ \\
\hline Maternal Grandmother's & $15-19$ & & & & -0.081 & 0.005 & $-0.091,-0.072$ & -0.043 & 0.005 & $-0.052,-0.033$ & -0.032 & 0.005 & $-0.041,-0.023$ \\
\hline \multirow[t]{5}{*}{ Age at Birth (G2) } & $20-24$ & & & & -0.041 & 0.003 & $-0.047,-0.036$ & -0.020 & 0.003 & $-0.025,-0.015$ & -0.015 & 0.003 & $-0.020,-0.010$ \\
\hline & $25-29$ & & & & 0.000 & & & 0.000 & & & 0.000 & & \\
\hline & $30-34$ & & & & 0.017 & 0.003 & $0.011,0.022$ & 0.006 & 0.003 & $0.001,0.011$ & 0.004 & 0.003 & $-0.001,0.009$ \\
\hline & $35-39$ & & & & 0.023 & 0.003 & $0.016,0.030$ & 0.008 & 0.003 & $0.002,0.015$ & 0.007 & 0.003 & $0.000,0.013$ \\
\hline & $40+$ & & & & 0.025 & 0.005 & $0.015,0.035$ & 0.013 & 0.005 & $0.003,0.022$ & 0.013 & 0.005 & $0.004,0.023$ \\
\hline Paternal Grandmother's & $15-19$ & & & & -0.087 & 0.005 & $-0.097,-0.077$ & -0.046 & 0.005 & $-0.056,-0.036$ & -0.035 & 0.005 & $-0.045,-0.025$ \\
\hline \multirow[t]{5}{*}{ Age at Birth (G2) } & $20-24$ & & & & -0.043 & 0.003 & $-0.049,-0.038$ & -0.024 & 0.003 & $-0.030,-0.019$ & -0.019 & 0.003 & $-0.024,-0.014$ \\
\hline & $25-29$ & & & & 0.000 & & & 0.000 & & & 0.000 & & \\
\hline & $30-34$ & & & & 0.014 & 0.003 & $0.009,0.020$ & 0.005 & 0.003 & $-0.001,0.010$ & 0.003 & 0.003 & $-0.003,0.008$ \\
\hline & $35-39$ & & & & 0.017 & 0.003 & $0.010,0.024$ & 0.006 & 0.003 & $-0.001,0.012$ & 0.005 & 0.003 & $-0.002,0.011$ \\
\hline & $40+$ & & & & 0.016 & 0.005 & $0.006,0.026$ & 0.006 & 0.005 & $-0.003,0.016$ & 0.008 & 0.005 & $-0.001,0.018$ \\
\hline \multirow[t]{3}{*}{ Maternal Birth Year (G2) } & $1938-1945$ & & & & -0.084 & 0.004 & $-0.091,-0.076$ & 0.047 & 0.005 & $0.037,0.058$ & 0.014 & 0.005 & $0.004,0.025$ \\
\hline & 1946-1949 & & & & -0.034 & 0.003 & $-0.040,-0.028$ & 0.019 & 0.003 & $0.012,0.026$ & -0.004 & 0.004 & $-0.011,0.003$ \\
\hline & $1950-1954$ & & & & 0.000 & & & 0.000 & & & 0.000 & & \\
\hline
\end{tabular}


Table S7 - Continued from previous page

\begin{tabular}{|c|c|c|c|c|c|c|c|c|c|c|c|c|c|}
\hline & & \multicolumn{3}{|c|}{ Model 1} & \multicolumn{3}{|c|}{ Model 2} & \multicolumn{3}{|c|}{ Model 3} & \multicolumn{3}{|c|}{ Model 4} \\
\hline & & $\mathrm{b}$ & se & $95 \% \mathrm{CI}$ & $\mathrm{b}$ & se & $95 \% \mathrm{CI}$ & $\mathrm{b}$ & se & $95 \% \mathrm{CI}$ & $\mathrm{b}$ & se & $95 \% \mathrm{CI}$ \\
\hline & 1960-1964 & & & & -0.074 & 0.011 & $-0.095,-0.054$ & -0.071 & 0.011 & $-0.092,-0.049$ & -0.053 & 0.011 & $-0.075,-0.032$ \\
\hline & $1965-1969$ & & & & -0.065 & 0.090 & $-0.242,0.111$ & -0.032 & 0.092 & $-0.212,0.149$ & -0.016 & 0.092 & $-0.197,0.164$ \\
\hline \multirow[t]{5}{*}{ Paternal Birth Year (G2) } & $1938-1945$ & & & & -0.094 & 0.004 & $-0.102,-0.086$ & 0.009 & 0.005 & $-0.001,0.020$ & -0.007 & 0.005 & $-0.017,0.004$ \\
\hline & 1946-1949 & & & & -0.026 & 0.003 & $-0.033,-0.020$ & 0.007 & 0.004 & $0.000,0.014$ & 0.004 & 0.004 & $-0.003,0.011$ \\
\hline & $1950-1954$ & & & & 0.000 & & & 0.000 & & & 0.000 & & \\
\hline & 1955-1959 & & & & -0.002 & 0.005 & $-0.013,0.009$ & -0.007 & 0.006 & $-0.018,0.004$ & -0.001 & 0.006 & $-0.012,0.010$ \\
\hline & $1960-1964$ & & & & -0.100 & 0.023 & $-0.145,-0.056$ & -0.079 & 0.023 & $-0.124,-0.034$ & -0.064 & 0.023 & $-0.109,-0.019$ \\
\hline \multirow[t]{5}{*}{ Index Birth Order (G3) } & 1 & & & & & & & 0.000 & & & 0.000 & & \\
\hline & 2 & & & & & & & -0.059 & 0.002 & $-0.063,-0.055$ & -0.048 & 0.002 & $-0.052,-0.043$ \\
\hline & 3 & & & & & & & -0.098 & 0.004 & $-0.106,-0.090$ & -0.077 & 0.004 & $-0.085,-0.068$ \\
\hline & 4 & & & & & & & -0.116 & 0.010 & $-0.136,-0.097$ & -0.087 & 0.010 & $-0.107,-0.068$ \\
\hline & $5+$ & & & & & & & -0.163 & 0.025 & $-0.213,-0.113$ & -0.127 & 0.025 & $-0.176,-0.077$ \\
\hline \multirow[t]{2}{*}{ Sex (G3) } & Male & & & & & & & 0.000 & & & 0.000 & & \\
\hline & Female & & & & & & & -0.348 & 0.002 & $-0.351,-0.344$ & -0.348 & 0.002 & $-0.351,-0.344$ \\
\hline \multirow[t]{4}{*}{ Sibling Group Size (G3) } & 1 & & & & & & & -0.129 & 0.003 & $-0.135,-0.123$ & -0.118 & 0.003 & $-0.125,-0.112$ \\
\hline & 2 & & & & & & & 0.000 & & & 0.000 & & \\
\hline & 4 & & & & & & & -0.040 & 0.005 & $-0.049,-0.031$ & -0.038 & 0.005 & $-0.047,-0.029$ \\
\hline & $5+$ & & & & & & & -0.104 & 0.008 & $-0.121,-0.087$ & -0.097 & 0.008 & $-0.114,-0.081$ \\
\hline \multirow[t]{16}{*}{ Birth Year (G3) } & 1960 & & & & & & & -0.081 & 0.013 & $-0.106,-0.055$ & -0.047 & 0.013 & $-0.072,-0.022$ \\
\hline & 1961 & & & & & & & -0.142 & 0.012 & $-0.165,-0.119$ & -0.116 & 0.012 & $-0.139,-0.093$ \\
\hline & 1962 & & & & & & & -0.214 & 0.011 & $-0.235,-0.193$ & -0.190 & 0.011 & $-0.211,-0.169$ \\
\hline & 1963 & & & & & & & -0.281 & 0.010 & $-0.299,-0.262$ & -0.258 & 0.010 & $-0.277,-0.239$ \\
\hline & 1964 & & & & & & & -0.296 & 0.009 & $-0.313,-0.279$ & -0.277 & 0.009 & $-0.294,-0.260$ \\
\hline & 1965 & & & & & & & -0.263 & 0.008 & $-0.278,-0.248$ & -0.247 & 0.008 & $-0.262,-0.232$ \\
\hline & 1966 & & & & & & & -0.233 & 0.007 & $-0.247,-0.219$ & -0.221 & 0.007 & $-0.235,-0.207$ \\
\hline & 1967 & & & & & & & -0.192 & 0.007 & $-0.205,-0.178$ & -0.183 & 0.007 & $-0.196,-0.170$ \\
\hline & 1968 & & & & & & & -0.125 & 0.006 & $-0.137,-0.112$ & -0.120 & 0.006 & $-0.132,-0.108$ \\
\hline & 1969 & & & & & & & -0.062 & 0.006 & $-0.074,-0.051$ & -0.061 & 0.006 & $-0.073,-0.049$ \\
\hline & 1970 & & & & & & & 0.000 & & & 0.000 & & \\
\hline & 1971 & & & & & & & 0.045 & 0.005 & $0.034,0.055$ & 0.033 & 0.005 & $0.023,0.044$ \\
\hline & 1972 & & & & & & & 0.060 & 0.005 & $0.049,0.071$ & 0.049 & 0.005 & $0.039,0.060$ \\
\hline & 1973 & & & & & & & 0.066 & 0.006 & $0.055,0.077$ & 0.055 & 0.006 & $0.044,0.066$ \\
\hline & 1974 & & & & & & & 0.074 & 0.006 & $0.063,0.086$ & 0.062 & 0.006 & $0.051,0.074$ \\
\hline & 1978 & & & & & & & 0.197 & 0.007 & $0.183,0.211$ & 0.177 & 0.007 & $0.163,0.192$ \\
\hline
\end{tabular}


Table S7 - Continued from previous page

\begin{tabular}{|c|c|c|c|c|c|c|c|c|c|c|c|c|c|}
\hline & & \multicolumn{3}{|c|}{ Model 1} & \multicolumn{3}{|c|}{ Model 2} & \multicolumn{3}{|c|}{ Model 3} & \multicolumn{3}{|c|}{ Model 4} \\
\hline & & $\mathrm{b}$ & se & $95 \% \mathrm{CI}$ & $\mathrm{b}$ & $\mathrm{se}$ & $95 \% \mathrm{CI}$ & $\mathrm{b}$ & se & $95 \% \mathrm{CI}$ & $\mathrm{b}$ & $\mathrm{se}$ & $95 \% \mathrm{CI}$ \\
\hline \multirow{7}{*}{ Maternal Age at Birth (G3) } & 1979 & & & & & & & 0.197 & 0.008 & $0.182,0.212$ & 0.176 & 0.008 & $0.161,0.191$ \\
\hline & 1980 & & & & & & & 0.202 & 0.008 & $0.186,0.218$ & 0.177 & 0.008 & $0.161,0.193$ \\
\hline & 1981 & & & & & & & 0.220 & 0.009 & $0.203,0.237$ & 0.187 & 0.009 & $0.170,0.204$ \\
\hline & $15-19$ & & & & & & & -0.104 & 0.006 & $-0.115,-0.093$ & -0.089 & 0.006 & $-0.100,-0.078$ \\
\hline & $20-24$ & & & & & & & -0.038 & 0.003 & $-0.044,-0.032$ & -0.028 & 0.003 & $-0.034,-0.022$ \\
\hline & $25-29$ & & & & & & & 0.000 & & & 0.000 & & \\
\hline & $30-34$ & & & & & & & -0.009 & 0.004 & $-0.016,-0.001$ & -0.009 & 0.004 & $-0.016,-0.001$ \\
\hline \multirow{4}{*}{ Paternal Age at Birth (G3) } & $40+$ & & & & & & & -0.032 & 0.033 & $-0.097,0.033$ & -0.015 & 0.033 & $-0.080,0.049$ \\
\hline & $15-19$ & & & & & & & -0.054 & 0.009 & $-0.071,-0.037$ & -0.058 & 0.009 & $-0.076,-0.041$ \\
\hline & $20-24$ & & & & & & & -0.030 & 0.003 & $-0.037,-0.024$ & -0.030 & 0.003 & $-0.037,-0.024$ \\
\hline & $25-29$ & & & & & & & 0.000 & & & 0.000 & & \\
\hline \multirow{7}{*}{$\begin{array}{l}\text { Maternal Educational Attainment } \\
\text { (G2) }\end{array}$} & $30-34$ & & & & & & & -0.008 & 0.003 & $-0.014,-0.001$ & -0.001 & 0.003 & $-0.007,0.005$ \\
\hline & $35-39$ & & & & & & & -0.035 & 0.006 & $-0.047,-0.022$ & -0.022 & 0.006 & $-0.034,-0.009$ \\
\hline & $40+$ & & & & & & & -0.070 & 0.016 & $-0.103,-0.038$ & -0.044 & 0.016 & $-0.077,-0.012$ \\
\hline & Primary $<9$ years & & & & & & & & & & -0.011 & 0.004 & $-0.020,-0.003$ \\
\hline & Primary - 9 years & & & & & & & & & & 0.000 & & \\
\hline & Secondary - 12 years & & & & & & & & & & 0.031 & 0.004 & $0.023,0.039$ \\
\hline & Tertiary - $13-15$ years & & & & & & & & & & 0.026 & 0.004 & $0.018,0.034$ \\
\hline \multirow{5}{*}{$\begin{array}{l}\text { Maternal Social Class (EGP) } \\
\text { (G2) }\end{array}$} & Tertiary - $15+$ years & & & & & & & & & & 0.031 & 0.004 & $0.023,0.039$ \\
\hline & Post-graduate & & & & & & & & & & 0.024 & 0.017 & $-0.010,0.058$ \\
\hline & Missing & & & & & & & & & & -0.145 & 0.047 & $-0.236,-0.053$ \\
\hline & I & & & & & & & & & & 0.001 & 0.012 & $-0.022,0.023$ \\
\hline & II & & & & & & & & & & 0.000 & & \\
\hline \multirow{10}{*}{$\begin{array}{l}\text { Paternal Educational Attainment } \\
\text { (G2) }\end{array}$} & III & & & & & & & & & & -0.028 & 0.004 & $-0.036,-0.021$ \\
\hline & IV & & & & & & & & & & -0.038 & 0.006 & $-0.050,-0.026$ \\
\hline & VI-VII & & & & & & & & & & -0.044 & 0.003 & $-0.050,-0.039$ \\
\hline & Unknown & & & & & & & & & & -0.086 & 0.003 & $-0.091,-0.080$ \\
\hline & Primary $<9$ years & & & & & & & & & & 0.000 & 0.004 & $-0.007,0.007$ \\
\hline & Primary - 9 years & & & & & & & & & & 0.000 & & \\
\hline & Secondary - $10-11$ years & & & & & & & & & & -0.013 & 0.003 & $-0.020,-0.007$ \\
\hline & Secondary - 12 years & & & & & & & & & & 0.036 & 0.004 & $0.029,0.043$ \\
\hline & Tertiary - $13-15$ years & & & & & & & & & & 0.032 & 0.004 & $0.024,0.041$ \\
\hline & Tertiary $-15+$ years & & & & & & & & & & 0.052 & 0.005 & $0.043,0.061$ \\
\hline $\begin{array}{l}\text { Paternal Social Class (EGP) } \\
\text { (G2) }\end{array}$ & II & & & & & & & & & & 0.000 & & \\
\hline
\end{tabular}


Table S7 - Continued from previous page

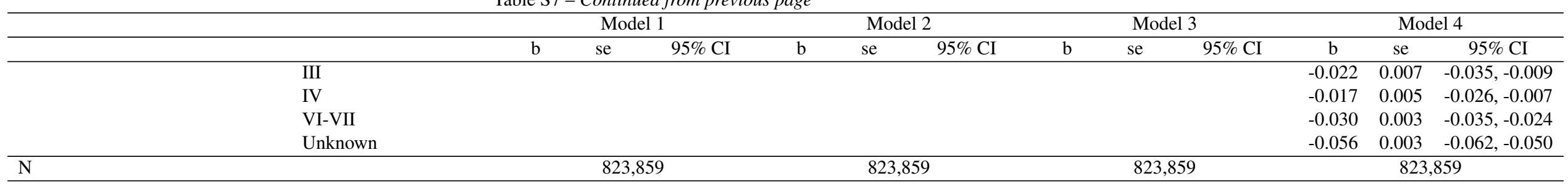


Table S8: Parental Birth Order and Offspring Inflation-adjusted (CPI) Log Earnings Averaged Over Ages 29-30, Fixed Effects Linear Regression on Maternal Cousin Sample of Swedish Men and Women Born 1960-1981.

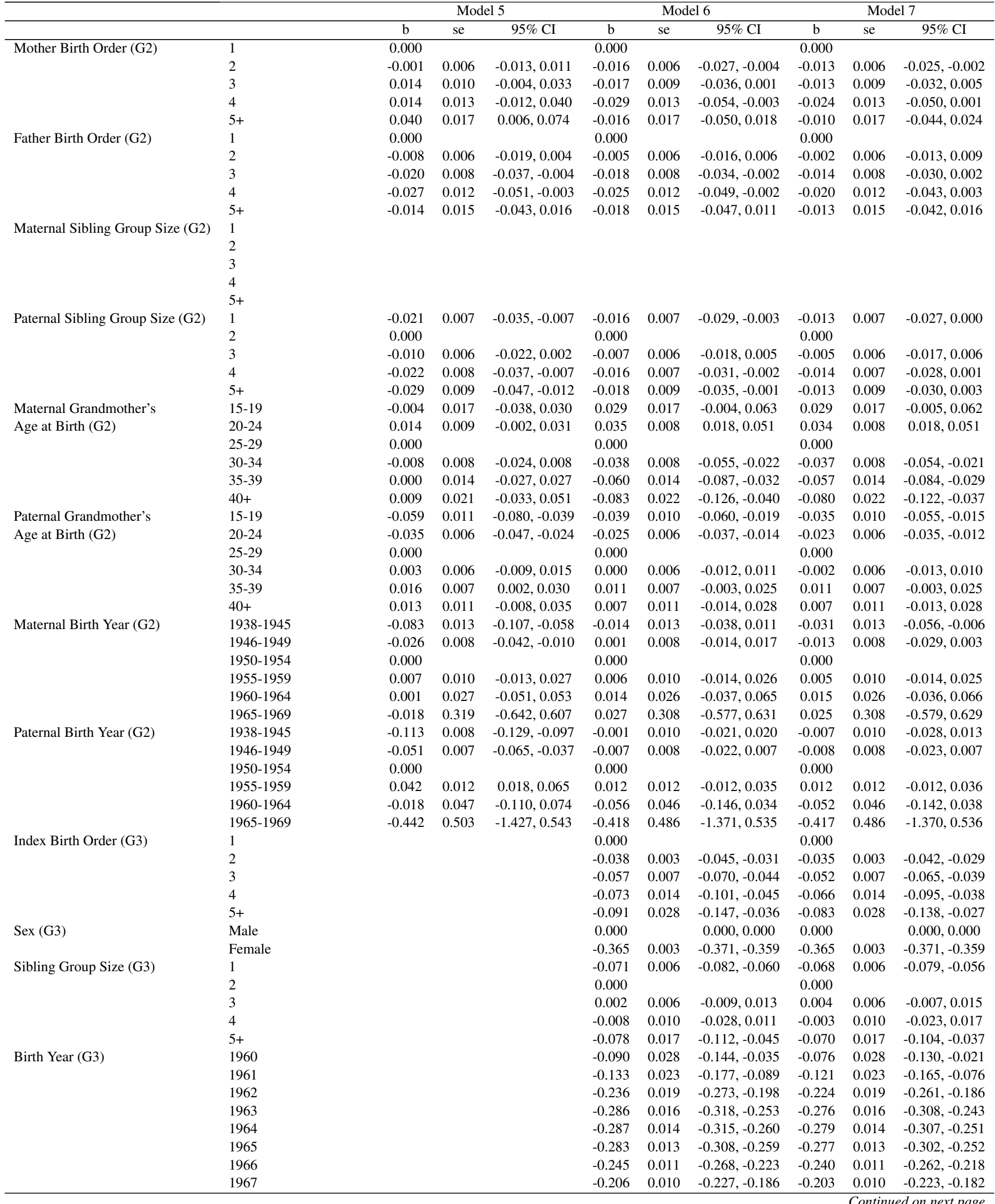


Table S8 - Continued from previous page

\begin{tabular}{|c|c|c|c|c|c|c|c|c|c|c|}
\hline & & \multicolumn{3}{|c|}{ Model 5} & \multicolumn{3}{|c|}{ Model 6} & \multicolumn{3}{|c|}{ Model 7} \\
\hline & & $\mathrm{b}$ & $\mathrm{se}$ & $95 \% \mathrm{CI}$ & $\mathrm{b}$ & $\mathrm{se}$ & $95 \% \mathrm{CI}$ & $\mathrm{b}$ & se & $95 \% \mathrm{CI}$ \\
\hline & 1968 & & & & -0.131 & 0.010 & $-0.150,-0.111$ & -0.129 & 0.010 & $-0.148,-0.109$ \\
\hline & 1969 & & & & -0.065 & 0.010 & $-0.084,-0.046$ & -0.064 & 0.010 & $-0.083,-0.045$ \\
\hline & 1970 & & & & 0.000 & & & 0.000 & & \\
\hline & 1971 & & & & 0.047 & 0.009 & $0.029,0.065$ & 0.043 & 0.009 & $0.026,0.061$ \\
\hline & 1972 & & & & 0.063 & 0.009 & $0.045,0.081$ & 0.060 & 0.009 & $0.042,0.078$ \\
\hline & 1973 & & & & 0.073 & 0.010 & $0.054,0.091$ & 0.069 & 0.010 & $0.050,0.087$ \\
\hline & 1974 & & & & 0.076 & 0.010 & $0.057,0.096$ & 0.072 & 0.010 & $0.052,0.092$ \\
\hline & 1975 & & & & 0.115 & 0.011 & $0.094,0.137$ & 0.110 & 0.011 & $0.088,0.131$ \\
\hline & 1976 & & & & 0.150 & 0.012 & $0.127,0.173$ & 0.144 & 0.012 & $0.121,0.167$ \\
\hline & 1977 & & & & 0.197 & 0.013 & $0.172,0.222$ & 0.190 & 0.013 & $0.165,0.215$ \\
\hline & 1978 & & & & 0.209 & 0.014 & $0.182,0.236$ & 0.201 & 0.014 & $0.174,0.228$ \\
\hline & 1979 & & & & 0.223 & 0.015 & $0.194,0.252$ & 0.215 & 0.015 & $0.185,0.244$ \\
\hline & 1980 & & & & 0.230 & 0.016 & $0.199,0.261$ & 0.219 & 0.016 & $0.188,0.251$ \\
\hline & 1981 & & & & 0.245 & 0.017 & $0.212,0.279$ & 0.231 & 0.017 & $0.198,0.265$ \\
\hline \multirow[t]{6}{*}{ Maternal Age at Birth (G3) } & $15-19$ & & & & -0.036 & 0.010 & $-0.056,-0.016$ & -0.035 & 0.010 & $-0.055,-0.015$ \\
\hline & $20-24$ & & & & -0.007 & 0.006 & $-0.019,0.004$ & -0.006 & 0.006 & $-0.018,0.005$ \\
\hline & $25-29$ & & & & 0.000 & & & 0.000 & & \\
\hline & $30-34$ & & & & -0.026 & 0.007 & $-0.040,-0.012$ & -0.025 & 0.007 & $-0.039,-0.011$ \\
\hline & $35-39$ & & & & -0.032 & 0.015 & $-0.062,-0.002$ & -0.030 & 0.015 & $-0.060,0.001$ \\
\hline & $40+$ & & & & -0.046 & 0.052 & $-0.149,0.056$ & -0.040 & 0.052 & $-0.143,0.062$ \\
\hline \multirow[t]{6}{*}{ Paternal Age at Birth (G3) } & $15-19$ & & & & -0.018 & 0.013 & $-0.044,0.008$ & -0.022 & 0.013 & $-0.048,0.005$ \\
\hline & $20-24$ & & & & 0.002 & 0.005 & $-0.009,0.012$ & 0.000 & 0.005 & $-0.010,0.011$ \\
\hline & $25-29$ & & & & 0.000 & & & 0.000 & & \\
\hline & $30-34$ & & & & -0.008 & 0.006 & $-0.019,0.003$ & -0.005 & 0.006 & $-0.016,0.006$ \\
\hline & $35-39$ & & & & -0.031 & 0.011 & $-0.053,-0.008$ & -0.025 & 0.011 & $-0.047,-0.003$ \\
\hline & $40+$ & & & & -0.034 & 0.026 & $-0.085,0.018$ & -0.023 & 0.027 & $-0.075,0.028$ \\
\hline \multirow{8}{*}{$\begin{array}{l}\text { Maternal Educational Attainment } \\
\text { (G2) }\end{array}$} & Primary $<9$ years & & & & & & & -0.003 & 0.010 & $-0.022,0.016$ \\
\hline & Primary - 9 years & & & & & & & 0.000 & & \\
\hline & Secondary - $10-11$ years & & & & & & & 0.007 & 0.007 & $-0.008,0.021$ \\
\hline & Secondary - 12 years & & & & & & & 0.019 & 0.010 & $-0.002,0.040$ \\
\hline & Tertiary $-13-15$ years & & & & & & & 0.015 & 0.010 & $-0.004,0.035$ \\
\hline & Tertiary $-15+$ years & & & & & & & 0.030 & 0.011 & $0.009,0.051$ \\
\hline & Post-graduate & & & & & & & -0.004 & 0.039 & $-0.081,0.072$ \\
\hline & Missing & & & & & & & -0.114 & 0.079 & $-0.269,0.041$ \\
\hline \multirow{6}{*}{$\begin{array}{l}\text { Maternal Social Class (EGP) } \\
(\mathrm{G} 2)\end{array}$} & I & & & & & & & -0.063 & 0.028 & $-0.118,-0.008$ \\
\hline & II & & & & & & & 0.000 & & \\
\hline & III & & & & & & & -0.014 & 0.009 & $-0.032,0.003$ \\
\hline & IV & & & & & & & -0.005 & 0.014 & $-0.033,0.023$ \\
\hline & VI-VII & & & & & & & -0.025 & 0.007 & $-0.038,-0.012$ \\
\hline & Unknown & & & & & & & -0.069 & 0.007 & $-0.082,-0.056$ \\
\hline \multirow{8}{*}{$\begin{array}{l}\text { Paternal Educational Attainment } \\
\text { (G2) }\end{array}$} & Primary $<9$ years & & & & & & & -0.008 & 0.008 & $-0.024,0.007$ \\
\hline & Primary - 9 years & & & & & & & 0.000 & & \\
\hline & Secondary - $10-11$ years & & & & & & & -0.017 & 0.007 & $-0.031,-0.003$ \\
\hline & Secondary - 12 years & & & & & & & 0.030 & 0.008 & $0.014,0.046$ \\
\hline & Tertiary $-13-15$ years & & & & & & & 0.011 & 0.009 & $-0.008,0.029$ \\
\hline & Tertiary $-15+$ years & & & & & & & 0.036 & 0.010 & $0.016,0.056$ \\
\hline & Post-graduate & & & & & & & 0.077 & 0.023 & $0.033,0.122$ \\
\hline & Missing & & & & & & & -0.026 & 0.038 & $-0.100,0.048$ \\
\hline \multirow{6}{*}{$\begin{array}{l}\text { Paternal Social Class (EGP) } \\
\text { (G2) }\end{array}$} & I & & & & & & & 0.005 & 0.020 & $-0.034,0.044$ \\
\hline & II & & & & & & & 0.000 & & \\
\hline & III & & & & & & & 0.004 & 0.015 & $-0.024,0.033$ \\
\hline & IV & & & & & & & -0.027 & 0.011 & $-0.048,-0.005$ \\
\hline & VI-VII & & & & & & & -0.016 & 0.006 & $-0.028,-0.004$ \\
\hline & Unknown & & & & & & & -0.038 & 0.007 & $-0.051,-0.025$ \\
\hline $\mathrm{N}$ & & & & & & 459 & 368 & & 459 & 68 \\
\hline
\end{tabular}


Table S9: Parental Birth Order and Offspring Inflation-adjusted (CPI) Log Earnings Averaged Over Ages 29-30, Fixed Effects Linear Regression on Paternal Cousin Sample of Swedish Men and Women Born 1960-1981.

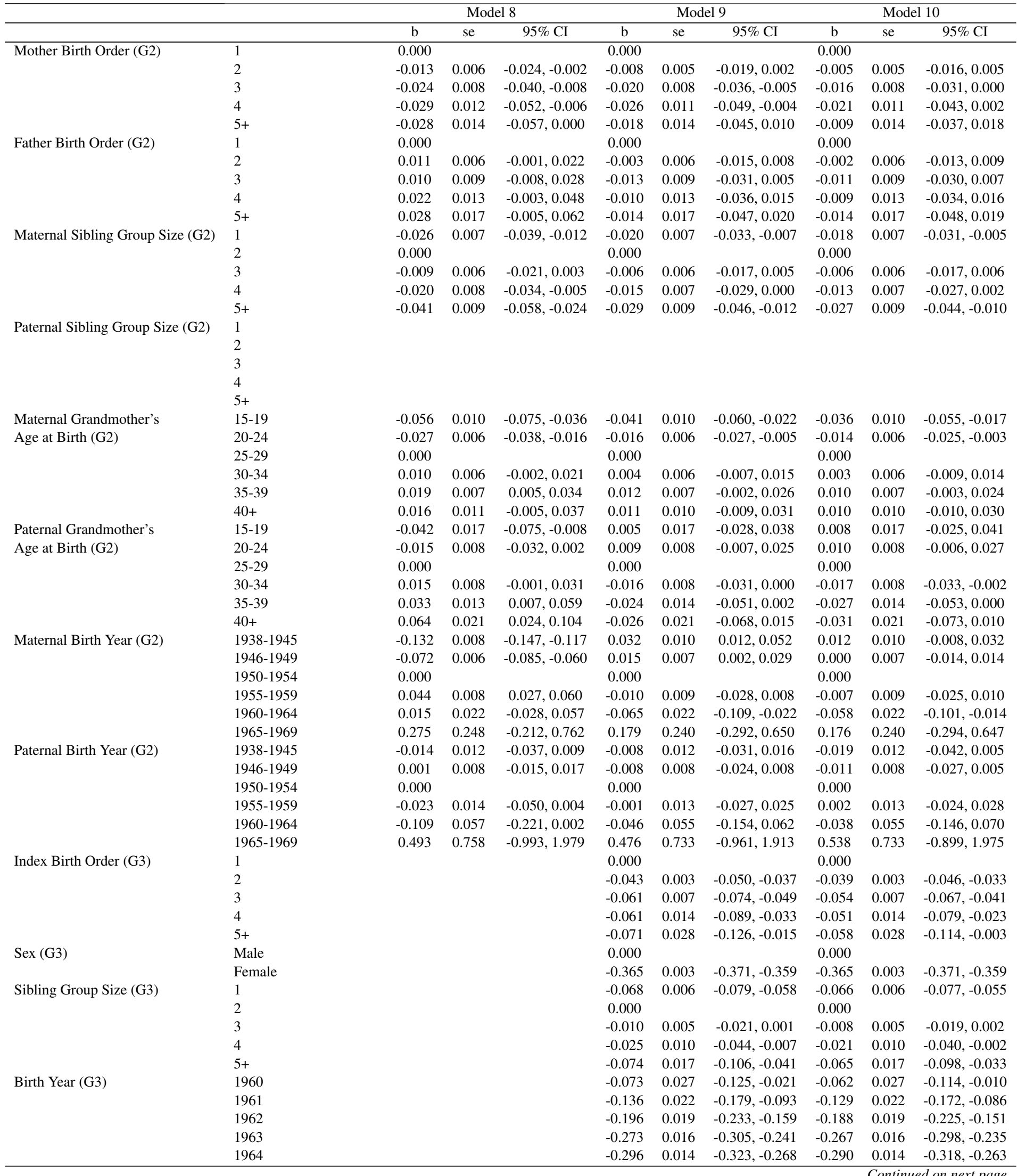


Table S9-Continued from previous page

\begin{tabular}{|c|c|c|c|c|c|c|c|c|c|c|}
\hline & & \multicolumn{3}{|c|}{ Model 8} & \multicolumn{3}{|c|}{ Model 9} & \multicolumn{3}{|c|}{ Model 10} \\
\hline & & $\mathrm{b}$ & se & $95 \% \mathrm{CI}$ & $\mathrm{b}$ & se & $95 \% \mathrm{CI}$ & $\mathrm{b}$ & se & $95 \% \mathrm{CI}$ \\
\hline & 1965 & & & & -0.248 & 0.012 & $-0.273,-0.224$ & -0.243 & 0.013 & $-0.268,-0.219$ \\
\hline & 1966 & & & & -0.235 & 0.011 & $-0.257,-0.212$ & -0.231 & 0.011 & $-0.253,-0.209$ \\
\hline & 1967 & & & & -0.195 & 0.010 & $-0.216,-0.175$ & -0.193 & 0.010 & $-0.213,-0.172$ \\
\hline & 1968 & & & & -0.122 & 0.010 & $-0.141,-0.102$ & -0.121 & 0.010 & $-0.140,-0.101$ \\
\hline & 1969 & & & & -0.072 & 0.010 & $-0.091,-0.053$ & -0.072 & 0.010 & $-0.091,-0.053$ \\
\hline & 1970 & & & & 0.000 & & & 0.000 & & \\
\hline & 1971 & & & & 0.050 & 0.009 & $0.032,0.067$ & 0.045 & 0.009 & $0.027,0.063$ \\
\hline & 1972 & & & & 0.062 & 0.009 & $0.044,0.080$ & 0.058 & 0.009 & $0.040,0.076$ \\
\hline & 1973 & & & & 0.076 & 0.009 & $0.058,0.095$ & 0.072 & 0.009 & $0.053,0.091$ \\
\hline & 1974 & & & & 0.082 & 0.010 & $0.063,0.102$ & 0.078 & 0.010 & $0.058,0.097$ \\
\hline & 1975 & & & & 0.116 & 0.011 & $0.095,0.137$ & 0.111 & 0.011 & $0.089,0.132$ \\
\hline & 1976 & & & & 0.151 & 0.012 & $0.128,0.174$ & 0.146 & 0.012 & $0.123,0.169$ \\
\hline & 1977 & & & & 0.204 & 0.013 & $0.179,0.229$ & 0.198 & 0.013 & $0.173,0.222$ \\
\hline & 1978 & & & & 0.216 & 0.014 & $0.189,0.243$ & 0.208 & 0.014 & $0.181,0.235$ \\
\hline & 1979 & & & & 0.217 & 0.015 & $0.188,0.246$ & 0.210 & 0.015 & $0.181,0.239$ \\
\hline & 1980 & & & & 0.224 & 0.016 & $0.193,0.255$ & 0.214 & 0.016 & $0.183,0.246$ \\
\hline & 1981 & & & & 0.251 & 0.017 & $0.217,0.284$ & 0.238 & 0.017 & $0.205,0.272$ \\
\hline \multirow[t]{6}{*}{ Maternal Age at Birth (G3) } & $15-19$ & & & & -0.021 & 0.009 & $-0.040,-0.003$ & -0.019 & 0.009 & $-0.037,0.000$ \\
\hline & $20-24$ & & & & 0.000 & 0.005 & $-0.011,0.010$ & 0.002 & 0.005 & $-0.008,0.013$ \\
\hline & $25-29$ & & & & 0.000 & & & 0.000 & & \\
\hline & $30-34$ & & & & -0.016 & 0.007 & $-0.029,-0.003$ & -0.016 & 0.007 & $-0.029,-0.003$ \\
\hline & $35-39$ & & & & -0.017 & 0.015 & $-0.045,0.012$ & -0.016 & 0.015 & $-0.044,0.013$ \\
\hline & $40+$ & & & & 0.010 & 0.050 & $-0.088,0.108$ & 0.016 & 0.050 & $-0.082,0.114$ \\
\hline \multirow[t]{6}{*}{ Paternal Age at Birth (G3) } & $15-19$ & & & & -0.045 & 0.014 & $-0.072,-0.018$ & -0.046 & 0.014 & $-0.073,-0.019$ \\
\hline & $20-24$ & & & & -0.017 & 0.006 & $-0.029,-0.006$ & -0.017 & 0.006 & $-0.029,-0.006$ \\
\hline & $25-29$ & & & & 0.000 & & & 0.000 & & \\
\hline & $30-34$ & & & & -0.009 & 0.006 & $-0.021,0.004$ & -0.007 & 0.006 & $-0.019,0.005$ \\
\hline & $35-39$ & & & & -0.029 & 0.012 & $-0.053,-0.005$ & -0.026 & 0.012 & $-0.050,-0.002$ \\
\hline & $40+$ & & & & -0.031 & 0.027 & $-0.083,0.021$ & -0.024 & 0.027 & $-0.076,0.028$ \\
\hline \multirow{8}{*}{$\begin{array}{l}\text { Maternal Educational Attainment } \\
\text { (G2) }\end{array}$} & Primary $<9$ years & & & & & & & 0.000 & 0.009 & $-0.017,0.017$ \\
\hline & Primary - 9 years & & & & & & & 0.000 & & \\
\hline & Secondary - $10-11$ years & & & & & & & 0.014 & 0.007 & $0.001,0.027$ \\
\hline & Secondary - 12 years & & & & & & & 0.011 & 0.009 & $-0.006,0.029$ \\
\hline & Tertiary - $13-15$ years & & & & & & & 0.029 & 0.009 & $0.012,0.046$ \\
\hline & Tertiary $-15+$ years & & & & & & & 0.047 & 0.009 & $0.030,0.065$ \\
\hline & Post-graduate & & & & & & & 0.022 & 0.034 & $-0.045,0.089$ \\
\hline & Missing & & & & & & & -0.117 & 0.061 & $-0.236,0.003$ \\
\hline \multirow{6}{*}{$\begin{array}{l}\text { Maternal Social Class (EGP) } \\
\text { (G2) }\end{array}$} & I & & & & & & & 0.030 & 0.025 & $-0.019,0.079$ \\
\hline & II & & & & & & & 0.000 & & \\
\hline & III & & & & & & & -0.019 & 0.008 & $-0.035,-0.003$ \\
\hline & IV & & & & & & & -0.057 & 0.013 & $-0.083,-0.031$ \\
\hline & VI-VII & & & & & & & -0.036 & 0.006 & $-0.047,-0.024$ \\
\hline & Unknown & & & & & & & -0.072 & 0.006 & $-0.083,-0.060$ \\
\hline \multirow{8}{*}{$\begin{array}{l}\text { Paternal Educational Attainment } \\
\text { (G2) }\end{array}$} & Primary $<9$ years & & & & & & & -0.002 & 0.009 & $-0.019,0.016$ \\
\hline & Primary - 9 years & & & & & & & 0.000 & & \\
\hline & Secondary - $10-11$ years & & & & & & & -0.021 & 0.008 & $-0.036,-0.005$ \\
\hline & Secondary - 12 years & & & & & & & 0.020 & 0.009 & $0.001,0.038$ \\
\hline & Tertiary - $13-15$ years & & & & & & & 0.014 & 0.011 & $-0.006,0.035$ \\
\hline & Tertiary $-15+$ years & & & & & & & 0.020 & 0.012 & $-0.003,0.042$ \\
\hline & Post-graduate & & & & & & & 0.015 & 0.024 & $-0.032,0.062$ \\
\hline & Missing & & & & & & & -0.019 & 0.044 & $-0.105,0.067$ \\
\hline \multirow{6}{*}{$\begin{array}{l}\text { Paternal Social Class (EGP) } \\
\text { (G2) }\end{array}$} & I & & & & & & & -0.004 & 0.022 & $-0.047,0.038$ \\
\hline & II & & & & & & & 0.000 & & \\
\hline & III & & & & & & & 0.001 & 0.016 & $-0.031,0.032$ \\
\hline & IV & & & & & & & -0.028 & 0.012 & $-0.051,-0.004$ \\
\hline & VI-VII & & & & & & & -0.020 & 0.007 & $-0.034,-0.007$ \\
\hline & Unknown & & & & & & & -0.034 & 0.007 & $-0.048,-0.019$ \\
\hline $\mathrm{N}$ & & & & & & 463 , & & & 463, & 578 \\
\hline
\end{tabular}


Table S10: Descriptive statistics for birth order and grade point average at age 16 for generation 3 (G3), Swedish men and women born 1982-1990.

\begin{tabular}{|c|c|c|c|c|c|c|c|c|c|c|c|c|c|c|c|c|}
\hline & & \multicolumn{5}{|c|}{ Index Birth Order } & \multicolumn{5}{|c|}{ Mother Birth Order } & \multicolumn{5}{|c|}{ Father Birth Order } \\
\hline & & 1 & 2 & 3 & 4 & $5+$ & 1 & 2 & 3 & 4 & $5+$ & 1 & 2 & 3 & 4 & $5+$ \\
\hline $\mathrm{N}$ & & 334,065 & 237,695 & 86,033 & 17,424 & 4,587 & 318,741 & 213,601 & 90,356 & 33,647 & 23,459 & 313,278 & 215,210 & 91,721 & 34,868 & 24,727 \\
\hline \multirow[t]{2}{*}{ Grade Point Average } & Mean & 207.8 & 207.2 & 205.5 & 198.3 & 190.4 & 206.5 & 208.8 & 207.2 & 203.9 & 199.3 & 206.5 & 209.0 & 207.2 & 203.2 & 198.5 \\
\hline & SD & 62.7 & 60.4 & 61.2 & 65.4 & 69.6 & 62.4 & 61.2 & 61.5 & 62.1 & 61.8 & 62.4 & 61.1 & 61.4 & 62.3 & 61.9 \\
\hline \multirow[t]{2}{*}{ Mother Birth Order } & Mean & 1.9 & 1.9 & 2.0 & 2.0 & 2.1 & 1.0 & 2.0 & 3.0 & 4.0 & 5.9 & 1.9 & 1.9 & 1.9 & 2.0 & 2.0 \\
\hline & SD & 1.1 & 1.2 & 1.2 & 1.3 & 1.5 & 0.0 & 0.0 & 0.0 & 0.0 & 1.3 & 1.1 & 1.2 & 1.2 & 1.3 & 1.3 \\
\hline \multirow[t]{2}{*}{ Father Birth Order } & Mean & 1.9 & 1.9 & 2.0 & 2.1 & 2.1 & 1.9 & 1.9 & 1.9 & 2.0 & 2.1 & 1.0 & 2.0 & 3.0 & 4.0 & 5.9 \\
\hline & SD & 1.1 & 1.2 & 1.3 & 1.3 & 1.4 & 1.2 & 1.2 & 1.2 & 1.3 & 1.4 & 0.0 & 0.0 & 0.0 & 0.0 & 1.3 \\
\hline \multirow[t]{2}{*}{ Index Birth Order } & Mean & 1.0 & 2.0 & 3.0 & 4.0 & 5.4 & 1.7 & 1.7 & 1.7 & 1.8 & 1.9 & 1.7 & 1.7 & 1.7 & 1.8 & 1.8 \\
\hline & SD & 0.0 & 0.0 & 0.0 & 0.0 & 0.8 & 0.8 & 0.8 & 0.9 & 0.9 & 1.0 & 0.8 & 0.8 & 0.9 & 0.9 & 0.9 \\
\hline \multirow[t]{2}{*}{ Index Sibling Group Size } & Mean & 2.0 & 2.4 & 3.3 & 4.3 & 6.0 & 2.4 & 2.4 & 2.5 & 2.5 & 2.6 & 2.4 & 2.4 & 2.5 & 2.5 & 2.6 \\
\hline & SD & 0.8 & 0.7 & 0.6 & 0.8 & 1.4 & 1.0 & 0.9 & 1.0 & 1.0 & 1.1 & 1.0 & 0.9 & 1.0 & 1.0 & 1.1 \\
\hline \multirow[t]{2}{*}{ Index Birth Year } & Mean & 1986.9 & 1986.8 & 1986.8 & 1987.1 & 1987.3 & 1986.9 & 1986.9 & 1986.8 & 1986.7 & 1986.6 & 1986.9 & 1986.9 & 1986.8 & 1986.8 & 1986.6 \\
\hline & SD & 2.9 & 2.9 & 2.9 & 2.8 & 2.8 & 2.9 & 2.9 & 2.9 & 2.8 & 2.8 & 2.9 & 2.9 & 2.9 & 2.9 & 2.8 \\
\hline \multirow[t]{2}{*}{ Index Mother Age } & Mean & 26.6 & 28.9 & 31.4 & 33.3 & 35.2 & 28.2 & 28.3 & 28.2 & 28.2 & 28.1 & 28.3 & 28.2 & 28.1 & 28.0 & 27.7 \\
\hline & SD & 4.8 & 4.2 & 4.0 & 4.1 & 4.2 & 4.9 & 4.8 & 4.8 & 4.8 & 4.8 & 4.9 & 4.8 & 4.8 & 4.8 & 4.8 \\
\hline \multirow{2}{*}{ Index Father Age } & Mean & 29.2 & 31.4 & 34.0 & 35.9 & 38.0 & 30.7 & 30.9 & 30.9 & 31.0 & 31.0 & 30.9 & 30.8 & 30.6 & 30.6 & 30.6 \\
\hline & SD & 5.4 & 4.7 & 4.4 & 4.4 & 4.4 & 5.4 & 5.3 & 5.3 & 5.3 & 5.4 & 5.5 & 5.3 & 5.2 & 5.2 & 5.1 \\
\hline \multirow[t]{2}{*}{ Mother Sibling Group Size } & Mean & 2.6 & 2.7 & 2.9 & 3.2 & 3.4 & 2.1 & 2.6 & 3.5 & 4.5 & 6.5 & 2.7 & 2.7 & 2.8 & 2.8 & 2.9 \\
\hline & $\mathrm{SD}$ & 1.3 & 1.4 & 1.5 & 1.7 & 2.0 & 1.0 & 0.9 & 0.9 & 0.9 & 1.7 & 1.3 & 1.4 & 1.4 & 1.5 & 1.6 \\
\hline \multirow[t]{2}{*}{ Father Sibling Group Size } & Mean & 2.7 & 2.8 & 3.0 & 3.2 & 3.5 & 2.7 & 2.8 & 2.8 & 2.9 & 3.0 & 2.1 & 2.7 & 3.6 & 4.6 & 6.6 \\
\hline & SD & 1.4 & 1.4 & 1.6 & 1.7 & 2.0 & 1.4 & 1.4 & 1.5 & 1.5 & 1.7 & 1.0 & 0.9 & 0.9 & 1.0 & 1.8 \\
\hline \multirow[t]{2}{*}{ Mother Birth Year } & Mean & 1960.3 & 1957.9 & 1955.4 & 1953.8 & 1952.2 & 1958.6 & 1958.6 & 1958.6 & 1958.5 & 1958.4 & 1958.6 & 1958.6 & 1958.7 & 1958.8 & 1958.9 \\
\hline & SD & 5.5 & 5.0 & 4.9 & 4.9 & 5.0 & 5.6 & 5.5 & 5.5 & 5.3 & 5.3 & 5.7 & 5.5 & 5.4 & 5.4 & 5.2 \\
\hline \multirow[t]{2}{*}{ Father Birth Year } & Mean & 1957.7 & 1955.4 & 1952.8 & 1951.1 & 1949.4 & 1956.2 & 1956.0 & 1955.9 & 1955.7 & 1955.6 & 1955.9 & 1956.1 & 1956.2 & 1956.1 & 1956.1 \\
\hline & SD & 6.0 & 5.4 & 5.1 & 5.1 & 5.1 & 6.0 & 5.9 & 5.9 & 5.8 & 5.8 & 6.1 & 5.9 & 5.8 & 5.7 & 5.4 \\
\hline Maternal Grandmother & Mean & 27.0 & 27.5 & 27.9 & 27.9 & 27.9 & 24.7 & 28.0 & 31.0 & 33.2 & 35.6 & 27.3 & 27.4 & 27.3 & 27.3 & 27.3 \\
\hline Age at Birth & SD & 6.0 & 6.1 & 6.1 & 6.2 & 6.4 & 5.4 & 5.2 & 5.3 & 5.2 & 5.0 & 6.1 & 6.1 & 6.1 & 6.2 & 6.2 \\
\hline Paternal Grandmother & Mean & 27.3 & 27.8 & 28.2 & 28.4 & 28.5 & 27.6 & 27.6 & 27.7 & 27.7 & 27.8 & 25.0 & 28.3 & 31.1 & 33.2 & 35.5 \\
\hline Age at Birth & $\mathrm{SD}$ & 6.1 & 6.1 & 6.1 & 6.2 & 6.3 & 6.1 & 6.0 & 6.1 & 6.2 & 6.3 & 5.4 & 5.2 & 5.2 & 5.2 & 5.0 \\
\hline Mother Education & Primary ( $¡ 9$ years) & 0.6 & 0.7 & 1.5 & 3.5 & 8.5 & 0.7 & 0.8 & 1.1 & 1.4 & 2.4 & 0.9 & 0.8 & 1.0 & 1.2 & 1.2 \\
\hline \multirow[t]{7}{*}{$(\%)$} & Primary (9 years) & 8.9 & 8.8 & 10.0 & 13.4 & 16.8 & 8.1 & 9.1 & 10.4 & 12.2 & 15.4 & 8.9 & 8.9 & 9.5 & 10.7 & 12.1 \\
\hline & Secondary (10-11 years) & 37.2 & 36.8 & 36.0 & 36.7 & 38.1 & 35.3 & 37.1 & 38.5 & 40.7 & 44.2 & 36.2 & 36.3 & 37.5 & 40.2 & 43.7 \\
\hline & Secondary (12 years) & 15.8 & 14.2 & 12.5 & 11.5 & 10.1 & 15.2 & 14.4 & 14.0 & 13.6 & 12.7 & 14.8 & 14.5 & 14.7 & 14.3 & 14.7 \\
\hline & Tertiary (13-15 years) & 16.1 & 16.9 & 16.1 & 13.3 & 10.3 & 16.9 & 16.6 & 15.4 & 13.8 & 11.9 & 16.5 & 16.8 & 15.8 & 14.7 & 12.9 \\
\hline & Tertiary (15+ years) & 20.6 & 21.9 & 23.2 & 21.0 & 15.7 & 22.8 & 21.2 & 19.9 & 17.7 & 13.1 & 21.9 & 22.0 & 20.9 & 18.4 & 14.9 \\
\hline & Graduate school & 0.7 & 0.7 & 0.8 & 0.7 & 0.4 & 0.8 & 0.7 & 0.6 & 0.5 & 0.3 & 0.8 & 0.7 & 0.6 & 0.5 & 0.4 \\
\hline & Missing & 0.1 & 0.0 & 0.1 & 0.0 & 0.0 & 0.1 & 0.1 & 0.1 & 0.1 & 0.1 & 0.1 & 0.1 & 0.1 & 0.0 & 0.1 \\
\hline
\end{tabular}


Table S10 - Continued from previous page

\begin{tabular}{|c|c|c|c|c|c|c|c|c|c|c|c|c|c|c|c|c|}
\hline & & \multicolumn{5}{|c|}{ Index Birth Order } & \multicolumn{5}{|c|}{ Mother Birth Order } & \multicolumn{5}{|c|}{ Father Birth Order } \\
\hline & & 1 & 2 & 3 & 4 & $5+$ & 1 & 2 & 3 & 4 & $5+$ & 1 & 2 & 3 & 4 & $5+$ \\
\hline Mother EGP & I & 3.7 & 3.5 & 2.7 & 1.7 & 0.8 & 3.9 & 3.3 & 2.9 & 2.4 & 1.6 & 3.7 & 3.6 & 3.2 & 2.6 & 1.7 \\
\hline \multirow[t]{5}{*}{$(\%)$} & II & 16.9 & 19.3 & 20.5 & 19.1 & 17.8 & 19.2 & 18.6 & 16.9 & 15.2 & 12.4 & 18.8 & 18.9 & 17.3 & 16.0 & 13.2 \\
\hline & III & 16.1 & 15.7 & 10.4 & 6.3 & 4.6 & 15.3 & 15.3 & 14.1 & 13.1 & 11.5 & 15.1 & 15.2 & 14.5 & 13.9 & 13.0 \\
\hline & IV & 1.4 & 1.5 & 1.9 & 2.9 & 4.2 & 1.5 & 1.5 & 1.7 & 1.7 & 1.6 & 1.4 & 1.5 & 1.8 & 1.8 & 1.7 \\
\hline & VI-VII & 40.6 & 37.4 & 32.1 & 27.4 & 22.9 & 36.6 & 37.7 & 40.1 & 41.6 & 45.6 & 37.3 & 37.3 & 39.0 & 41.1 & 44.4 \\
\hline & Unknown & 21.3 & 22.6 & 32.5 & 42.7 & 49.8 & 23.5 & 23.6 & 24.4 & 26.0 & 27.4 & 23.8 & 23.6 & 24.2 & 24.7 & 26.0 \\
\hline Father Education & Primary ( $¡ 9$ years) & 2.7 & 3.7 & 6.6 & 10.8 & 16.1 & 3.6 & 3.6 & 4.2 & 4.8 & 6.1 & 3.2 & 3.6 & 4.6 & 6.0 & 7.7 \\
\hline \multirow[t]{7}{*}{$(\%)$} & Primary (9 years) & 15.9 & 15.9 & 15.6 & 15.7 & 15.1 & 15.5 & 15.6 & 16.2 & 17.7 & 18.8 & 14.4 & 15.7 & 17.5 & 20.0 & 24.0 \\
\hline & Secondary (10-11 years) & 40.9 & 36.7 & 32.6 & 31.8 & 32.5 & 37.7 & 37.8 & 38.3 & 39.4 & 42.2 & 36.8 & 38.1 & 39.5 & 41.2 & 42.9 \\
\hline & Secondary (12 years) & 11.9 & 12.6 & 13.1 & 12.9 & 12.1 & 12.4 & 12.3 & 12.2 & 12.2 & 11.5 & 13.1 & 12.3 & 11.3 & 10.1 & 8.9 \\
\hline & Tertiary (13-15 years) & 13.5 & 14.1 & 13.2 & 11.0 & 8.9 & 13.8 & 13.9 & 13.3 & 12.2 & 11.0 & 14.6 & 13.7 & 12.3 & 10.9 & 9.0 \\
\hline & Tertiary $(15+$ years $)$ & 13.6 & 15.3 & 17.0 & 15.8 & 13.7 & 15.2 & 15.1 & 14.1 & 12.4 & 9.6 & 16.0 & 14.9 & 13.3 & 10.7 & 6.6 \\
\hline & Graduate school & 1.3 & 1.6 & 1.9 & 1.9 & 1.6 & 1.6 & 1.6 & 1.4 & 1.2 & 0.7 & 1.7 & 1.5 & 1.3 & 0.9 & 0.7 \\
\hline & Missing & 0.3 & 0.2 & 0.1 & 0.1 & 0.1 & 0.2 & 0.2 & 0.2 & 0.2 & 0.2 & 0.2 & 0.2 & 0.2 & 0.2 & 0.2 \\
\hline Father EGP & I & 5.8 & 6.1 & 5.1 & 3.9 & 3.1 & 6.0 & 5.9 & 5.5 & 4.6 & 3.5 & 6.2 & 5.9 & 5.1 & 4.3 & 2.5 \\
\hline \multirow[t]{5}{*}{$(\%)$} & II & 14.0 & 15.5 & 15.7 & 14.8 & 13.9 & 15.2 & 15.0 & 14.2 & 13.0 & 11.7 & 16.2 & 15.0 & 12.9 & 10.5 & 8.3 \\
\hline & III & 7.9 & 7.8 & 5.9 & 4.3 & 3.8 & 7.6 & 7.6 & 7.3 & 6.8 & 6.3 & 7.7 & 7.7 & 7.1 & 6.6 & 5.6 \\
\hline & IV & 4.3 & 4.9 & 6.3 & 7.6 & 7.7 & 4.7 & 4.8 & 5.2 & 5.7 & 5.8 & 4.4 & 4.9 & 5.8 & 5.9 & 5.8 \\
\hline & VI-VII & 50.8 & 48.9 & 46.4 & 47.3 & 48.5 & 48.8 & 48.8 & 50.2 & 53.2 & 56.6 & 47.0 & 49.3 & 52.0 & 56.2 & 62.1 \\
\hline & Unknown & 17.3 & 16.8 & 20.7 & 22.2 & 23.0 & 17.8 & 17.9 & 17.6 & 16.7 & 16.1 & 18.5 & 17.2 & 17.0 & 16.4 & 15.8 \\
\hline
\end{tabular}


Table S11: Parental Birth Order and Offspring Grade Point Average (GPA) at Age 16, Linear Regression Model on Full Population of Swedish Men and Women Born 1982-1991.

\begin{tabular}{|c|c|c|c|c|c|c|c|c|c|c|c|c|c|}
\hline & & \multicolumn{3}{|c|}{ Model 1} & \multicolumn{3}{|c|}{ Model 2} & \multicolumn{3}{|c|}{ Model 3} & \multicolumn{3}{|c|}{ Model 4} \\
\hline & & $\mathrm{b}$ & $\mathrm{se}$ & $95 \% \mathrm{CI}$ & $\mathrm{b}$ & se & $95 \% \mathrm{CI}$ & $\mathrm{b}$ & $\mathrm{se}$ & $95 \% \mathrm{CI}$ & $\mathrm{b}$ & se & $95 \% \mathrm{CI}$ \\
\hline \multirow{5}{*}{ Mother Birth Order (G2) } & 1 & 0.00 & & & 0.00 & & & 0.00 & & & 0.00 & & \\
\hline & 2 & 0.04 & 0.00 & $0.03,0.04$ & -0.09 & 0.00 & $-0.10,-0.08$ & -0.07 & 0.00 & $-0.08,-0.07$ & -0.01 & 0.00 & $-0.02,-0.01$ \\
\hline & 3 & 0.01 & 0.00 & $0.00,0.02$ & -0.16 & 0.01 & $-0.17,-0.15$ & -0.13 & 0.01 & $-0.14,-0.12$ & -0.03 & 0.00 & $-0.04,-0.02$ \\
\hline & 4 & -0.04 & 0.01 & $-0.05,-0.03$ & -0.20 & 0.01 & $-0.21,-0.18$ & -0.16 & 0.01 & $-0.18,-0.15$ & -0.04 & 0.01 & $-0.06,-0.03$ \\
\hline & $5+$ & -0.11 & 0.01 & $-0.13,-0.10$ & -0.24 & 0.01 & $-0.26,-0.21$ & -0.19 & 0.01 & $-0.21,-0.17$ & -0.04 & 0.01 & $-0.06,-0.02$ \\
\hline \multirow{5}{*}{ Father Birth Order (G2) } & 1 & 0.00 & & & 0.00 & & & 0.00 & & & 0.00 & & \\
\hline & 2 & 0.04 & 0.00 & $0.03,0.05$ & -0.07 & 0.00 & $-0.08,-0.07$ & -0.06 & 0.00 & $-0.06,-0.05$ & -0.01 & 0.00 & $-0.01,0.00$ \\
\hline & 3 & 0.01 & 0.00 & $0.00,0.02$ & -0.13 & 0.01 & $-0.15,-0.12$ & -0.11 & 0.01 & $-0.12,-0.10$ & -0.02 & 0.00 & $-0.03,-0.02$ \\
\hline & 4 & -0.05 & 0.01 & $-0.07,-0.04$ & -0.17 & 0.01 & $-0.19,-0.15$ & -0.14 & 0.01 & $-0.16,-0.13$ & -0.04 & 0.01 & $-0.05,-0.02$ \\
\hline & $5+$ & -0.12 & 0.01 & $-0.14,-0.11$ & -0.20 & 0.01 & $-0.22,-0.18$ & -0.16 & 0.01 & $-0.18,-0.14$ & -0.03 & 0.01 & $-0.05,-0.02$ \\
\hline \multirow[t]{5}{*}{ Maternal Sibling Group Size (G2) } & 1 & & & & -0.15 & 0.00 & $-0.16,-0.14$ & -0.13 & 0.00 & $-0.13,-0.12$ & -0.07 & 0.00 & $-0.08,-0.06$ \\
\hline & 2 & & & & 0.00 & & & 0.00 & & & 0.00 & & \\
\hline & 3 & & & & 0.00 & 0.00 & $0.00,0.01$ & 0.00 & 0.00 & $0.00,0.01$ & 0.00 & 0.00 & $-0.01,0.01$ \\
\hline & 4 & & & & -0.03 & 0.01 & $-0.04,-0.02$ & -0.02 & 0.01 & $-0.03,-0.01$ & -0.01 & 0.00 & $-0.02,0.00$ \\
\hline & $5+$ & & & & -0.10 & 0.01 & $-0.12,-0.09$ & -0.08 & 0.01 & $-0.09,-0.06$ & -0.02 & 0.01 & $-0.04,-0.01$ \\
\hline \multirow[t]{5}{*}{ Paternal Sibling Group Size (G2) } & 1 & & & & -0.13 & 0.00 & $-0.13,-0.12$ & -0.11 & 0.00 & $-0.12,-0.10$ & -0.06 & 0.00 & $-0.07,-0.05$ \\
\hline & 2 & & & & 0.00 & & & 0.00 & & & 0.00 & & \\
\hline & 3 & & & & 0.02 & 0.00 & $0.01,0.02$ & 0.02 & 0.00 & $0.01,0.03$ & 0.02 & 0.00 & $0.01,0.02$ \\
\hline & 4 & & & & -0.02 & 0.01 & $-0.03,-0.01$ & -0.01 & 0.01 & $-0.02,0.00$ & 0.01 & 0.00 & $0.00,0.02$ \\
\hline & $5+$ & & & & -0.11 & 0.01 & $-0.12,-0.09$ & -0.08 & 0.01 & $-0.09,-0.06$ & -0.01 & 0.01 & $-0.02,0.00$ \\
\hline Maternal Grandmother's & $15-19$ & & & & -0.34 & 0.01 & $-0.35,-0.33$ & -0.27 & 0.01 & $-0.28,-0.26$ & -0.15 & 0.01 & $-0.17,-0.14$ \\
\hline \multirow[t]{5}{*}{ Age at Birth (G2) } & $20-24$ & & & & -0.17 & 0.00 & $-0.17,-0.16$ & -0.14 & 0.00 & $-0.14,-0.13$ & -0.07 & 0.00 & $-0.08,-0.06$ \\
\hline & $25-29$ & & & & 0.00 & & & 0.00 & & & 0.00 & & \\
\hline & $30-34$ & & & & 0.08 & 0.00 & $0.07,0.08$ & 0.06 & 0.00 & $0.05,0.07$ & 0.03 & 0.00 & $0.02,0.04$ \\
\hline & $35-39$ & & & & 0.10 & 0.01 & $0.09,0.11$ & 0.08 & 0.00 & $0.07,0.09$ & 0.04 & 0.00 & $0.03,0.05$ \\
\hline & $40+$ & & & & 0.10 & 0.01 & $0.08,0.11$ & 0.08 & 0.01 & $0.06,0.09$ & 0.04 & 0.01 & $0.03,0.06$ \\
\hline Paternal Grandmother's & $15-19$ & & & & -0.31 & 0.01 & $-0.32,-0.30$ & -0.26 & 0.01 & $-0.27,-0.25$ & -0.14 & 0.01 & $-0.15,-0.13$ \\
\hline Age at Birth (G2) & $20-24$ & & & & -0.15 & 0.00 & $-0.15,-0.14$ & -0.12 & 0.00 & $-0.13,-0.11$ & -0.06 & 0.00 & $-0.07,-0.05$ \\
\hline & $25-29$ & & & & 0.00 & & & 0.00 & & & 0.00 & & \\
\hline & $30-34$ & & & & 0.07 & 0.00 & $0.06,0.07$ & 0.05 & 0.00 & $0.05,0.06$ & 0.03 & 0.00 & $0.02,0.04$ \\
\hline & $35-39$ & & & & 0.08 & 0.01 & $0.07,0.09$ & 0.07 & 0.00 & $0.06,0.08$ & 0.04 & 0.00 & $0.03,0.05$ \\
\hline & $40+$ & & & & 0.08 & 0.01 & $0.06,0.09$ & 0.06 & 0.01 & $0.05,0.08$ & 0.04 & 0.01 & $0.03,0.06$ \\
\hline Maternal Birth Year (G2) & $1938-1945$ & & & & -0.01 & 0.01 & $-0.03,0.02$ & 0.13 & 0.01 & $0.10,0.15$ & 0.06 & 0.01 & $0.04,0.09$ \\
\hline & 1946-1949 & & & & 0.03 & 0.01 & $0.02,0.05$ & 0.10 & 0.01 & $0.08,0.11$ & 0.07 & 0.01 & $0.06,0.09$ \\
\hline & $1950-1954$ & & & & 0.00 & & & 0.00 & & & 0.00 & & \\
\hline & 1955-1959 & & & & -0.07 & 0.00 & $-0.08,-0.06$ & -0.11 & 0.01 & $-0.12,-0.10$ & -0.05 & 0.00 & $-0.06,-0.04$ \\
\hline & 1960-1964 & & & & -0.17 & 0.01 & $-0.18,-0.16$ & -0.21 & 0.01 & $-0.23,-0.20$ & -0.10 & 0.01 & $-0.11,-0.08$ \\
\hline & 1965-1969 & & & & -0.27 & 0.01 & $-0.28,-0.25$ & -0.28 & 0.01 & $-0.30,-0.26$ & -0.13 & 0.01 & $-0.15,-0.11$ \\
\hline & 1970-1974 & & & & -0.48 & 0.01 & $-0.50,-0.45$ & -0.39 & 0.02 & $-0.42,-0.36$ & -0.20 & 0.02 & $-0.23,-0.17$ \\
\hline & 1975-1979 & & & & -0.93 & 0.15 & $-1.22,-0.63$ & -0.65 & 0.15 & $-0.94,-0.35$ & -0.41 & 0.15 & $-0.70,-0.13$ \\
\hline Paternal Birth Year (G2) & $1938-1945$ & & & & -0.11 & 0.01 & $-0.12,-0.09$ & 0.00 & 0.01 & $-0.02,0.02$ & 0.02 & 0.01 & $0.00,0.04$ \\
\hline & 1946-1949 & & & & -0.06 & 0.01 & $-0.07,-0.05$ & -0.01 & 0.01 & $-0.02,0.00$ & 0.03 & 0.01 & $0.02,0.04$ \\
\hline & 1950-1954 & & & & 0.00 & & & 0.00 & & & 0.00 & & \\
\hline & 1955-1959 & & & & 0.02 & 0.00 & $0.01,0.03$ & -0.02 & 0.00 & $-0.03,-0.01$ & -0.01 & 0.00 & $-0.02,0.00$ \\
\hline & $1960-1964$ & & & & 0.00 & 0.01 & $-0.01,0.01$ & -0.05 & 0.01 & $-0.07,-0.04$ & -0.02 & 0.01 & $-0.04,-0.01$ \\
\hline & 1965-1969 & & & & -0.06 & 0.01 & $-0.07,-0.04$ & -0.08 & 0.01 & $-0.10,-0.06$ & -0.04 & 0.01 & $-0.06,-0.02$ \\
\hline & 1970-1974 & & & & -0.20 & 0.02 & $-0.24,-0.16$ & -0.11 & 0.03 & $-0.16,-0.06$ & -0.04 & 0.02 & $-0.09,0.01$ \\
\hline & 1975-1979 & & & & 0.28 & 0.48 & $-0.67,1.22$ & 0.55 & 0.44 & $-0.32,1.42$ & 0.55 & 0.43 & $-0.29,1.38$ \\
\hline Index Birth Order (G3) & 1 & & & & & & & 0.00 & & & 0.00 & & \\
\hline & 2 & & & & & & & -0.26 & 0.00 & $-0.26,-0.25$ & -0.18 & 0.00 & $-0.18,-0.17$ \\
\hline & 3 & & & & & & & -0.44 & 0.00 & $-0.45,-0.44$ & -0.27 & 0.00 & $-0.27,-0.26$ \\
\hline & 4 & & & & & & & -0.56 & 0.01 & $-0.58,-0.54$ & -0.32 & 0.01 & $-0.34,-0.30$ \\
\hline & $5+$ & & & & & & & -0.67 & 0.02 & $-0.71,-0.62$ & -0.37 & 0.02 & $-0.40,-0.33$ \\
\hline Sex (G3) & Male & & & & & & & 0.00 & & & 0.00 & & \\
\hline & Female & & & & & & & 0.36 & 0.00 & $0.35,0.36$ & 0.36 & 0.00 & $0.35,0.36$ \\
\hline Sibling Group Size (G3) & 1 & & & & & & & -0.37 & 0.00 & $-0.38,-0.36$ & -0.25 & 0.00 & $-0.26,-0.25$ \\
\hline & 2 & & & & & & & 0.00 & & & 0.00 & & \\
\hline & 3 & & & & & & & 0.11 & 0.00 & $0.10,0.12$ & 0.05 & 0.00 & $0.04,0.05$ \\
\hline & 4 & & & & & & & 0.08 & 0.01 & $0.06,0.09$ & 0.02 & 0.01 & $0.00,0.03$ \\
\hline & $5+$ & & & & & & & 0.02 & 0.01 & $0.00,0.05$ & -0.01 & 0.01 & $-0.03,0.01$ \\
\hline Birth Year (G3) & 1982 & & & & & & & -0.09 & 0.01 & $-0.10,-0.08$ & -0.05 & 0.01 & $-0.07,-0.04$ \\
\hline & 1983 & & & & & & & -0.05 & 0.01 & $-0.06,-0.04$ & -0.03 & 0.01 & $-0.04,-0.02$ \\
\hline & 1984 & & & & & & & -0.03 & 0.01 & $-0.04,-0.01$ & -0.02 & 0.00 & $-0.03,-0.01$ \\
\hline & 1985 & & & & & & & 0.00 & & & 0.00 & & \\
\hline
\end{tabular}


Table S11 - Continued from previous page

\begin{tabular}{|c|c|c|c|c|c|c|c|c|c|c|c|c|c|}
\hline & & \multicolumn{3}{|c|}{ Model 1} & \multicolumn{3}{|c|}{ Model 2} & \multicolumn{3}{|c|}{ Model 3} & \multicolumn{3}{|c|}{ Model 4} \\
\hline & & $\mathrm{b}$ & se & $95 \% \mathrm{CI}$ & $\mathrm{b}$ & se & $95 \% \mathrm{CI}$ & $\mathrm{b}$ & se & $95 \% \mathrm{CI}$ & $\mathrm{b}$ & se & $95 \% \mathrm{CI}$ \\
\hline & 1986 & & & & & & & 0.05 & 0.01 & $0.04,0.06$ & 0.03 & 0.00 & $0.02,0.04$ \\
\hline & 1987 & & & & & & & 0.08 & 0.01 & $0.07,0.09$ & 0.04 & 0.00 & $0.03,0.05$ \\
\hline & 1988 & & & & & & & 0.13 & 0.01 & $0.12,0.14$ & 0.08 & 0.01 & $0.07,0.09$ \\
\hline & 1989 & & & & & & & 0.14 & 0.01 & $0.13,0.15$ & 0.08 & 0.01 & $0.07,0.09$ \\
\hline & 1990 & & & & & & & 0.17 & 0.01 & $0.16,0.18$ & 0.09 & 0.01 & $0.08,0.10$ \\
\hline & 1991 & & & & & & & 0.23 & 0.01 & $0.22,0.24$ & 0.13 & 0.01 & $0.11,0.14$ \\
\hline \multirow[t]{6}{*}{ Maternal Age at Birth (G3) } & $15-19$ & & & & & & & -0.34 & 0.01 & $-0.36,-0.31$ & -0.24 & 0.01 & $-0.26,-0.22$ \\
\hline & $20-24$ & & & & & & & -0.15 & 0.00 & $-0.16,-0.14$ & -0.08 & 0.00 & $-0.09,-0.07$ \\
\hline & $25-29$ & & & & & & & 0.00 & & & 0.00 & & \\
\hline & $30-34$ & & & & & & & 0.06 & 0.00 & $0.05,0.07$ & 0.01 & 0.00 & $0.00,0.02$ \\
\hline & $35-39$ & & & & & & & 0.07 & 0.01 & $0.05,0.08$ & 0.01 & 0.01 & $0.00,0.03$ \\
\hline & $40+$ & & & & & & & 0.02 & 0.01 & $-0.01,0.05$ & 0.00 & 0.01 & $-0.02,0.03$ \\
\hline \multirow[t]{8}{*}{ Paternal Age at Birth (G3) } & $15-19$ & & & & & & & -0.18 & 0.02 & $-0.23,-0.14$ & -0.16 & 0.02 & $-0.21,-0.12$ \\
\hline & $20-24$ & & & & & & & -0.11 & 0.01 & $-0.12,-0.10$ & -0.08 & 0.01 & $-0.09,-0.07$ \\
\hline & $25-29$ & & & & & & & 0.00 & & & 0.00 & & \\
\hline & $30-34$ & & & & & & & 0.03 & 0.00 & $0.03,0.04$ & 0.02 & 0.00 & $0.01,0.03$ \\
\hline & $35-39$ & & & & & & & 0.01 & 0.01 & $-0.01,0.02$ & 0.01 & 0.01 & $0.00,0.02$ \\
\hline & $40-44$ & & & & & & & -0.05 & 0.01 & $-0.08,-0.03$ & -0.03 & 0.01 & $-0.05,-0.01$ \\
\hline & $45-49$ & & & & & & & -0.12 & 0.02 & $-0.16,-0.09$ & -0.07 & 0.02 & $-0.11,-0.04$ \\
\hline & $50+$ & & & & & & & -0.20 & 0.05 & $-0.29,-0.10$ & -0.12 & 0.05 & $-0.21,-0.03$ \\
\hline \multirow{8}{*}{$\begin{array}{l}\text { Maternal Educational Attainment } \\
\text { (G2) }\end{array}$} & Primary $<9$ years & & & & & & & & & & -0.06 & 0.01 & $-0.08,-0.03$ \\
\hline & Primary - 9 years & & & & & & & & & & 0.00 & & \\
\hline & Secondary - 10-11 years & & & & & & & & & & 0.20 & 0.00 & $0.19,0.21$ \\
\hline & Secondary - 12 years & & & & & & & & & & 0.34 & 0.01 & $0.33,0.35$ \\
\hline & Tertiary - $13-15$ years & & & & & & & & & & 0.43 & 0.01 & $0.42,0.44$ \\
\hline & Tertiary $-15+$ years & & & & & & & & & & 0.53 & 0.01 & $0.52,0.54$ \\
\hline & Post-graduate & & & & & & & & & & 0.66 & 0.02 & $0.63,0.69$ \\
\hline & Missing & & & & & & & & & & 0.13 & 0.06 & $0.01,0.26$ \\
\hline \multirow{6}{*}{$\begin{array}{l}\text { Maternal Social Class (EGP) } \\
\text { (G2) }\end{array}$} & I & & & & & & & & & & 0.07 & 0.01 & $0.06,0.09$ \\
\hline & II & & & & & & & & & & 0.00 & & \\
\hline & III & & & & & & & & & & 0.00 & 0.00 & $-0.01,0.01$ \\
\hline & IV & & & & & & & & & & 0.00 & 0.01 & $-0.02,0.02$ \\
\hline & VI-VII & & & & & & & & & & -0.14 & 0.00 & $-0.15,-0.13$ \\
\hline & Unknown & & & & & & & & & & -0.18 & 0.00 & $-0.19,-0.17$ \\
\hline \multirow{8}{*}{$\begin{array}{l}\text { Paternal Educational Attainment } \\
\text { (G2) }\end{array}$} & Primary $<9$ years & & & & & & & & & & -0.01 & 0.01 & $-0.03,0.00$ \\
\hline & Primary - 9 years & & & & & & & & & & 0.00 & & \\
\hline & Secondary - 10-11 years & & & & & & & & & & 0.10 & 0.00 & $0.09,0.10$ \\
\hline & Secondary - 12 years & & & & & & & & & & 0.27 & 0.00 & $0.26,0.28$ \\
\hline & Tertiary - $13-15$ years & & & & & & & & & & 0.34 & 0.00 & $0.33,0.35$ \\
\hline & Tertiary $-15+$ years & & & & & & & & & & 0.45 & 0.01 & $0.44,0.46$ \\
\hline & Post-graduate & & & & & & & & & & 0.56 & 0.01 & $0.54,0.59$ \\
\hline & Missing & & & & & & & & & & -0.04 & 0.03 & $-0.10,0.03$ \\
\hline \multirow{6}{*}{$\begin{array}{l}\text { Paternal Social Class (EGP) } \\
\text { (G2) }\end{array}$} & I & & & & & & & & & & 0.04 & 0.01 & $0.02,0.05$ \\
\hline & II & & & & & & & & & & 0.00 & & \\
\hline & III & & & & & & & & & & -0.01 & 0.01 & $-0.03,0.00$ \\
\hline & IV & & & & & & & & & & 0.01 & 0.01 & $0.00,0.02$ \\
\hline & VI-VII & & & & & & & & & & -0.11 & 0.00 & $-0.12,-0.10$ \\
\hline & Unknown & & & & & & & & & & -0.15 & 0.00 & $-0.16,-0.15$ \\
\hline $\mathrm{N}$ & & & 67 & & & 679 & & & 679 & 804 & & 679 & 304 \\
\hline
\end{tabular}


Table S12: Parental Birth Order and Offspring Grade Point Average (GPA) at Age 16, Fixed Effects Linear Regression on Maternal Cousin Sample of Swedish Men and Women Born 1982-1991.

\begin{tabular}{|c|c|c|c|c|c|c|c|c|c|c|}
\hline & & \multicolumn{3}{|c|}{ Model 5} & \multicolumn{3}{|c|}{ Model 6} & \multicolumn{3}{|c|}{ Model 7} \\
\hline & & $\mathrm{b}$ & $\mathrm{se}$ & $95 \% \mathrm{CI}$ & $\mathrm{b}$ & se & $95 \% \mathrm{CI}$ & $\mathrm{b}$ & se & $95 \% \mathrm{CI}$ \\
\hline \multirow{5}{*}{ Mother Birth Order (G2) } & 1 & 0.00 & & & 0.00 & & & 0.00 & & \\
\hline & 2 & 0.00 & 0.01 & $-0.01,0.02$ & -0.01 & 0.01 & $-0.02,0.00$ & 0.02 & 0.01 & $0.00,0.03$ \\
\hline & 3 & 0.01 & 0.01 & $-0.01,0.03$ & -0.02 & 0.01 & $-0.04,0.01$ & 0.03 & 0.01 & $0.00,0.05$ \\
\hline & 4 & 0.00 & 0.02 & $-0.03,0.03$ & -0.03 & 0.02 & $-0.07,0.00$ & 0.01 & 0.02 & $-0.02,0.04$ \\
\hline & $5+$ & 0.00 & 0.02 & $-0.05,0.04$ & -0.03 & 0.02 & $-0.07,0.01$ & 0.03 & 0.02 & $-0.02,0.07$ \\
\hline \multirow[t]{5}{*}{ Father Birth Order (G2) } & 1 & 0.00 & & & 0.00 & & & 0.00 & & \\
\hline & 2 & -0.03 & 0.01 & $-0.05,-0.02$ & -0.03 & 0.01 & $-0.04,-0.01$ & 0.00 & 0.01 & $-0.01,0.01$ \\
\hline & 3 & -0.05 & 0.01 & $-0.07,-0.03$ & -0.04 & 0.01 & $-0.06,-0.02$ & 0.01 & 0.01 & $-0.01,0.02$ \\
\hline & 4 & -0.06 & 0.01 & $-0.08,-0.03$ & -0.05 & 0.01 & $-0.07,-0.02$ & 0.00 & 0.01 & $-0.03,0.03$ \\
\hline & $5+$ & -0.08 & 0.02 & $-0.12,-0.04$ & -0.07 & 0.02 & $-0.10,-0.03$ & 0.00 & 0.02 & $-0.04,0.03$ \\
\hline \multirow[t]{5}{*}{ Maternal Sibling Group Size (G2) } & 1 & & & & & & & & & \\
\hline & 2 & & & & & & & & & \\
\hline & 3 & & & & & & & & & \\
\hline & 4 & & & & & & & & & \\
\hline & $5+$ & & & & & & & & & \\
\hline \multirow[t]{5}{*}{ Paternal Sibling Group Size (G2) } & 1 & -0.06 & 0.01 & $-0.08,-0.04$ & -0.05 & 0.01 & $-0.07,-0.04$ & -0.03 & 0.01 & $-0.05,-0.02$ \\
\hline & 2 & 0.00 & & & 0.00 & & & 0.00 & & \\
\hline & 3 & 0.01 & 0.01 & $-0.01,0.02$ & 0.01 & 0.01 & $0.00,0.02$ & 0.01 & 0.01 & $0.00,0.02$ \\
\hline & 4 & -0.03 & 0.01 & $-0.05,-0.01$ & -0.02 & 0.01 & $-0.04,0.00$ & -0.01 & 0.01 & $-0.02,0.01$ \\
\hline & $5+$ & -0.06 & 0.01 & $-0.08,-0.03$ & -0.04 & 0.01 & $-0.06,-0.02$ & -0.02 & 0.01 & $-0.04,0.01$ \\
\hline Maternal Grandmother's & $15-19$ & 0.04 & 0.02 & $0.01,0.08$ & 0.06 & 0.02 & $0.02,0.09$ & 0.06 & 0.02 & $0.02,0.09$ \\
\hline \multirow[t]{5}{*}{ Age at Birth (G2) } & $20-24$ & 0.00 & 0.01 & $-0.02,0.02$ & 0.02 & 0.01 & $0.00,0.03$ & 0.01 & 0.01 & $-0.01,0.03$ \\
\hline & $25-29$ & 0.00 & & & 0.00 & & & 0.00 & & \\
\hline & $30-34$ & -0.01 & 0.01 & $-0.03,0.01$ & -0.03 & 0.01 & $-0.05,-0.02$ & -0.03 & 0.01 & $-0.04,-0.01$ \\
\hline & $35-39$ & -0.01 & 0.02 & $-0.04,0.02$ & -0.06 & 0.02 & $-0.09,-0.03$ & -0.04 & 0.02 & $-0.08,-0.01$ \\
\hline & $40+$ & -0.05 & 0.03 & $-0.11,0.00$ & -0.13 & 0.03 & $-0.18,-0.07$ & -0.10 & 0.03 & $-0.16,-0.05$ \\
\hline Paternal Grandmother's & $15-19$ & -0.19 & 0.01 & $-0.21,-0.16$ & -0.17 & 0.01 & $-0.19,-0.15$ & -0.11 & 0.01 & $-0.13,-0.09$ \\
\hline \multirow[t]{5}{*}{ Age at Birth (G2) } & $20-24$ & -0.08 & 0.01 & $-0.10,-0.07$ & -0.07 & 0.01 & $-0.09,-0.06$ & -0.05 & 0.01 & $-0.06,-0.04$ \\
\hline & $25-29$ & 0.00 & & & 0.00 & & & 0.00 & & \\
\hline & $30-34$ & 0.02 & 0.01 & $0.01,0.04$ & 0.02 & 0.01 & $0.01,0.03$ & 0.01 & 0.01 & $0.00,0.03$ \\
\hline & $35-39$ & 0.03 & 0.01 & $0.01,0.05$ & 0.03 & 0.01 & $0.01,0.04$ & 0.01 & 0.01 & $-0.01,0.02$ \\
\hline & $40+$ & 0.03 & 0.01 & $0.00,0.05$ & 0.02 & 0.01 & $0.00,0.05$ & 0.01 & 0.01 & $-0.01,0.04$ \\
\hline \multirow[t]{8}{*}{ Maternal Birth Year (G2) } & $1938-1945$ & -0.04 & 0.04 & $-0.11,0.04$ & -0.01 & 0.04 & $-0.08,0.07$ & 0.01 & 0.04 & $-0.06,0.09$ \\
\hline & 1946-1949 & 0.01 & 0.02 & $-0.02,0.04$ & 0.02 & 0.02 & $-0.01,0.06$ & 0.04 & 0.02 & $0.01,0.07$ \\
\hline & $1950-1954$ & 0.00 & & & 0.00 & & & 0.00 & & \\
\hline & $1955-1959$ & -0.02 & 0.01 & $-0.04,0.00$ & -0.04 & 0.01 & $-0.06,-0.02$ & -0.03 & 0.01 & $-0.05,-0.01$ \\
\hline & 1960-1964 & 0.00 & 0.02 & $-0.04,0.03$ & -0.05 & 0.02 & $-0.08,-0.02$ & -0.03 & 0.02 & $-0.07,0.00$ \\
\hline & 1965-1969 & 0.02 & 0.02 & $-0.03,0.06$ & -0.03 & 0.02 & $-0.08,0.01$ & -0.02 & 0.02 & $-0.07,0.02$ \\
\hline & 1970-1974 & 0.00 & 0.04 & $-0.08,0.07$ & -0.06 & 0.04 & $-0.13,0.02$ & -0.05 & 0.04 & $-0.12,0.02$ \\
\hline & 1975-1979 & -0.32 & 0.36 & $-1.03,0.39$ & -0.35 & 0.35 & $-1.03,0.34$ & -0.26 & 0.35 & $-0.94,0.42$ \\
\hline \multirow[t]{8}{*}{ Paternal Birth Year (G2) } & $1938-1945$ & -0.07 & 0.02 & $-0.10,-0.04$ & -0.03 & 0.02 & $-0.07,0.01$ & -0.01 & 0.02 & $-0.04,0.03$ \\
\hline & 1946-1949 & -0.03 & 0.01 & $-0.05,-0.01$ & 0.00 & 0.01 & $-0.03,0.02$ & 0.02 & 0.01 & $0.00,0.05$ \\
\hline & $1950-1954$ & 0.00 & & & 0.00 & & & 0.00 & & \\
\hline & $1955-1959$ & 0.03 & 0.01 & $0.02,0.05$ & 0.00 & 0.01 & $-0.01,0.02$ & 0.00 & 0.01 & $-0.01,0.02$ \\
\hline & $1960-1964$ & 0.03 & 0.01 & $0.01,0.05$ & -0.03 & 0.01 & $-0.06,-0.01$ & -0.03 & 0.01 & $-0.05,-0.01$ \\
\hline & 1965-1969 & -0.01 & 0.01 & $-0.03,0.02$ & -0.11 & 0.02 & $-0.14,-0.07$ & -0.09 & 0.02 & $-0.13,-0.05$ \\
\hline & $1970-1974$ & -0.07 & 0.05 & $-0.16,0.02$ & -0.18 & 0.05 & $-0.28,-0.09$ & -0.14 & 0.05 & $-0.24,-0.05$ \\
\hline & 1975-1979 & 1.83 & 1.17 & $-0.45,4.12$ & 1.74 & 1.13 & $-0.47,3.95$ & 1.72 & 1.11 & $-0.47,3.90$ \\
\hline \multirow{5}{*}{ Index Birth Order (G3) } & 1 & & & & 0.00 & & & 0.00 & & \\
\hline & 2 & & & & -0.16 & 0.00 & $-0.16,-0.15$ & -0.14 & 0.00 & $-0.14,-0.13$ \\
\hline & 3 & & & & -0.26 & 0.01 & $-0.28,-0.25$ & -0.22 & 0.01 & $-0.23,-0.20$ \\
\hline & 4 & & & & -0.33 & 0.01 & $-0.36,-0.31$ & -0.27 & 0.01 & $-0.30,-0.25$ \\
\hline & $5+$ & & & & -0.42 & 0.02 & $-0.46,-0.38$ & -0.34 & 0.02 & $-0.39,-0.30$ \\
\hline Sex (G3) & Male & & & & 0.00 & & & 0.00 & & \\
\hline & Female & & & & 0.35 & 0.00 & $0.34,0.36$ & 0.35 & 0.00 & $0.34,0.36$ \\
\hline Sibling Group Size (G3) & 1 & & & & -0.16 & 0.01 & $-0.18,-0.15$ & -0.14 & 0.01 & $-0.15,-0.12$ \\
\hline & 2 & & & & 0.00 & & & 0.00 & & \\
\hline & 3 & & & & 0.04 & 0.01 & $0.03,0.05$ & 0.03 & 0.01 & $0.02,0.04$ \\
\hline & 4 & & & & 0.02 & 0.01 & $0.00,0.04$ & 0.02 & 0.01 & $-0.01,0.04$ \\
\hline & $5+$ & & & & -0.03 & 0.02 & $-0.06,0.01$ & -0.02 & 0.02 & $-0.05,0.02$ \\
\hline Birth Year (G3) & 1982 & & & & -0.07 & 0.01 & $-0.09,-0.06$ & -0.06 & 0.01 & $-0.08,-0.04$ \\
\hline
\end{tabular}


Table S12 - Continued from previous page

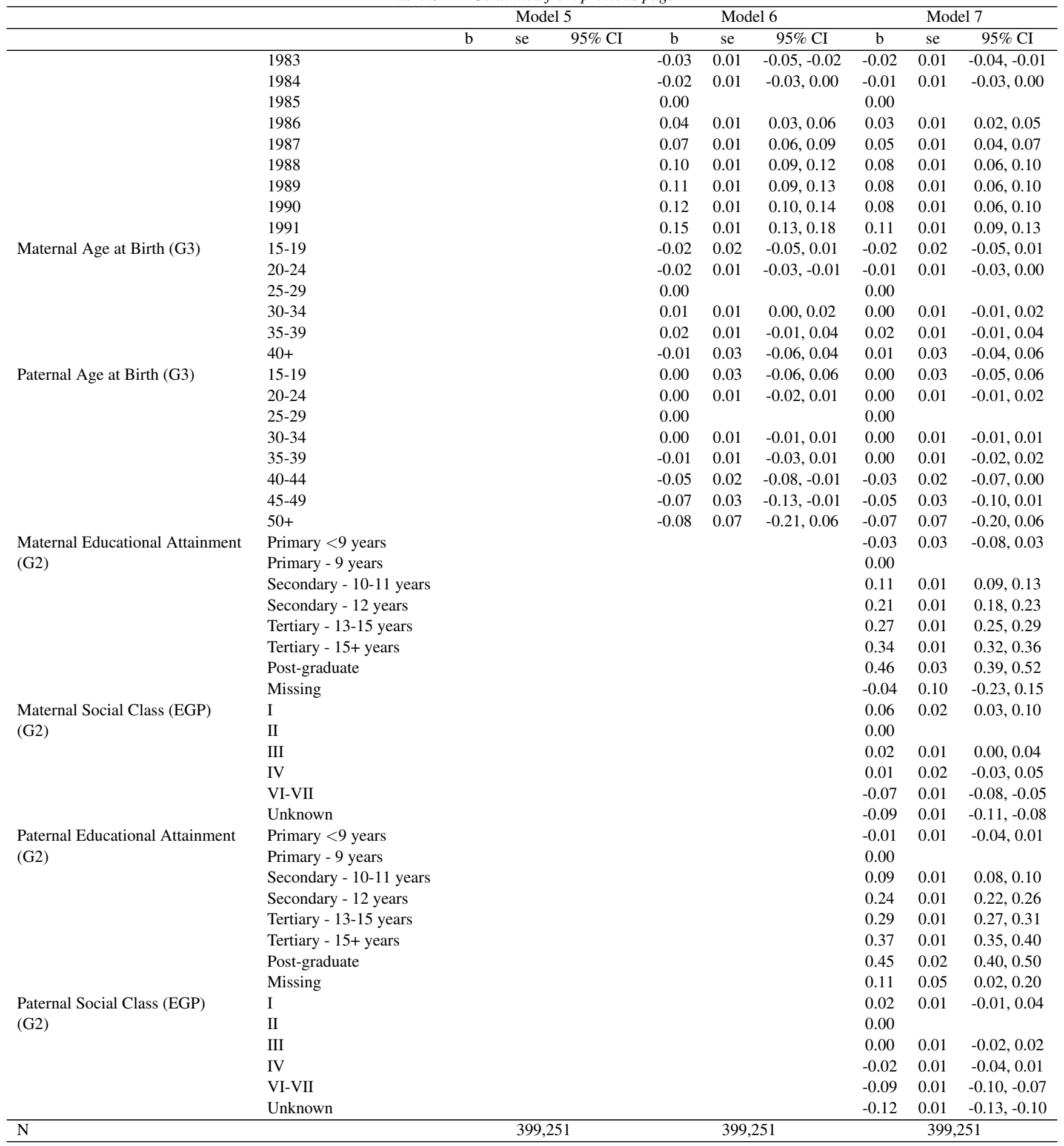


Table S13: Parental Birth Order and Offspring Grade Point Average (GPA) at Age 16, Fixed Effects Linear Regression on Paternal Cousin Sample of Swedish Men and Women Born 1982-1991.

\begin{tabular}{|c|c|c|c|c|c|c|c|c|c|c|}
\hline & & \multicolumn{3}{|c|}{ Model 8} & \multicolumn{3}{|c|}{ Model 9} & \multicolumn{3}{|c|}{ Model 10} \\
\hline & & $\mathrm{b}$ & se & $95 \% \mathrm{CI}$ & $\mathrm{b}$ & se & $95 \% \mathrm{CI}$ & $\mathrm{b}$ & se & $95 \% \mathrm{CI}$ \\
\hline \multirow[t]{5}{*}{ Mother Birth Order (G2) } & 1 & 0.00 & & & 0.00 & & & 0.00 & & \\
\hline & 2 & -0.04 & 0.01 & $-0.05,-0.03$ & -0.03 & 0.01 & $-0.04,-0.02$ & 0.00 & 0.01 & $-0.01,0.01$ \\
\hline & 3 & -0.07 & 0.01 & $-0.09,-0.05$ & -0.06 & 0.01 & $-0.07,-0.04$ & 0.00 & 0.01 & $-0.02,0.02$ \\
\hline & 4 & -0.04 & 0.02 & $-0.07,-0.01$ & -0.03 & 0.01 & $-0.06,-0.01$ & 0.03 & 0.01 & $0.00,0.06$ \\
\hline & $5+$ & -0.12 & 0.02 & $-0.15,-0.08$ & -0.10 & 0.02 & $-0.14,-0.07$ & -0.02 & 0.02 & $-0.06,0.02$ \\
\hline \multirow[t]{5}{*}{ Father Birth Order (G2) } & 1 & 0.00 & & & 0.00 & & & 0.00 & & \\
\hline & 2 & 0.00 & 0.01 & $-0.01,0.01$ & -0.01 & 0.01 & $-0.02,0.00$ & 0.01 & 0.01 & $0.00,0.02$ \\
\hline & 3 & 0.00 & 0.01 & $-0.02,0.02$ & -0.02 & 0.01 & $-0.04,0.00$ & 0.01 & 0.01 & $-0.01,0.03$ \\
\hline & 4 & 0.00 & 0.02 & $-0.03,0.04$ & -0.02 & 0.02 & $-0.05,0.01$ & 0.02 & 0.02 & $-0.01,0.05$ \\
\hline & $5+$ & 0.00 & 0.02 & $-0.05,0.04$ & -0.04 & 0.02 & $-0.08,0.01$ & 0.00 & 0.02 & $-0.04,0.04$ \\
\hline \multirow[t]{5}{*}{ Maternal Sibling Group Size (G2) } & 1 & -0.09 & 0.01 & $-0.11,-0.07$ & -0.08 & 0.01 & $-0.10,-0.07$ & -0.06 & 0.01 & $-0.08,-0.05$ \\
\hline & 2 & 0.00 & & & & & & 0.00 & & \\
\hline & 3 & -0.01 & 0.01 & $-0.03,0.00$ & -0.01 & 0.01 & $-0.02,0.01$ & -0.01 & 0.01 & $-0.02,0.00$ \\
\hline & 4 & -0.04 & 0.01 & $-0.05,-0.02$ & -0.02 & 0.01 & $-0.04,-0.01$ & -0.02 & 0.01 & $-0.04,0.00$ \\
\hline & $5+$ & -0.08 & 0.01 & $-0.10,-0.05$ & -0.06 & 0.01 & $-0.08,-0.03$ & -0.04 & 0.01 & $-0.07,-0.02$ \\
\hline \multirow[t]{5}{*}{ Paternal Sibling Group Size (G2) } & 1 & & & & & & & & & \\
\hline & 2 & & & & & & & & & \\
\hline & 3 & & & & & & & & & \\
\hline & 4 & & & & & & & & & \\
\hline & $5+$ & & & & & & & & & \\
\hline Maternal Grandmother's & $15-19$ & -0.21 & 0.01 & $-0.23,-0.18$ & -0.18 & 0.01 & $-0.20,-0.16$ & -0.13 & 0.01 & $-0.15,-0.11$ \\
\hline \multirow{5}{*}{ Age at Birth (G2) } & $20-24$ & -0.10 & 0.01 & $-0.11,-0.08$ & -0.09 & 0.01 & $-0.10,-0.07$ & -0.06 & 0.01 & $-0.07,-0.05$ \\
\hline & $25-29$ & 0.00 & & & 0.00 & & & 0.00 & & \\
\hline & $30-34$ & 0.04 & 0.01 & $0.03,0.06$ & 0.03 & 0.01 & $0.02,0.05$ & 0.02 & 0.01 & $0.00,0.03$ \\
\hline & $35-39$ & 0.04 & 0.01 & $0.02,0.06$ & 0.03 & 0.01 & $0.02,0.05$ & 0.02 & 0.01 & $0.00,0.03$ \\
\hline & $40+$ & 0.05 & 0.01 & $0.02,0.08$ & 0.04 & 0.01 & $0.01,0.06$ & 0.01 & 0.01 & $-0.01,0.04$ \\
\hline Paternal Grandmother's & $15-19$ & 0.01 & 0.02 & $-0.03,0.05$ & 0.03 & 0.02 & $-0.01,0.06$ & 0.04 & 0.02 & $0.01,0.08$ \\
\hline \multirow{5}{*}{ Age at Birth (G2) } & $20-24$ & 0.02 & 0.01 & $0.00,0.04$ & 0.03 & 0.01 & $0.01,0.05$ & 0.04 & 0.01 & $0.02,0.06$ \\
\hline & $25-29$ & 0.00 & & & 0.00 & & & 0.00 & & \\
\hline & $30-34$ & 0.00 & 0.01 & $-0.01,0.02$ & -0.02 & 0.01 & $-0.03,0.00$ & -0.02 & 0.01 & $-0.03,0.00$ \\
\hline & $35-39$ & -0.03 & 0.02 & $-0.06,0.01$ & -0.07 & 0.02 & $-0.10,-0.03$ & -0.07 & 0.02 & $-0.10,-0.04$ \\
\hline & $40+$ & -0.03 & 0.03 & $-0.08,0.02$ & -0.10 & 0.03 & $-0.15,-0.04$ & -0.10 & 0.03 & $-0.15,-0.05$ \\
\hline \multirow[t]{8}{*}{ Maternal Birth Year (G2) } & $1938-1945$ & 0.01 & 0.03 & $-0.05,0.06$ & 0.08 & 0.03 & $0.02,0.15$ & 0.08 & 0.03 & $0.01,0.14$ \\
\hline & 1946-1949 & 0.00 & 0.01 & $-0.03,0.03$ & 0.04 & 0.02 & $0.01,0.07$ & 0.05 & 0.02 & $0.02,0.08$ \\
\hline & $1950-1954$ & 0.00 & & & 0.00 & & & 0.00 & & \\
\hline & $1955-1959$ & 0.00 & 0.01 & $-0.02,0.01$ & -0.05 & 0.01 & $-0.07,-0.04$ & -0.03 & 0.01 & $-0.05,-0.01$ \\
\hline & $1960-1964$ & -0.01 & 0.01 & $-0.03,0.01$ & -0.11 & 0.01 & $-0.13,-0.08$ & -0.07 & 0.01 & $-0.09,-0.04$ \\
\hline & 1965-1969 & 0.00 & 0.01 & $-0.03,0.02$ & -0.14 & 0.02 & $-0.18,-0.11$ & -0.09 & 0.02 & $-0.12,-0.05$ \\
\hline & $1970-1974$ & -0.08 & 0.03 & $-0.14,-0.03$ & -0.24 & 0.03 & $-0.30,-0.18$ & -0.15 & 0.03 & $-0.21,-0.09$ \\
\hline & 1975-1979 & -0.61 & 0.41 & $-1.42,0.20$ & -0.63 & 0.40 & $-1.42,0.16$ & -0.53 & 0.40 & $-1.31,0.25$ \\
\hline \multirow[t]{8}{*}{ Paternal Birth Year (G2) } & $1938-1945$ & -0.07 & 0.02 & $-0.11,-0.02$ & -0.05 & 0.02 & $-0.10,-0.01$ & -0.04 & 0.02 & $-0.08,0.01$ \\
\hline & 1946-1949 & -0.02 & 0.01 & $-0.04,0.00$ & 0.00 & 0.01 & $-0.03,0.02$ & 0.02 & 0.01 & $0.00,0.04$ \\
\hline & $1950-1954$ & 0.00 & & & 0.00 & & & 0.00 & & \\
\hline & 1955-1959 & 0.02 & 0.01 & $0.01,0.04$ & 0.01 & 0.01 & $-0.01,0.03$ & 0.02 & 0.01 & $0.00,0.04$ \\
\hline & $1960-1964$ & 0.03 & 0.02 & $0.00,0.06$ & 0.01 & 0.02 & $-0.03,0.04$ & 0.01 & 0.02 & $-0.02,0.04$ \\
\hline & $1965-1969$ & 0.01 & 0.02 & $-0.04,0.05$ & -0.01 & 0.02 & $-0.06,0.03$ & 0.00 & 0.02 & $-0.04,0.05$ \\
\hline & $1970-1974$ & -0.01 & 0.06 & $-0.13,0.12$ & -0.01 & 0.06 & $-0.13,0.12$ & 0.00 & 0.06 & $-0.12,0.12$ \\
\hline & $1975-1979$ & & & & & & & & & \\
\hline \multirow[t]{5}{*}{ Index Birth Order (G3) } & 1 & & & & 0.00 & & & 0.00 & & \\
\hline & 2 & & & & -0.18 & 0.00 & $-0.18,-0.17$ & -0.15 & 0.00 & $-0.16,-0.15$ \\
\hline & 3 & & & & -0.30 & 0.01 & $-0.31,-0.28$ & -0.24 & 0.01 & $-0.26,-0.23$ \\
\hline & 4 & & & & -0.38 & 0.01 & $-0.41,-0.36$ & -0.30 & 0.01 & $-0.33,-0.28$ \\
\hline & $5+$ & & & & -0.51 & 0.02 & $-0.55,-0.46$ & -0.41 & 0.02 & $-0.45,-0.36$ \\
\hline Sex (G3) & Male & & & & 0.00 & & & 0.00 & & \\
\hline & Female & & & & 0.35 & 0.00 & $0.35,0.36$ & 0.35 & 0.00 & $0.35,0.36$ \\
\hline Sibling Group Size (G3) & 1 & & & & -0.22 & 0.01 & $-0.23,-0.20$ & -0.18 & 0.01 & $-0.19,-0.16$ \\
\hline & 2 & & & & 0.00 & & & 0.00 & & \\
\hline & 3 & & & & 0.03 & 0.01 & $0.02,0.05$ & 0.02 & 0.01 & $0.01,0.04$ \\
\hline & 4 & & & & 0.01 & 0.01 & $-0.01,0.03$ & 0.01 & 0.01 & $-0.01,0.03$ \\
\hline & $5+$ & & & & -0.03 & 0.02 & $-0.06,0.01$ & 0.01 & 0.02 & $-0.03,0.04$ \\
\hline Birth Year (G3) & 1982 & & & & -0.09 & 0.01 & $-0.11,-0.07$ & -0.07 & 0.01 & $-0.09,-0.05$ \\
\hline
\end{tabular}


Table S13 - Continued from previous page

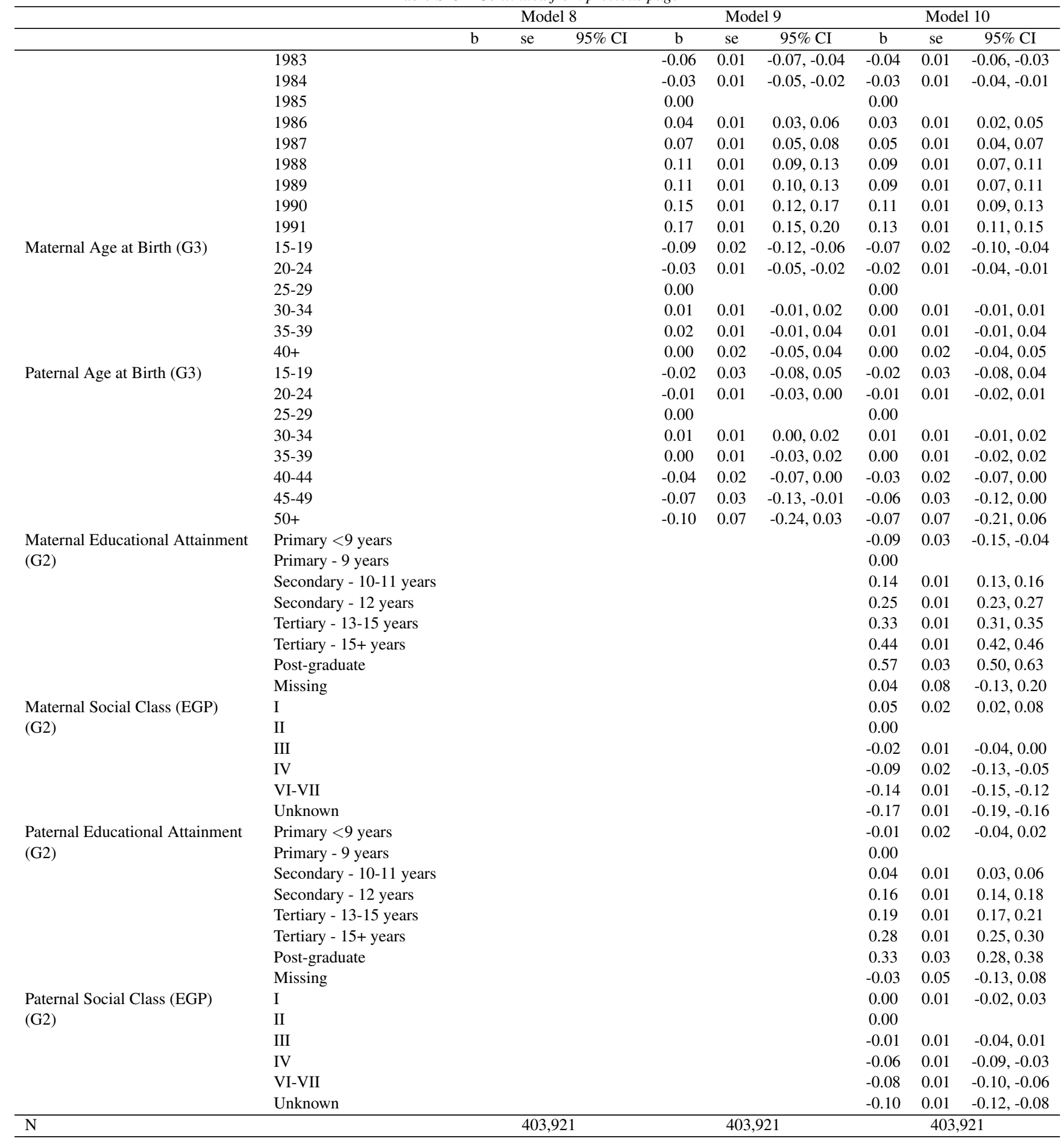


Table S14: Effect of parental sibling group size on offspring attainment, using twin births as a measure of an exogenous increase in parental family size for Swedish men and women. Offspring born 1960-1982 for educational attainment, 1960-1981 for logged income, and 1982-1991 for GPA. Controls for maternal age at birth and birth year (single-year categories) included in model.

\begin{tabular}{|c|c|c|c|c|c|c|}
\hline Outcome & Sample & Estimation & beta & se & $95 \% \mathrm{CI}$ & $\mathrm{N}$ \\
\hline \multirow[t]{12}{*}{ Years of Education } & \multirow[t]{2}{*}{ First-born mothers } & First Stage & 0.771 & 0.014 & $0.743,0.799$ & 404,554 \\
\hline & & Second Stage & 0.007 & 0.046 & $-0.083,0.098$ & 404,554 \\
\hline & \multirow[t]{2}{*}{ First-born fathers } & First Stage & 0.769 & 0.015 & $0.740,0.799$ & 366,574 \\
\hline & & Second Stage & -0.052 & 0.050 & $-0.150,0.046$ & 366,574 \\
\hline & \multirow[t]{2}{*}{ First- and second-born mothers } & First Stage & 0.768 & 0.014 & $0.740,0.797$ & 372,580 \\
\hline & & Second Stage & -0.018 & 0.046 & $-0.109,0.072$ & 372,580 \\
\hline & \multirow[t]{2}{*}{ First- and second-born fathers } & First Stage & 0.761 & 0.014 & $0.734,0.788$ & 341,091 \\
\hline & & Second Stage & -0.041 & 0.047 & $-0.133,0.051$ & 341,091 \\
\hline & \multirow[t]{2}{*}{ First-, second- and third-born mothers } & First Stage & 0.770 & 0.018 & $0.735,0.806$ & 226,649 \\
\hline & & Second Stage & 0.005 & 0.056 & $-0.105,0.116$ & 226,649 \\
\hline & \multirow[t]{2}{*}{ First-, second- and third-born fathers } & First Stage & 0.759 & 0.019 & $0.721,0.796$ & 207,898 \\
\hline & & Second Stage & -0.178 & 0.060 & $-0.296,-0.059$ & 207,898 \\
\hline \multirow[t]{12}{*}{ Logged Income } & \multirow[t]{2}{*}{ First-born mothers } & First Stage & 0.770 & 0.015 & $0.741,0.800$ & 369,630 \\
\hline & & Second Stage & 0.018 & 0.018 & $-0.018,0.053$ & 369,630 \\
\hline & \multirow[t]{2}{*}{ First-born fathers } & First Stage & 0.772 & 0.016 & $0.740,0.803$ & 334,458 \\
\hline & & Second Stage & -0.012 & 0.020 & $-0.052,0.027$ & 334,458 \\
\hline & \multirow[t]{2}{*}{ First- and second-born mothers } & First Stage & 0.768 & 0.015 & $0.738,0.798$ & 341,014 \\
\hline & & Second Stage & 0.015 & 0.019 & $-0.022,0.051$ & 341,014 \\
\hline & \multirow[t]{2}{*}{ First- and second-born fathers } & First Stage & 0.761 & 0.015 & $0.733,0.790$ & 311,394 \\
\hline & & Second Stage & 0.004 & 0.019 & $-0.033,0.040$ & 311,394 \\
\hline & \multirow[t]{2}{*}{ First-, second- and third-born mothers } & First Stage & 0.765 & 0.019 & $0.728,0.802$ & 208,162 \\
\hline & & Second Stage & -0.078 & 0.026 & $-0.129,-0.028$ & 208,162 \\
\hline & \multirow[t]{2}{*}{ First-, second- and third-born fathers } & First Stage & 0.757 & 0.020 & $0.718,0.796$ & 190,167 \\
\hline & & Second Stage & -0.002 & 0.025 & $-0.051,0.047$ & 190,167 \\
\hline \multirow[t]{12}{*}{ GPA } & \multirow[t]{2}{*}{ First-born mothers } & First Stage & 0.758 & 0.049 & $0.661,0.854$ & 22,178 \\
\hline & & Second Stage & -0.014 & 0.076 & $-0.163,0.136$ & 22,178 \\
\hline & \multirow[t]{2}{*}{ First-born fathers } & First Stage & 0.787 & 0.054 & $0.681,0.892$ & 20,911 \\
\hline & & Second Stage & 0.020 & 0.075 & $-0.128,0.168$ & 20,911 \\
\hline & \multirow[t]{2}{*}{ First- and second-born mothers } & First Stage & 0.782 & 0.053 & $0.678,0.886$ & 19,324 \\
\hline & & Second Stage & 0.125 & 0.072 & $-0.016,0.266$ & 19,324 \\
\hline & \multirow[t]{2}{*}{ First- and second-born fathers } & First Stage & 0.791 & 0.051 & $0.690,0.891$ & 18,972 \\
\hline & & Second Stage & -0.136 & 0.083 & $-0.298,0.026$ & 18,972 \\
\hline & \multirow[t]{2}{*}{ First-, second- and third-born mothers } & First Stage & 0.858 & 0.073 & $0.714,1.002$ & 10,470 \\
\hline & & Second Stage & 0.083 & 0.098 & $-0.109,0.274$ & 10,470 \\
\hline & \multirow[t]{2}{*}{ First-, second- and third-born fathers } & First Stage & 0.789 & 0.070 & $0.652,0.925$ & 10,644 \\
\hline & & Second Stage & -0.019 & 0.109 & $-0.233,0.195$ & 10,644 \\
\hline
\end{tabular}

